\title{
The Ancillary Effects of Selected Acid Deposition Control Policies
}
R. J. Moe
A. J. Lyke
R. J. Nesse

August 1986

Prepared for

the U.S. Environmental Protection Agency under a Related Services Agreement with the U.S. Department of Energy Contract DE-AC06-76RLO 1830

Pacific Northwest Laboratory Operated for the U.S. Department of Energy by Battelle Memorial Institute 
Although the research described in this article has been funded wholly or in part by the United States Environmental Protection Agency (EPA), it has not been subjected to EPA review and therefore does not necessarily reflect the views of EPA and no official endorsement should be inferred.

\title{
DISCLAIMER
}

This report was prepared as an account of work sponsored by an agency of the United States Government. Neither the United States Government nor any agency thereof, nor any of their employees, makes any warranty, express or implied, or assumes any legal liability or responsibility for the accuracy, completeness, or usefulness of any information, apparatus, product, or process disclosed, or represents that its use would not infringe privately owned rights. Reference herein to any specific commercial product, process, or service by trade name, trademark, manufacturer, or otherwise, does not necessarily constitute or imply its endorsement, recommendation, or favoring by the United States Government or any agency thereof. The views and opinions of authors expressed herein do not necessarily state or reflect those of the United States Government or any agency thereof.

\author{
PACIFIC NORTHWEST LABORATORY \\ operated by \\ BATTELLE \\ for the \\ UNITED STATES DEPARTMENT OF ENERGY \\ under Contract DE-AC06-76RLO 1830
}

\begin{tabular}{|c|c|}
\hline \multirow{2}{*}{\multicolumn{2}{|c|}{ Printed in the United States of America }} \\
\hline & \\
\hline \multicolumn{2}{|c|}{$\begin{array}{l}\text { Available fiom } \\
\text { National Technical Information Service }\end{array}$} \\
\hline \multicolumn{2}{|c|}{ United States Department of Commerce } \\
\hline \multicolumn{2}{|c|}{5285 Port Royal Road } \\
\hline \multicolumn{2}{|c|}{ Springfield, Virginia 22161} \\
\hline \multirow{2}{*}{\multicolumn{2}{|c|}{$\begin{array}{l}\text { NTIS Price Codes } \\
\text { Microfiche A01 }\end{array}$}} \\
\hline & \\
\hline \multicolumn{2}{|c|}{ Printed Copy } \\
\hline & Price \\
\hline Pages & Codes \\
\hline $001-025$ & $\mathrm{~A} 02$ \\
\hline 026-050 & $\mathrm{A} 03$ \\
\hline 051-075 & $A 04$ \\
\hline 076-100 & $\wedge 05$ \\
\hline $101-125$ & A06 \\
\hline $126-150$ & A07 \\
\hline $151-175$ & $\mathrm{~A} 0 \mathrm{~B}$ \\
\hline $176-200$ & $\mathrm{~A} 09$ \\
\hline $201-225$ & $\wedge 010$ \\
\hline $226-250$ & A011 \\
\hline $251-275$ & A012 \\
\hline $276-300$ & A013 \\
\hline
\end{tabular}




\section{0}

PNL -5938

UC-11

THE ANCILLARY EFFECTS OF SELECTEO

ACID DEPOSITION CONTROL. POLICIES

R. J. Moe
A. J. Lyke
R. J. Nesse

August 1986

Prepared for

the U.S. Environmental Protection Agency

under a Related Services Agreement with the

U.S. Department of Energy

Under Contract DE-AC06-76RLO 1830

Pacific Northwest Laboratory

Richland, Washington 99352 


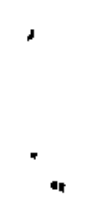

4

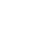

. 
INTRODUCTION

This research was performed by Pacific Northwest Laboratory (PNL) for the Environmental Protection Agency (EPA), Office of Research and Development (ORD). The research was funded as part of the National Acid Precipitation Assessment Program (NAPAP). NAPAP is an inter-agency program to research and assess the causes and effects of acid deposition.

NAPAP is examining a number of potential ways to reduce the precursors (sulfur dioxide and nitrogen oxides) to acid deposition. However, the policies to reduce acid deposition will have other physical, biological and economic effects unrelated to acid deposition. For example, control policies that reduce sulfur dioxide emissions may also increase visibility. The effects of an acid deposition policy that are unrelated to acid deposition are referred to as "ancillary" effects. This research identifies and characterizes the principle physical and economic ancillary effects associated with acid deposition control and mitigation policies.

APPROACH

In this study the ancillary benefits associated with four specific acid deposition policy options were investigated. The four policy options investigated are: 1) flue gas desulfurization, 2) coal blending or switching, 3) reductions in automobile emissions of $N D_{x}$, and 4) lake liming. Potential ancillary benefits of each option were identified and characterized. Particular attention was paid to the literature on economic valuation of potential ancillary effects.

Each of the first three policy options to be considered involves a reduction in emissions of an acid deposition precursor: the first two focus on $\mathrm{SO}_{2}$ emissions, the third on $\mathrm{NO}_{x}$ emissions. Each of the three options are investigated in a similar manner, which will be slightly different from that used to investigate the fourth option. Each of the three options were investigated in a four-step process. 
First, the technological aspects of each option are investigated through a review of the engineering/technology literature on emissions control and coal combustion. This review permits identification and characterization of changes in emissions of compounds other than those targeted by the policy $\left(\mathrm{SO}_{2}\right.$ and $\left.\mathrm{NO}_{x}\right)$. Second, the changes in air quality associated with both the targeted and ancillary emission changes (other than changes in acid deposition) are investigated. This involves a review of the literature on atmospheric chemistry. Potential ambient air-pollutant changes are identified and characterized. Third, the physical and biological changes associated with the ancillary airquality changes are investigated. This involves a review of the literature on air pollution impacts. Potential ancillary physical and biological effects are identified and characterized. Third, the physical and biological changes associated with the ancillary air-quality changes are investigated. This involves a review of the literature on air pollution impacts. Potential ancillary physical and biological effects are identified and characterized. Fourth, the economic value of potential ancillary physical and biological effects are investigated. The economic literature dealing with each of the specific physical and biological effects are reviewed. Estimates of the value of the ancillary effects are identified and summarized; the usefulness of these estimates and the relevant extant literature in general for NAPAP's assessments are also evaluated.

For the lake-liming option, a similar though not identical procedure is utilized. First, the technical aspects of lake liming is investigated. The literature on lake liming and aquatic chemistry is reviewed in this step. Second, the potential ancillary biological effects of potential and ancillary chemical changes are investigated.

The economic value of ancillary aquatic effects is not assessed. NAPAP is including the value of the changes in fish levels as part of its economic capability and since fish impacts are considered direct, not ancillary impacts of lake liming, they are not included in this report. Also, a preliminary review of the literature indicated no economic valuation studies were available on the other aquatic life affected by lake liming. 
$\underline{\text { RESULTS }}$

The research indicates that acid deposition policies will likely have a number of consequences unrelated to acid deposition emissions or deposition. For example, widespread use of flue gas desulfurization (FGD) systems may affect sulfate aerosols, a major component of total suspended particulates, sulfur dioxide and possibly ozone.

In addition to $F G D$ systems, each of the major policies to reduce acid deposition will affect other aspects of air quality and, in turn, affect human health and wellbeing. The research identified seven pollutants whose concentrations could change as a result of acid deposition policies. These are sulfur oxides $\left(\mathrm{SO}_{x}\right)$, nitrogen oxides $\left(\mathrm{NO}_{x}\right)$, ozone $\left(\mathrm{O}_{3}\right)$, trace metals, carbon monoxide $(\mathrm{CO})$, carbon dioxide $\left(\mathrm{CO}_{2}\right)$ and hydrocarbons. Table ES.1 summarizes the effects these seven pollutants could have on human health, vegetation, visibility, climate, or material lifetimes. It must be pointed out that some effects, especially some human health effects, are noticed at higher than ambient concentrations. Whether these effects are also found at ambient conditions is less clear from our review of the literature.

The frequency of respiratory illness may be influenced by $\mathrm{SO}_{x}, \mathrm{NO}_{x}, \mathrm{O}_{3}$ and metals. $\mathrm{SO}_{\mathrm{x}}, \mathrm{NO}_{\mathrm{x}}$ and $\mathrm{CO}$ may affect the risk of cardiopulmonary disease, while the risk of other health effects may change depending on levels of $\mathrm{SO}_{x}, \mathrm{O}_{3}$, metals, $\mathrm{CO}$ and organic pollutants. $\mathrm{SO}_{x}$ and $\mathrm{NO}_{x}$ can affect visibility and haziness; ancillary pollutants may also perturb the climate $\left(\mathrm{CO}_{2}\right.$ and $\left.\mathrm{SO}_{x}\right)$ and radiation-filtering properties of the stratosphere $\left(D_{3}\right)$. Durability of elastomers, such as rubber, and some fabrics and dyes may be affected by changes in $\mathrm{NO}_{x}$ and $\mathrm{O}_{3}$ levels. $\mathrm{CO}_{2}$ and $\mathrm{O}_{3}$ may affect forest growth and crops; crop changes may also be induced by effects of $\mathrm{SO}_{x}, \mathrm{NO}_{x}$ and specific organic pollutants. Metals may disrupt ecosystems with possible impacts on grazing animals.

The review of economic value of ancillary effects centered on two effects visibility and health. These two were selected because they were not explicitly included in NAPAP economics assessments and an initial review of the literature indicated the value of changes in health or visibility could be significant. 
TABLE ES.1. Surmary of the Ancillary Effects of Acid Deposition Reduction Policy-Induced Air Quality Changes

\begin{tabular}{|c|c|c|c|c|c|c|c|}
\hline \multirow[b]{2}{*}{ Effects } & \multicolumn{7}{|c|}{ Changes in Concentrations } \\
\hline & $\overline{\mathrm{SO}_{x}}$ & $\underline{\mathrm{No}_{y}}$ & Oxidants & Metals & $\mathrm{CO}$ & $\mathrm{CO}_{2}$ & Hydrocarbons \\
\hline $\begin{array}{c}\text { Health-Mortality } \\
\text { and Morbidity }\end{array}$ & $x$ & $x$ & & $x$ & $x$ & $x$ & $x$ \\
\hline Vegetation & & $\mathrm{x}$ & $x$ & & $x$ & $x$ & $x$ \\
\hline visibility & & $x$ & $x$ & & & & \\
\hline Climate & & & & & & & $x$ \\
\hline Materials & & (a) & $x$ & & $x$ & & \\
\hline
\end{tabular}

(a) Not considered an ancillary effect by NAPAP.

The review of past studies related to visibility indicates that existing estimates vary considerably and are not easily generalized to be useful for assessing a visibility improvement affecting a large number of communities. Recent estimates (Tolley 1983) indicate visibility improvements of 10-30\% would be worth about $\$ 0.5$ to $\$ 2.0$ billion annually. Again, our review of studies valuing changes in mortality and morbidity did not find studies that would be useful for measuring values associated with changes in mortality or morbidity rates for both present and future periods. 


\section{CONTENTS}

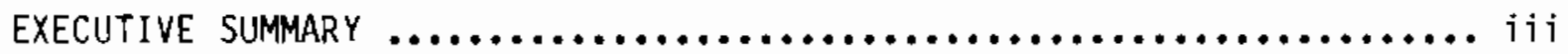

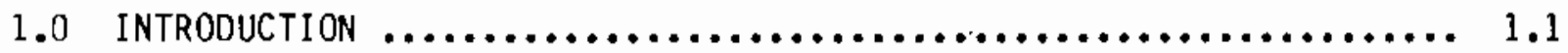

1.1 BACKGROUND AND RATIONALE $\ldots \ldots \ldots \ldots \ldots \ldots \ldots \ldots \ldots \ldots \ldots \ldots, 1.1$

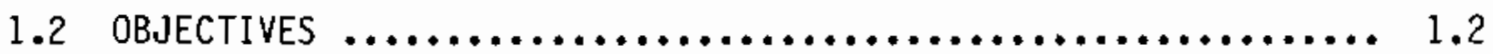

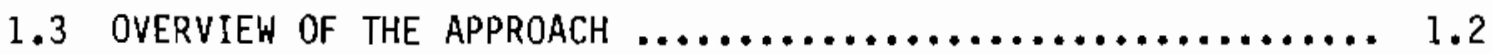

2.0 CONCLUSIONS AND RECOMMENDATIONS $\ldots \ldots \ldots \ldots \ldots \ldots \ldots \ldots \ldots \ldots \ldots . . \ldots \ldots$

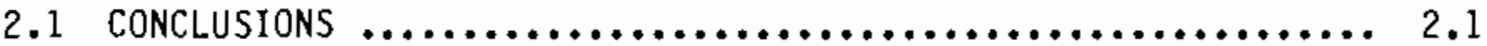

2.1.1 Air Quality Changes $\ldots \ldots \ldots \ldots \ldots \ldots \ldots \ldots \ldots \ldots \ldots, 2.1$

2.1.2 Effects of Air Quality Changes on Human Health and Wellbeing..................................... 2.2

2.1.3 Ancillary Effects of Lake Liming ................ 2.3

2.1.4 Economic Values of Ancillary Effects .............. 2.3

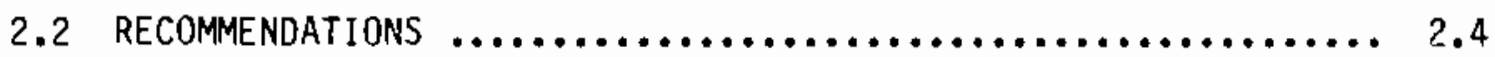

3.0 POTENTIAL ANCILLARY CHANGES IN AiR QUALITY $\ldots \ldots \ldots \ldots \ldots \ldots \ldots \ldots . . .1$

3.1 POTENTIAL ANCILLARY AIR QUALITY EFFECTS OF

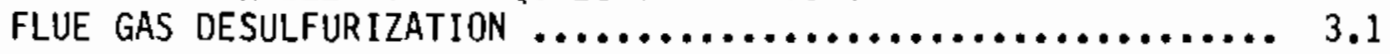

3.1.1 Description of Technology $\ldots \ldots \ldots \ldots \ldots \ldots \ldots \ldots \ldots, 3.2$

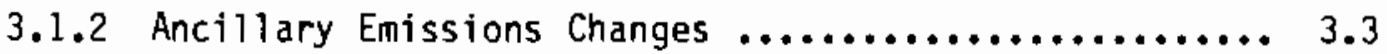

3.1.3 Ancillary Air Quality Changes from

Ancillary Emissions Changes $\ldots \ldots \ldots \ldots \ldots \ldots \ldots \ldots \ldots . .6 .4$

3.1.4 Ancillary Air Quality Changes from
Reduced Sulfur Dioxide Emissions ................. 3.5

3.1.5 Summary of Potential Ancillary Air Quality
Changes from Flue Gas Desulfurization .............. 3.7

3.2 POTENTIAL ANCILLARY AIR QUALITY EFFECTS OF CDAL SWITCHING/BLENDING $\ldots \ldots \ldots \ldots \ldots \ldots \ldots \ldots \ldots \ldots \ldots \ldots \ldots \ldots \ldots, 3.8$

3.2.1 Technical Aspects of Coal Switching and Blending ..... 3.9 
3.2.2 Ancillary Emissions Changes $\ldots \ldots \ldots \ldots \ldots \ldots \ldots \ldots \ldots . . .6 .10$

3.2.3 Potential Air Quality Changes from

Ancillary Emissions Changes $. . . \ldots \ldots \ldots \ldots \ldots \ldots \ldots . . .6 .12$

3.2.4 Ancillary Air Quality Changes from Reduced

Sulfur Dioxide Emissions $. . \ldots \ldots \ldots \ldots \ldots \ldots \ldots, \ldots \ldots, 3.14$

3.2.5 Summary of Ancillary Air Quality Changes from

Coal Switching and Blending ....................... 3.14

3.3 POTENTIAL ANCILLARY AIR QUALITY EFFECTS OF

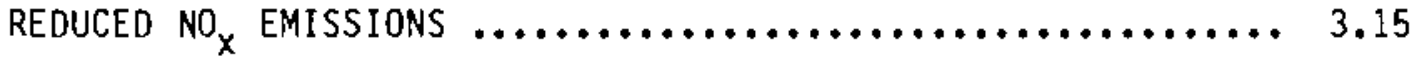

3.3.1 Description of Motor Vehicle $\mathrm{NO}_{x}$ Emissions

Reduction Technologies .......................... 3.16

3.3.2 Potential Ancillary Emissions Changes from Motor

Vehicle $\mathrm{NO}_{x}$ Emission Reduction Technologies ......... 3.19

3.3.3 Ancillary Air Quality Changes Associated with

Ancillary Emission Changes ......................... 3.21

3.3.4 Ancillary Air Quality Changes from Reduced

Nitrogen 0xide Emissions ........................... 3.21

3.3.5 Summary of Potential Ancillary Air Quality

Changes from $\mathrm{NO}_{x}$ Emissions Reductions ............... 3.24

3.4 SUMMARY OF POTENTIAL ANCILLARY AIR QUALITY CHANGES $\ldots \ldots \ldots \ldots .3 .24$

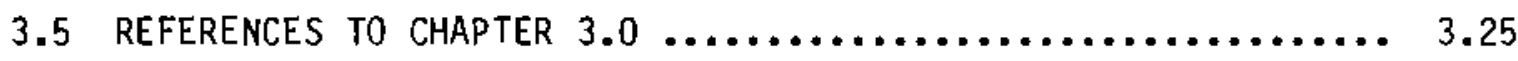

4.0 POTENTIAL EFFECTS OF ANCILLARY AIR QuALITY CHANGES $\ldots \ldots \ldots \ldots \ldots . .1$

4.1 ANCILLARY EFFECTS OF CHANGES IN CDNCENTRATIONS OF

SULFUR DIOXIDE AND SULFATES $\ldots \ldots \ldots \ldots \ldots \ldots \ldots \ldots \ldots \ldots \ldots \ldots \ldots, 4.1$

4.1.1 Health Effects of Sulfur Dioxide $\ldots \ldots \ldots \ldots \ldots \ldots \ldots . . .2$

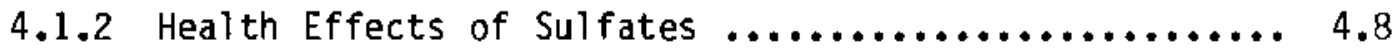

4.1.3 Visibility Effects of Sulfate Particulate ........... 4.9

4.1.4 Climate Effects of Sulfate ...................... 4.11

4.1.5 Vegetation Effects of Sulfur Dioxide .............. 4.11

4.1.6 Vegetation Effects of Sulfate Particulate .......... 4.13 
4.1.7 Materials Effects of Sulfur Dioxide and

Sulfate Particulate ............................. 4.14

4.2 ANCILLARY EFFECTS OF CHANGES IN CONCENTRATIONS OF

NITROGEN OXIDES $\ldots \ldots \ldots \ldots \ldots \ldots \ldots \ldots \ldots \ldots \ldots \ldots \ldots \ldots \ldots \ldots, 4.14$

4.2.1 Health Effects of Nitrogen Dioxide ................. 4.15

4.2.2 Health Effects of Other Nitrogen Oxides ........... 4.17

4.2.3 Effects of Nitrogen Dioxide and Nitrite Particulate

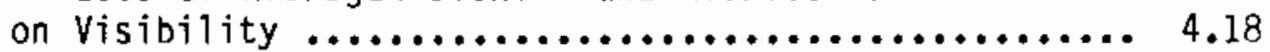

4.2.4 Effects on Vegetation of Nitrogen Dioxide .......... 4.20

4.2.5 Effects of Nitrogen 0xides on Materials ............ 4.21

4.3 ANCILLARY EFFECTS OF CHANGES IN CONCENTRATIONS OF

PHOTOCHEMICAL OXIDANTS--DZONE AND PERDXYACETYL

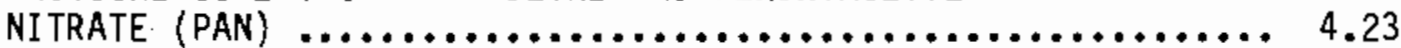

4.3.1 Health Effects of Stratospheric Ozone $\ldots . \ldots \ldots \ldots \ldots . . .4 .23$

4.3.2 Health Effects of Atmospheric Ozone and PAN .......... 4.24

4.3.3 Crop Effects of Tropospheric Ozone and PAN .......... 4.26

4.3.4 Forest Effects of Atmospheric Ozone .............. 4.27

4.3.5 Materials Effects of Atmospheric Ozone ............. 4.27

4.4 ANCILLARY EFFECTS OF CHANGES IN AIRBORNE METALS AND

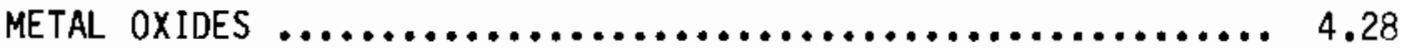

4.4.1 Description of Potential Effects $. . \ldots \ldots \ldots \ldots \ldots \ldots . . .28$

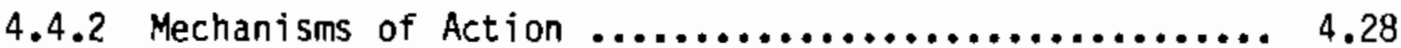

4.4.3 Estimates of Effects $\ldots \ldots \ldots \ldots \ldots \ldots \ldots \ldots \ldots \ldots \ldots, 4.28$

4.5 ANCILLARY EFFECTS OF CARBON MONOXIDE CONCENTRATION

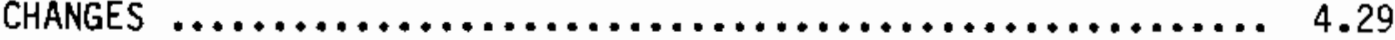

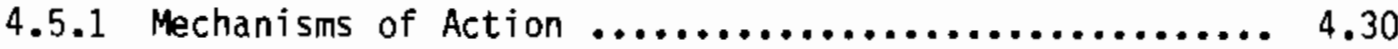

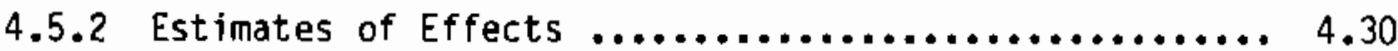

4.6 ANCILLARY EFFECTS OF CHANGES IN CARBON DIOXIDE LEVELS $\ldots \ldots \ldots 4.32$

4.6.1 Potential Effects on Climate..$\ldots \ldots \ldots \ldots \ldots \ldots \ldots \ldots .4 .32$ 
4.6.2 Potential Effects on Vegetation ................ 4........

4.7 POTENTIAL EFFECTS OF CHANGES IN THE LEVELS OF

HYDROCARBONS AND OTHER ORGANIC POLLUTANTS $\ldots \ldots \ldots \ldots \ldots \ldots \ldots \ldots 4.33$

4.7.1 Organic Pollutants and Human Health .............. 4.33

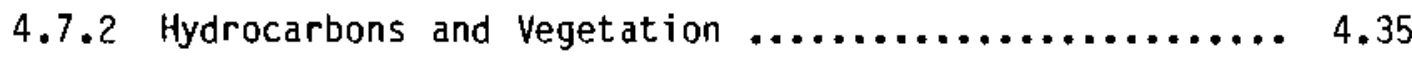

4.8 POTENTIAL EFFECTS OF ANCILLARY POLLUTANTS IN

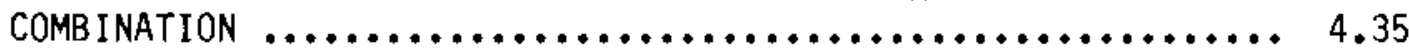

4.8 .1 Effects on Health $\ldots \ldots \ldots \ldots \ldots \ldots \ldots \ldots \ldots \ldots \ldots \ldots . \ldots \ldots . \ldots \ldots$

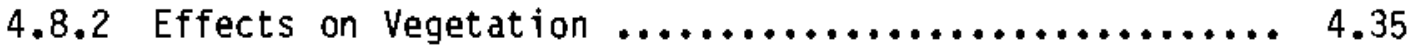

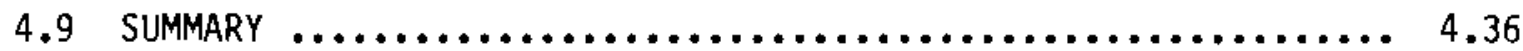

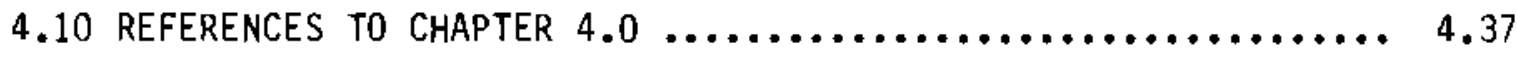

5.0 THE ANCILLARY EFFECTS OF LAKE LIMING $\ldots \ldots \ldots \ldots \ldots \ldots \ldots \ldots \ldots \ldots \ldots \ldots$

5.1 DESCRIPTION OF TECHNOLOGY $\ldots \ldots \ldots \ldots \ldots \ldots \ldots \ldots \ldots \ldots \ldots \ldots \ldots \ldots \ldots$

5.2 IMPACT OF LIMING ON LAKE CHEMISTRY $\ldots \ldots \ldots \ldots \ldots \ldots \ldots \ldots \ldots \ldots \ldots . \ldots \ldots$

5.2 .1 Mechanism of Action ...................... 5.3

5.2 .2 Chemical Changes $\ldots \ldots \ldots \ldots \ldots \ldots \ldots \ldots \ldots \ldots \ldots \ldots \ldots \ldots . . \ldots .4$

5.3 PHYSICAL EFFECTS 0 F LAKE LIMING $\ldots \ldots \ldots \ldots \ldots \ldots \ldots \ldots \ldots \ldots \ldots . \ldots \ldots$

5.4 BIOLDGICAL EFFECTS OF LAKE LIMING ................. 5.7

5.5 SUMMARY OF LAKE LIMING ANCILLARY EFFECTS $\ldots \ldots \ldots \ldots \ldots \ldots \ldots \ldots$

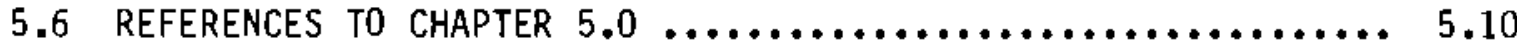

6.0 ECONOMIC VALUATION OF POTENTIAL ANCILLARY EFFECTS $\ldots \ldots \ldots \ldots \ldots \ldots$

6.1 ECONOMIC VALUATION OF ENVIRONMENTAL CHANGES $\ldots \ldots \ldots \ldots \ldots \ldots \ldots .6 . . . .$.

6.2 VALUATION OF CHANGES IN VISIBILITY $\ldots \ldots \ldots \ldots \ldots \ldots \ldots \ldots \ldots \ldots .6 .10$

6.2.1 Empirical Methods of Valuing Visibility Changes ..... 6.11

6.2.2 Review of Economic Valuation Studies ............. 6.16

6.2 .3 Sumary and Evaluation of Literature ............ 6.24

6.3 VALUATION OF CHANGES IN HEALTH $\ldots \ldots \ldots \ldots \ldots \ldots \ldots \ldots \ldots \ldots \ldots \ldots . \ldots . . \ldots$ 
6.3.1 Approaches to Measuring The Value of Mortality

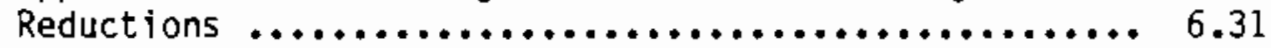

6.3.2 A Basic Model of The Willingness to Pay for

Mortality Reductions .............................. 6.34

6.3.3 Approaches to Measuring Willingness to Pay for

Mortality Reductions ............................ 6.35

6.3.4 The value of Life: A Review of The Estimates ....... 6.42

6.3 .5 The value of Morbidity $\ldots \ldots \ldots \ldots \ldots \ldots \ldots \ldots \ldots \ldots \ldots .6 .49$

6.3.6 Summary of Health Valuation $\ldots \ldots \ldots \ldots \ldots \ldots \ldots \ldots \ldots .6 .50$

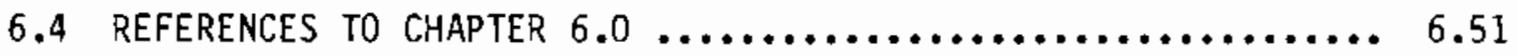




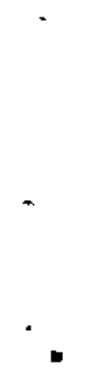

.

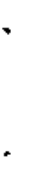

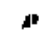

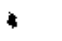

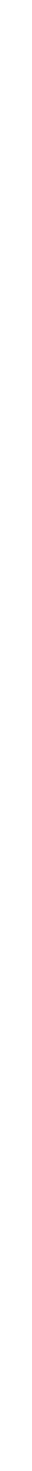




\section{FIGURES}

6.1 Marginal Willingness to Pay Function for an

Environmental Good ................................... 6.8

6.2 Benefits of Total Willingness to Pay for a Change in

Environmental Good from $q^{0}$ to $q^{1}$

6.9

\section{TABLES}

2.1 Summary of the Ancillary Effects of Acid Deposition Reduction

Policy-Induced Air Quality Changes ....................... 2.3

3.1 Changes in Ozone Concentrations Associated with Changes in Emissions of Nitrogen Oxides

3.2 A Summary of Potential Ancillary Air Quality Changes ........... 3.25

4.1 Light Absorption by $\mathrm{NO}_{2}$ as a Function of Wavelength ........... 4.19

4.2 Human Response to Various Concentrations of

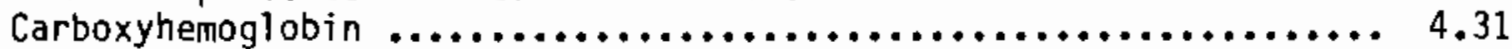

4.3 Summary of the Ancillary Effects of Acid Deposition

Reduction Policy-Induced Air Quality Changes ................ 4.36

5.1 Summary of Ancillary Effects of Lake Liming ................. 5.9

6.1 Contingent Market Estimates of The Value of

Visibility Improvements ............................... 6.18

6.2 Estimates of the Value of a Statistical Life ................ 6.43 
.

.

.

. 


\section{D INTRODUCTION}

This research was performed by Pacific Northwest Laboratory (PNL) for the Environmentai Protection Agency (EPA), Office of Research and Development (ORD). The research was funded as part of the National Acid Precipitation Assessment Program (NAPAP). NAPAP is an inter-agency program to research and assess the causes and effects of acid deposition.

NAPAP is examining a number of potential ways to reduce the precursors (sulfur dioxide and nitrogen oxides) to acid deposition. However, the policies to reduce acid deposition will have other physical, biological and economic effects unrelated to acid deposition. For example, control policies that reduce sulfur dioxide emissions may also increase visibility. The effects of an acid deposition policy that are unrelated to acid deposition are referred to as "ancillary" effects. This research identifies and characterizes the principle physical and economic ancillary effects associated with acid deposition control and mitigation policies.

\subsection{BACKGROUND AND RATIONALE}

One of the basic principles of policy or benefit-cost analysis is that all of the impacts of the policy under consideration that may have value to society should be included in the analysis, either as benefits or costs. In some cases it may be difficult to explicitly value potential impacts; if so, qualitative descriptions of the impacts should be included in the benefit-cost anaiysis. If this principle is not followed, misleading information about the effects of policies on societal welfare will be provided to decision makers, who might, as a result, make decisions which have unintended consequences. For example, exclusion of benefits may lead to rejecting a policy that actually has net benefits to society. Exclusion of costs (or damages associated with a policy) may lead to implementation of a policy that will actually reduce economic welfare, since the net benefits would be overstated. Thus, it is important that the ancillary effects of proposed acid deposition reduction and mitigation policies be considered in benefit-cost analyses of these policies, since it is likely that some of these ancillary effects have value to society. For example, 
reductions in the probability of morbidity or mortality associated with sulfur dioxide-induced respiratory irritation are valuable to society, since they may lead to reductions in 1) time spent away from work (and the corresponding lost production), 2) medical treatment costs, and 3) pain and suffering.

NAPAP recognized that it was misleading to limit an assessment of the benefits and costs of acid deposition policies to the consequences of acid deposition. However, most of the research on the effects of other pollutants occurs in EPA and other agency offices that are not organizationally 1 inked to NAPAP. For that reason, EPA and NAPAP requested that PNL review existing literature and research to determine the ancillary effects of several key technologies to control or mitigate acid deposition.

\subsection{OBJECTIVES}

This study was funded by the EPA and NAPAP to provide a review and summary of the ancillary effects and their economic values of several policies to reduce or mitigate acid deposition effects. Specifically, the objectives of the research were to:

- identify and characterize the atmospheric, physical and biological ancillary effects associated with acid deposition control and mitigation policies.

- review existing studies that estimate the value of atmospheric physical and biological ancillary effects.

- assess the potential economic importance of ancillary effects and the usefulness of including these effects in subsequent NAPAP assessments.

\subsection{OVERVIEW OF THE APPROACH}

In this study the ancillary benefits associated with four specific acid deposition policy options were investigated. The four policy options investigated are: 1) flue gas desulfurization, 2) coal blending or switching, 3) reductions in automobile emissions of $\mathrm{NO}_{x}$, and 4) lake liming. Potential 
ancillary benefits of each policy option were identified and characterized. Particular attention was paid to the literature on economic valuation of potential ancillary effects.

Each of the first three policy options to be considered involves a reduction in emissions of an acid deposition precursor: the first two focus on $\mathrm{SO}_{2}$ emissions, the third on $\mathrm{NO}_{x}$ emissions. Each of the three options are investigated in a similar manner, which will be slightly different from that used to investigate the fourth option. Each of the three options will be investigated in a four-step process.

First, the technological aspects of each option are investigated through a review of the engineering/technology literature on emissions control and coal combustion. This review permits identification and characterization of changes in emissions of compounds other than those targeted by the policy $\left(\mathrm{SO}_{2}\right.$ and $\mathrm{NO}_{\mathrm{X}}$ ). Existing quantitative studies are examined as well. An example of such an ancillary emission change is the potential change in emissions of fly-ash, carbon oxides, and trace metals that may occur as a result of switching from use of high-sulfur eastern coal to low-sulfur western coal.

Second, the changes in air quality associated with both the targeted and ancillary emission changes (other than changes in acid deposition) are investigated. This involves a review of the literature on atmospheric chemistry. Potential ambient air-pollutant changes are identified and characterized. Past quantitative studies in this area are also examined. Examples of such ancillary air-quality changes are 1) local changes in ambient $\mathrm{SO}_{2}$ concentrations and total suspended particulates that may accompany $\mathrm{SO}_{2}$ emission changes; and 2) changes in $\mathrm{O}_{3}$ concentrations that may accompany $\mathrm{NO}_{\mathrm{x}}$ emission changes.

Third, the physical and biological changes associated with the ancillary air-quality changes are investigated. This involves a review of the literature on air pollution impacts. Potential ancillary physical and biological effects are identified and characterized. Again, quantitative estimates and relationships are reviewed. Examples of potential ancillary physical and biological effects are visibility changes, health effects, and plant growth changes that may accompany changes in ambient $\mathrm{SO}_{2}$ and $\mathrm{O}_{3}$ concentrations and changes in total suspended particulates. 
Fourth, the economic value of potential ancillary physical and biological effects are investigated. The economic literature dealing with each of the specific physical and biological effects are reviewed. Estimates of the value of the ancillary effects are identified and summarized; the usefulness of these estimates and the relevant extant literature in general for NAPAP's assessments are al so evaluated.

For the lake-liming option, a similar though not identical procedure consisting of two steps is utilized. First, the technical aspects of lake liming is investigated. The literature on lake liming and aquatic chemistry is reviewed in this step. Potential ancillary changes in the chemical composition of lakes are identified and characterized.

Second, the potential ancillary biological effects of potential ancillary chemical changes are investigated. The literature on aquatic biology is reviewed in this step. Potential impacts on fish are not considered since they are direct impacts and not ancillary. Impacts on other aquatic organisms are identified and characterized.

The economic value of ancillary aquatic effects is not assessed. NAPAP is including the value of the changes in fish levels as part of its economic capability and since fish impacts are considered direct, not ancillary impacts of lake liming, they are not included in this report. Also, a preliminary review of the literature indicated no economic valuation studies were available on the other aquatic life affected by lake liming. 


\subsection{CONCLUSIONS AND RECOMMENDATIONS}

This research was designed to provide EPA and NAPAP with a review of the ancillary effects and their economic values associated with three emission reduction policies and one mitigation policy. The principle conclusions and recommendations from this research are discussed below.

\subsection{CONCLUSIONS}

The conclusions of this research relate to the physical, air, and water quality changes caused by emission reduction technologies or mitigation options and the economic values of these changes. We first present the air quality changes due to the 3 emission reduction technologies (flue gas desulfurization, coal switching or blending, and automotive technologies) to reduce sulfur and nitrogen oxides. We next present the conclusions of our research on the linkage between air quality changes and human health and wellbeing. Third, we present the conclusions for our analysis of the ancillary effects of lake liming. Finally, we present our conclusions of the economic values of these ancillary effects.

\subsubsection{Air Quality Changes}

It was concluded that the principle air quality changes due to use of flue gas desulfurization (FGD) are:

- FGD systems will reduce airborne concentrations of sulfate aerosols, a major component of total suspended particulates, and sulfur dioxide;

- FGD systems will also likely reduce, although to a lesser extent, concentrations of nitrogen dioxide, gaseous and particulate nitrites and nitrates. These changes may effect ozone concentrations, although the direction of this change is uncertain;

- FGD systems may decrease large non-sulfate particulates but could increase small non-sulfate particulates. 
The principle air quality changes due to widespread use of coal switching/blending are:

- Coal switching/blending should significantly reduce sulfate aerosols and sulfur dioxide:

- Other airborne pollutants (e.g. nitrogen dioxide, ozone, carbon monoxide, trace metals) may either increase or decrease depending on:

1) the amounts of the "new" coal used to displace the "old" coal;

2) the pollutant content of "new" coal versus the "old" coal; 3) the change in temperature at which the plant operates, and 4) the difference in efficiency of the system, including pollution control systems, for the "new" versus "old" coal.

The principle conclusions regarding air quality changes due to automobile $\mathrm{NO}_{\mathrm{x}}$ policies are:

- The policies should reduce concentrations of nitrogen dioxide and gaseous and particulate nitrites and nitrates;

- Concentrations of ozone should change and will likely decrease if the ratio of hydrocarbons to nitrogen oxides in the area is high;

- Depending on the form of the technological changes used to reduce $\mathrm{NO}_{\mathrm{x}}$, there could be small increases in carbon monoxide.

\subsubsection{Effects of Air Quality Changes on Human Health and Wellbeing}

Table 2.1 summarizes the effects of seven pollutants that could affect human health, vegetation, visibility, climate, or material lifetimes. It must be pointed out that some effects, especially some human health effects, are noticed at higher than ambient concentrations. Whether these effects are also found at ambient conditions is less clear from our review of the literature.

The frequency of respiratory illness may be influenced by $\mathrm{SO}_{x} \mathrm{NO}_{x}, \mathrm{O}_{3}$ and metals. $\mathrm{SO}_{x}, \mathrm{NO}_{x}$ and $\mathrm{CO}$ may affect the risk of cardiopulmonary disease, while the risk of other health effects may change depending on levels of $\mathrm{SO}_{x}, \mathrm{O}_{3}$, metals, $\mathrm{CO}$ and organic pollutants. $\mathrm{SO}_{x}$ and $\mathrm{NO}_{x}$ can affect visibility and hazi.ness; ancillary pollutants may also perturb the climate $\left(\mathrm{CO}_{2}\right.$ and $\left.\mathrm{SO}_{\mathrm{x}}\right)$ and 
TABLE 2.1. Summary of the Ancillary Effects of Acid Deposition Reduction Policy-Induced Air Quality Changes

\begin{tabular}{|c|c|c|c|c|c|c|c|}
\hline \multirow{2}{*}{ Effects } & \multicolumn{7}{|c|}{ Changes in Concentrations } \\
\hline & $\mathrm{SO}_{\mathrm{x}}$ & $\mathrm{NO}_{\mathrm{x}}$ & Oxidants & Metals & CO & $\mathrm{CO}_{2}$ & Hydrocarbons \\
\hline Health-Mortality & $x$ & $\bar{x}$ & & $x$ & $x$ & $x$ & $x$ \\
\hline and Morbidity & & & & & & & \\
\hline Vegetation & & $x$ & $x$ & & $x$ & $x$ & $x$ \\
\hline Visibility & & $x$ & $x$ & & & & \\
\hline Climate & & & & & & & $x$ \\
\hline Materials & & $\mathrm{a}$ & $x$ & & $x$ & & \\
\hline
\end{tabular}

(a) Not considered an ancillary effect by NAPAP.

radiation-filtering properties of the stratosphere $\left(0_{3}\right)$. Durability of elastomers, such as rubber, and some fabrics and dyes may be affected by changes in $\mathrm{NO}_{\mathrm{x}}$ and $\mathrm{O}_{3}$ levels. $\mathrm{CO}_{2}$ and $\mathrm{O}_{3}$ may affect forest growth and crops; crop changes may also be induced by effects of $\mathrm{SO}_{x}, \mathrm{NO}_{x}$ and specific organic pollutants. Metals may disrupt ecosystems with possible impacts on grazing animals.

\subsubsection{Ancillary Effects of Lake Liming}

The ancillary effects of lake liming do not include the impacts on fish populations since these are considered the direct impacts of the mitigation option. As would be expected, lake liming changes a number of chemical parameters of the lake, including $\mathrm{pH}$, alkalinity, hardness, calcium concentrations, metal concentrations, soluble metals, and dissolved organic compounds. In a clear body of water, the short term effect of the chemical changes is an increase in transparency followed later by a decrease in transparency. This is usually accompanied by a decrease in temperature. Biologically, the effects are increases in bacteria, short-term decreases in small aquatic organisms (phytoplankton, zooplankton and benthic organisms). There are also shifts in the species of these organisms as $\mathrm{pH}$ increases.

\subsubsection{Economic Values of Ancillary Effects}

The review of economic value of ancillary effects centered on two effects visibility and health. These two were selected because they were not 
explicitly included in NAPAP economics assessments and an initial review of the literature indicated the value of changes in health (mortality or morbidity) or visibility could be significant.

The review of past studies related to the value of changes in visibility indicates that existing estimates vary considerably and are not easily generalized to be useful for assessing a visibility improvement affecting a large number of communities. Recent estimates (Tolley 1983) indicate visibility improvements of $10-30 \%$ would be worth about $\$ 0.5$ to $\$ 2.0$ billion annually. Again, our review of studies valuing changes in mortality and morbidity found few studies that would be useful for measuring values associated with changes in mortality or morbidity rates for both present and future periods. We feel there are large uncertainties associated with these studies. Therefore, we did not feel these studies relevant for assessments of acid rain reduction policies. In our recommendations below, we describe a research effort to correct this shortcoming.

\subsection{RECOMMENDATIONS}

The principle recomendations resulting from the economics portion of this study are listed below.

Recommendation Number 1. NAPAP should include ancillary and acid deposition effects and their economic values in any assessment of acid deposition control policies.

Our research indicates that the values associated with visibility or health changes are sufficiently large that they should be explicitly included in any policy assessment. Ignoring these effects or attempting to treat them qualitatively could lead to incorrect decisions.

Recommendation Number 2. EPA should undertake research necessary to develop a model capable of estimating willingness-to-pay for improvements in visibility. 
The proposed model would be based on a contingent valuation survey of a number of individuals in cities and rural areas scattered across the United States. Individuals would be asked to state their willingness to pay for particular improvements in 1) visual range, 2) color contrast, 3) atmospheric discoloration, and 4) combinations of these three, both in the area surrounding their residence and in other (e.g., vacation) areas.

The responses to this survey would then be economically analyzed to develop an equation (or set of equations) explaining an individual's willingness-topay for visibility improvements in the area surrounding his residence. A similar equation would be developed for areas not immediately adjacent to the respondent's residence. Combined with data on income, urban/rural population, and existing visibility, this model could be used to predict the WTP of all individuals in an affected population for an air quality improvement affecting each of the three measures of visibility.

The important characteristics of such a model, distinguishing it from the other contingent valuation studies of visibility, are the following. First, it would be able to predict the WTP of individuals in the United States. Second, it would be able to consider visibility improvements at any relevant location or set of locations in the United States. Third, it would be able to consider air quality changes leading to visibility improvements of any relevant magnitude. Fourth, it would be able to consider improvements in any or all of the three visibility characteristics.

We believe these four characteristics are important in considering the value of visibility-related ancillary benefits. Because such improvements will occur in the future, it is important to be able to predict their value, not merely measure what their value was in a particular reference year. Acid deposition policies may affect visibility in a number of cities and rural areas scattered across the United States, and it is important to be able to value the improvements in all of these areas. Moreover, one must take into account that improvements of a particular magnitude will have different values in different places. Acid deposition policies to be considered may result in visibility changes of various magnitudes, and each of these policies must be consistently valued. Moreover, one must take into account that a $10 \%$ visibility improvement 
is not twice as valuable as a $5 \%$ visibility improvement. For these reasons, we believe development of the model proposed above is both warranted and necessary for a complete benefit-cost analysis of acid deposition control policies.

Recommendation Number 3. EPA should undertake research to help answer empirical questions on the value of air pollution related changes in mortality and morbidity.

Valuing policy-induced changes in rates of mortality and morbidity is a relatively new or young endeavor for economics. The relatively "simple" questions, like the types of values that should be included in such a valuation process, have only recently been answered in a manner consistent with established welfare economic theory. Estimation of each of these types of values has occurred slowly. It is obvious from a review of the literature that many questions remain to be answered in this field.

Answers to many of these questions are required in order to value all of the benefits of potential acid deposition control policies, because such policies may affect human health. We therefore recommend a research program to answer some of these questions. Specificaliy, we believe theoretical research should focus on the types of values that should be included in an analysis of policies affecting both present and future health, how these values ought to be addressed and, in particular, how the individual's willingness-to-pay for future mortality reductions should be approached. We believe that an empirical component should obtain data on both mortality and morbidity and develop estimates of the values of present and future changes in these rates in a manner consistent with the theoretical framework and the relevant aspects of the policies in question. Until such a program is implemented, policymakers will have to rely on cursory literature reviews, instead of real numbers. 


\subsection{POTENTIAL ANCILLARY CHANGES IN AIR QUALITY}

This chapter identifies and characterizes the ancillary air quality changes that may accompany implementation of the three emissions control options and one mitigation option considered in this study. An ancillary air quality change is defined in this study as a change in the ambient air concentration of a particular chemical compound or pollutant that results directly from implementation of an emissions control option. The pollutant may be a compound which, after falling to the ground, is considered acid deposition (e.g., one of the sulfate aerosols); conversely, the pollutant may be a compound such as ozone that is less directly related to acid deposition.

The chapter consists of three sections, one devoted to each technology/ policy option. Flue gas desulfurization is described in Section 3.1, coal blending in Section 3.2, and nitrogen oxides emission reduction technologies in Section 3.3. A summary of potential ancillary air quality changes is presented in Section 3.4.

\subsection{POTENTIAL ANCILLARY AIR QUALITY EFFECTS OF FLUE GAS DESULFURIZATION}

Flue gas desulfurization (FGD) equipment, commonly called scrubbers, is frequently used in coal-fired power plants to remove sulfur dioxide from the flue gases or exhaust emissions produced in the combustion process. Greater use of this technology (either by retrofitting existing plants or by equipping all new plants with the equipment) has been suggested as one means of reducing acid deposition in the United States and Canada. The basic technological characteristics of the FGD process are described in Section 3.1.1. In Section 3.1.2, the changes caused by installation of FGD equipment in power-plant emissions of pollutants other than sulfur dioxide are discussed; in Section 3.1.3, the air quality changes associated with these ancillary emissions changes are described. Section 3.1.4 identifies and characterizes the changes in air quality (other than acid deposition reductions) that may accompany reductions in sulfur dioxide emissions. Section 3.1 .5 sumarizes the potential ancillary air quality changes associated with increased utilization of flue gas desulfurization equipment. 


\subsubsection{Description of Technology}

Several different flue gas desulfurization processes or designs were developed and installed in U.S. power plants during the 1970's and early 1980's (EPRI 1980). During combustion of coal in the power plant, flue gases or exhaust are generated; these gases contain sulfur dioxide as well as flyash, nitrogen oxides (particularly nitric oxide, N0), and other compounds. In the absence of FGD and other emission control equipment, these gases are discharged into the atmosphere from the plant's chimney or smokestack. FGD removes sulfur dioxide from these gases by passing the gases through or by an alkaline reagent, such as wet calcium (lime or limestone slurry); the sulfur dioxide reacts with the reagent to form solid and liquid sulfate and sulfide salts. These salts can be removed from the stack as wet sludge for disposal or further processing. The remaining flue gases are then discharged into the atmosphere. The process typically removes $85-95 \%$ of the sulfur dioxide from the original flue gases (OTA 1979).

The eight variants of the basic FGD process that are used in the United States differ primarily in three respects. First, they differ according to the compound used as the alkaline reagent. In addition to wet calcium, sodium, dry calcium, magnesium, and sodium citrate are used. Second, they differ according to the fate of the sludge generated in the FGD process. In some of the processes, the sludge is stabilized and then disposed in a landfill, creating a solid-waste disposal/pollution problem; (a) in other FGD processes, the sludge is processed further, producing saleable items such as elemental sulfur, gypsum (calcium sulfate), and sulfuric acid (Duvel et al. 1979, Prior 1977, Kinetic and Rossoff 1978). Third, they differ according to the pollutants that are removed by design along with sulfur dioxide from the flue gases; some FGD processes contain an optional subprocess which removes flyash and particulates from the flue gases prior to removal of the sulfur dioxide (OTA 1979, Duvel 1979).

(a) The solid-waste disposal problem, although important, is outside the scope of this study. 


\subsubsection{Ancillary Emissions Changes}

Ancillary air quality changes associated with implementation of flue gas desulfurization (or any technology which reduces sulfur dioxide emissions) can arise from either of two sources. First, such changes can be caused by FGDinduced reductions in the emissions of pollutants other than sulfur dioxide; since emissions of these pollutants decrease, airborne concentrations of the particular pollutants are likely to decrease, particularly in the area surrounding the affected power plant. Second, ancillary air quality changes can be caused directly by sulfur dioxide emissions reductions, which cause reductions in the airborne concentrations of sulfur dioxide and related pollutants, such as sulfate aerosols. In this and the following section the first of these two sources of FGD-induced ancillary air quality changes will be considered.

There is conflicting evidence about whether the installation of FGD equipment leads directly to reductions in emissions of other compounds or pollutants. However, initial tests of a number of prototype FGD processes showed that specific designs may be able to reduce power plant emissions of nitric oxide (NO) by 5-40\% (EPRI 1978). Other tests were unable to confirm these findings (i.e., no nitric oxide reductions were discovered in similar studies; EPRI 1978), so that the existence and extent of nitric oxide removal by FGD equipment is uncertain. Recently some researchers have speculated (Markowski et al. 1983) that FGD first generates, then fails to efficiently remove, very small sulfate and other particulate (i.e., particles less than 0.8 micrometers in diameter). These researchers measured emissions of sulfate aerosols from four coal-fired boilers equipped with FGD, and observed some cases in which net generation of small particulate and sulfate occurred. However, they did not observe any cases in which there was net generation of particulate or sulfate on a total mass basis. If these research results are confirmed by other studies, the findings would imply that emissions of small sulfate aerosol particulate may be increased by $F G D$ installation, with an off setting reduction (in terms of total mass of emissions) in emissions of large particulate (Markowski et al. 1983). Because small particulate may be a much greater health hazard than large particulate, this potential ancillary emissions change may be important. 
In addition to these potential ancillary emissions changes, flyash emissions are also reduced by $F G D$ installation if the flyash removal subprocess is contained in the main FGD equipment. Because such emissions changes are more a result of the installation of this optional removal subprocess than of installation of the FGD equipment itself, they will not be considered here.

In summary, then, installation of FGD equipment may result in two types of ancillary emissions changes: 1) reduced emissions of nitric oxide and other nitrogen oxides and 2) increased emissions of "small" sulfate aerosol particulates combined with decreased emissions of "large" sulfate particulates.

\subsubsection{Ancillary Air Quality Changes From Ancillary Emissions Changes}

This section briefly describes the air quality changes that may result from the ancillary emissions changes described in Section 3.1.2. Such air quality changes are one of the two components described above of the ancillary air quality changes associated with FGD use. The second is associated directiy with sulfur dioxide emissions reductions described in the next section. The air quality changes in this section include change associated with reduction ir nitrogen oxides emissions as well as changes in the concentrations of small anc large particulates.

Reductions in nitrogen oxide $\left(\mathrm{NO}_{x}\right)$ emissions, particularly nitric oxide (N0) emissions, will, as discussed in greater detail Section 3.3, have a number of effects on ambient air quality. First, such emission reductions will result in reduced airborne concentrations of nitrogen dioxide $\left(\mathrm{NO}_{2}\right)$, which may be is an irritant to human health. Second, such emission reductions will result in decreased airborne concentrations of gaseous as well as particulate nitrites and nitrates. Several of these species, particularly nitric acid $\left(\mathrm{HNO}_{3}\right)$ take the form of acid deposition when removed from the atmosphere. Third, nitric oxide is a precursor, along with various hydrocarbons, of ozone and other oxidants, such as peroxyacetyl nitrate (PAN), nitramines, and amides. It cannot be concluded, however, that reductions in nitric oxide emissions necessarily result in reduced concentrations of these secondary pollutants; the conversion process is highly nonlinear and quite complex. This issue is discussed in more detail in Section 3.3. 
Changes in the quantity and size distribution of primary sulfate emissions from emission changes cause a corresponding change in the airborne concentrations of these sulfates; i.e., the increase in emissions of small sulfate and other pollutants causes the airborne concentrations of small particulates to increase. However, although emissions of primary sulfates, particularly small particles, may increase because of $F G D$ installation, and may thus cause airborne concentrations of sulfate particulates to increase, these latter increases are likely to be overwhelmed by decreases of sulfate particulate of all sizes caused by reductions that result from reductions in sulfur dioxide emissions (see Section 3.1.4).

\subsubsection{Ancillary Air Quality Changes From Reduced Sulfur Dioxide Emissions}

The primary effect of $F G D$ installation is to reduce emissions of sulfur dioxide $\left(\mathrm{SO}_{2}\right)$. In the context of acid deposition, $\mathrm{FGD}$ is of interest because sulfur dioxide emissions are, through a number of atmospheric chemical reactions, transformed into sulfate aerosols $\left(\mathrm{SO}_{4}\right)$, particularly sulfuric acid $\left(\mathrm{H}_{2} \mathrm{SO}_{4}\right)$, which is believed to be the primary component of acid deposition. Thus, by reducing emissions of sulfur dioxide, levels of wet and dry acid deposition can be reduced (National Research Council/National Academy of Sciences 1983).

Reducing emissions of sulfur dioxide has other effects as well. In particular, such emissions reductions may lead to reductions in the airborne or atmospheric concentrations of several pollutants. First, although most of the emitted sulfur dioxide reacts in the atmosphere to form sulfates and other compounds, some portion of the sulfur dioxide typically does not react in this manner; i.e., some of the emitted sulfur dioxide remains in this form and is removed from the atmosphere as sulfur dioxide. Such removal is typically through either of two processes: 1) dry deposition or 2) precipitation scavenging. Moreover, emitted sulfur dioxide does not immediately react to form sulfate, so that at any given time some of the emitted sulfur dioxide, even that portion destined to become another compound, remains in the atmosphere in gaseous (i.e., $\mathrm{SO}_{2}$ ) form. Thus, sulfur dioxide emission reductions will result in reductions in the airborne concentration of sulfur dioxide, as well as reductions in the dry deposition and precipitation scavenging of the gas. 
Second, because the major portion of atmospheric sulfur dioxide reacts via an oxidation process to form other compounds, airborne concentrations of these secondary pollutants will decrease as a result of sulfur dioxide emissions reductions. In particular, sulfur dioxide may oxidize to sulfur trioxide ( $\mathrm{SO}_{3}$ ) which inmediately reacts with water in the atmosphere to form sulfuric acid $\left(\mathrm{H}_{2} \mathrm{SO}_{4}\right)$. Other oxidation processes may also yjeld sulfuric acid (i.e., without first forming $\mathrm{SO}_{3}$ ), as well as a number of other sulfate aerosols, including ammonium sulfate $\left(\mathrm{NH}_{4} \mathrm{HSO}_{4}\right)$, calcium sulfate $\left(\mathrm{CaSO}_{4}\right)$, magnesium sulfate, manganese sulfate, and letovicite. All of these sulfates may contributor to acidic deposition. The oxidation of sulfur dioxide to sulfate is thus the central link between sulfur dioxide emissions and acid deposition. However, prior to their removal from the atmosphere, these sulfate aerosols are, by definition, fine particulates of either solid or liquid form which, in fact, are the largest component of total suspended particulate (TSP) in the United States. As discussed in Chapter 4.0, these particulates may scatter light, causing reductions in visibility as well as potential climatic changes; they may adversely affect the respiratory functions of humans and animals, and also affect plants. Thus, reductions in sulfur dioxide emissions may cause potentially important reductions in airborne concentrations of sulfate aerosols.

The ancillary air quality changes that may accompany sulfur dioxide emission reductions are identified above will affect some regions more than others. If a large enough region and a long enough time period are considered, a one-ton reduction in sulfur dioxide emissions will result in a one-ton reduc.tion in the concentration of $\mathrm{SO}_{2}$-related pollutants (EPA 1982). This region may have to be very large before emissions and atmospheric concentrations are linearly related.

At a particular location, the quantity and location of reductions in airborne concentrations of sulfur dioxide and specific sulfate aerosols (components of total suspended particulates, TSP) caused by sulfur dioxide emission reductions is uncertain. Generally, the sulfur dioxide and sulfate concentrations associated (either directly or indirectly) with emissions from a particular source become less concentrated the farther one moves away from the 
source. The height of the stack, wind speed and direction, temperature stratification, and other factors affect 1) whether or not and 2) the degree to which this general rule is true.

Such meteorological and other factors are taken into account by sourcereceptor models. These models project the effects of emission changes on air quality at specific locations. Many source-receptor models have been developed to predict regional sulphur dioxide and sulfate (or TSP) concentrations given a region-specific emissions inventory or scenario. Such a model would he required to actually estimate the ancillary air quality changes associated with a particular emissions reduction strategy. Selecting the appropriate model is important, since model results may be highly sensitive to assumptions concerning emissions inventories (Ditto et a1. 1976), meteorological inputs (Morgenstern and Hagg 1972), and physical and chemical processes. (a)

An extensive review of source-receptor models is outside the scope of this study, as is model selection. However, it is important to note that most models are specific to a pollutant, a geographic region, the resolution desired for air quality estimates. As a result of these limitations in scope, a model chosen to project the impact of emission changes on acidic deposition may not be the best predictor of ancillary air quality changes.

\subsubsection{Summary of Potential Ancillary Air Quality Changes from Flue Gas Desulfurization}

More widespread use of flue gas desulfurization equipment will result in reductions in the airborne concentrations of sulfate aerosols, which are a major component of total suspended particulates. The airborne concentrations of sulfuric acid $\left(\mathrm{H}_{2} \mathrm{SO}_{4}\right)$ in particular will likely be reduced. These sulfate aerosol concentration reductions occur directly as a result of the FGDassociated sulfur dioxide emission changes. For small sulfate particulates, the magnitude of the sulfate concentration reductions caused by FGD installation may be less than what would normally result from these sulfur dioxide

(a) From U.S. Environmental Protection Agency. 1983. Acid Deposition: Current Knowledge and Policy Options. Briefing Document for the Administrator by the Acid Deposition Task Force. Washington, D.C. 
enission reductions. The reason for this is that FGD may result in small increases in primary enissions of small sulfate aerosols. On the other hand, concentrations of large sulfate particulates are likely to decrease more than would be expected from these sulfur dioxide emission reductions because the FGD may result in small decreases of primary emissions of large sulfate aerosols.

In addition, installation of $F G D$ equipment may result in significant reductions in ambient concentrations of sulfur dioxide. These reductions will occur in a much smaller area and be more highly concentrated in the local vicinity of the plant. Other air quality changes might also occur as a result of FGD installation, although with much lower probability and to a much smaller extent. Airborne concentrations of nitrogen dioxide as well as gaseous and particulate nitrite and nitrates may decrease as a result of possible FGDcaused reductions in nitric oxide and nitrogen dioxide emissions; in addition, concentrations of ozone and other oxidants may change due to this emission reduction. The direction of these concentration changes depends on a number of source- and receptor-specific factors. Finally, FGD installation may result in a change in the relative airborne proportions of small and large aerosol particulates; FGD causes relatively more small and fewer large particulates to be directly emitted by the plant.

\subsection{POTENTIAL ANCILLARY AIR QUALITY EFFECTS OF COAL SWITCHING/BLENDING}

A second proposed method for reducing U.S. sulfur dioxide emissions and thus acid deposition is coal switching or blending. This method involves substituting low-sulfur coal for high-sulfur coal in coal burning power plants. This section discusses the ancillary air quality changes that may accompany coal switching or blending. The section is organized in a manner similar to that of the previous one. Technical aspects of coal switching/blending are briefly discussed in Section 3.2.1. Potential changes in emissions of compounds other than sulfur dioxide are identified and characterized in Section 3.2.2; their potential impacts on ambient air quality are described in Section 3.2.3. Ancillary air quality changes associated with reduced sulfur dioxide emissions are discussed in Section 3.2.4, which draws heavily from Section 3.1.4. 


\subsubsection{Technical Aspects of Coal Switching and Blending}

The sulfur content of U.S. coal varies tremendously, from less than $0.5 \%$ (by weight) to well over $6.0 \%$. With minor exceptions, most of this variation is interregional; coal mined in the Rocky Mountain area typically has lower sulfur content than coal mined in the Appalachian and Ohio Valley areas, (Monsanto 1975; Rieber 1975; Miller et a1. 1979). Since most of the coal used in U.S. power plants is mined in these latter regions (DOE/EIA 1983), one proposal for reducing the sulfur content of coal burned at power plants, and thus power plant sulfur dioxide emissions, is to substitute low-sulfur, primarily western, coal for high-sulfur, primarily eastern, coal.

Coal switching refers to complete substitution of low-sulfur for highsulfur coal at a plant. Coal blending refers to judicious mixing of high-and low-sulfur coal, either at the mine, at a beneficiation plant, at a transshipment facility or at the power plant. Rhoades and Middleton (1983) claim that if implemented fully, coal switching could achieve a reduction of up to $90 \%$ in sulfur dioxide emissions. However, this figure has, been questioned (Streets et al. 1983). The emissions reductions associated with blending be smaller than reductions from complete switching.

Both coal switching and coal blending, but particularly the former, may require that plant operations be changed. First, because low-sulfur coal typically has a lower heat content than high-sulfur coal (DOE/EIA 1983), more coal may have to be burned to produce the same quantity of electricity. However, because coal blending can create a mixture of coal with better burning properties than unblended coal, it is possible that less, rather than more, coal would have to be burned. Second, because most coal-burning power plants are designed to use a particular grade or range of grades of coal (i.e., specific heat content, specific sulfur content, specific flyash content), use of blended or entirely low-sulfur coal may require that combustion temperatures be changed. Third, the effectiveness of existing emissions control equipment (e.g., to reduce particulate emissions) may be reduced because of the change in the grade of coal burned at the plant. 


\subsubsection{Ancillary Emissions Changes}

Coal switching and/or blending may have a substantial impact on the emissions of a number of pollutants. These emission changes in general arise from four characteristics of power plant operations with low-sulfur coal: 1) more or less coal may need to be burned; 2) the coal may have a different overalt composition; 3 ) the plant may have to be operated at a different temperature; and 4) the effectiveness of particulate control equipment may be reduced.

Because different amounts of the switched or blended coal will have to be burned to generate the same amount of electricity, emissions of nonsulfur compounds, which are positively related to the amount of coal burned, will change. If more coal has to be burned, emissions of nonsulfur compounds would increase because the heat content of western low-sulfur coals. If the proportions of nonsulfur pollutants in the low-sulfur coal are identical to those in high-sulfur coal, and if operating temperatures remain constant, then emissions of all pollutants associated with coal combustion would increase. These pollutants include nitrogen oxides (particularly nitric oxide, NO, but also nitrogen dioxide, $\mathrm{NO}_{2}$ ), hydrocarbons and other organic compounds (including anthracenes, benzanthracenes, benzpyrenes, napthatenes, and phenols; Mahlum 1978), carbon monoxide, carbon dioxide, radionuclides, trace metals (including arsenic, mercury, and vanadium, as well as chromium, copper, iron, magnesium, manganese, nicke1, lead, tin, strontium, titanium, and zinc; Battelle 1975), and other types of flyash (Battelle 1975; Berkowitz and Squires 1971; Duvel et a. 1979).

Generally, the nonsulfur composition of eastern and western coals is different. Changes in the overall pollutant composition of coal used in power plants may offset (either partially or completely) or augment the tendency (described in the previous paragraph) toward increased emissions of nonsulfur pollutants due to increased coal use. For example, if low-sulfur coal also contains less arsenic than high-sulfur coal, power plant emissions of arsenic would not increase as much as if low-sulfur coal and high-sulfur coal were identical in this respect (as assumed in the previous paragraph. In fact, if the percentage reduction in arsenic content of the switched or blended coal (relative to what was previously used) was greater in absolute value than the 
percentage increase in the amount of coal burned (due to the heat content reduction), total power plant emissions of arsenic might actually decrease because of coa? switching/blending.

Insufficient information is available to predict the impact of switching/ blending on emissions of individual pollutants other than sulfur. The composition of coal varies tremendously even within a given locality; in fact, sulfur is one of the few compounds about which regional generalizations can be made (Torrey 1978). A few studies comparing the composition of eastern and western coals have been performed. These studies were typically chemical analyses of very small samples of mined coal, not exhaustive state-level inventories of the emissions of specific elements and/or compounds. One study (Monsanto 1975) found that western coals tend to have lower iron and potassium content but higher calcium, magnesium, cadmium, and selenium content than eastern coals, but that intraregional variation in the content of these elements was nearly as significant as these interregional differences. Duvel et al. (1979) present information on these and other components of flyash (trace metal emissions are typically a component of flyash) which suggests that eastern and western coals are not identical regarding pollutant composition: the flyash emitted from burning power plants using western coal contained more sodium, magnesium, and calcium and less silicon, aluminum, and titanium than did flyash emitted from eastern-coal-burning power plants.

Burning coal of a different grade may require operating the plant at different temperatures. Operating a coal-burning power plant at lower temperatures may significantly reduce the quantity of nitrogen oxides $\left(\mathrm{NO}_{\mathrm{x}}\right)$ emitted by the plant, particularly nitric oxide (NO). This emission reduction may occur because nitrogen and oxygen are less likely to react to form nitric oxide at lower temperatures (EPRI 1983). This emission reduction may, again, offset or augment changes in nitrogen oxide emissions caused by 1) burning more coal and 2) the changed composition of burned coal. In addition, operating at a lower temperature may cause less of the coal to be completely combusted. As discussed further in Section 3.3, this may lead to increased emissions of carbon monoxide and hydrocarbons, which result totally from incomplete combustion. 
Higher operating temperatures lead to the opposite results: emission of nitrogen oxides could increase; emissions of carbon monoxide and hydrocarbons could decrease.

If operating temperatures were to increase rather than decrease, the opposite effects could occur: emissions of nitrogen oxides could increase; emissions of carbon monoxide and hydrocarbons could decrease.

Finally, coal switching/blending may cause power plant emissions of specific particulates, particularly components of flyash, to increase because of reductions in the efficiency of particulate control equipment. Such equipment is typically designed to operate in conjunction with coal of a particular grade (i.e., a narrow range of composition of specific particulates). Using coal of a grade outside of the designed range may significantly reduce or have no impact on the effectiveness of the equipment. This effect can be reduced by modifying the equipment EPRI 1983).

\subsubsection{Potential Air Quality Changes from Ancillary Emissions Changes}

This section describes the ancillary air quality changes that may result from the ancillary emissions changes described in section 3.2.2. Due to the uncertainty about the direction and magnitude of many of the emissions changes identified in that section, this section will be more qualitative than quantitative, and will describe the air quality changes that would be caused by increases in emissions of specific pollutants (i.e., unless otherwise stated, it is assumed that emissions of each pollutant increases); from this discussion, the reader can infer the direction, if not the magnitude, of air quality changes associated with emission decreases.

As will be discussed further in Section 3.3, an increase in emissions of nitric oxide (NO) or nitrogen dioxide $\left(\mathrm{NO}_{2}\right)$, the two species of nitrogen oxides most affected by coal switching/burning, will cause the airborne concentrations of a number of pollutants to change. First, ambient concentrations of nitrogen dioxide would increase, due both to the increase in $\mathrm{NO}_{2}$ emissions and the increase in $\mathrm{NO}$ emissions, because most nitric oxide oxidizes to $\mathrm{NO}_{2}$. Nitrogen dioxide is a respiratory irritant and also contributes to haze. Second, concentrations of gaseous and particulate nitrites and nitrates would increase; 
one species of gaseous nitrate, nitric acid $\left(\mathrm{HNO}_{3}\right)$, is of particular interest because it is believed to be the second largest (behind sulfuric acid, $\mathrm{H}_{2} \mathrm{SO}_{4}$ ) component of acid deposition. These nitrites and nitrates may have significant impacts on health, vegetation, and visibility. Third, increased emissions of nitrogen oxides may lead to changes in airborne concentrations of ozone and other oxidants; again; as discussed in Section 3.1.3 and in more detail in Section 3.3, the direction of these concentrations depends on the direction of changes in hydrocarbon emissions as well as the prevailing nitrogen oxide/ hydrocarbon ratio. Because the directions of changes in both nitrogen oxide emissions and this ratio cannot be determined without more information, it is not clear whether switching/blending would cause ozone concentrations to increase or decrease.

Increases in emissions of carbon monoxide (CO), due to increased burning of coal as well as a potential increase in the amount of incomplete combustion (which is the cause of $\mathrm{CO}$ emissions) per unit of coal burned, would likely increase the airborne concentrations of carbon monoxide and, to a lesser extent, carbon dioxide. Increases in emissions of carbon dioxide would also cause such concentration increases, although carbon dioxide concentrations would be increased more than would those of carbon monoxide.

Generally, coal switching will cause emissions of hydrocarbons (HC) to increase, because more coal will have to be burned. However, emissions of particular species of hydrocarbons may decrease because the composition of the switched coal may be different than the high-sulfur coal used previousiy. The direction of change for coal blending is unknown. Generally, when emissions of a particular hydrocarbon increase, ambient concentrations of that specific hydrocarbon and other types of hydrocarbons and organic compounds will increase. Many of the emitted hydrocarbons (particularly polycyclic organic matter, such as benzene) will not react in the atmosphere, and thus remain in their emitted form; others may react in a number of complex and not very well understood ways to create other hydrocarbons and more complicated non-HC organic compounds. In addition, hydrocarbons contribute to the creation of ozone and other photochemical oxidants; if emissions of both hydrocarbons and nitrogen oxides increase, concentrations of ozone and other oxidants will 
increase. As explained in Section 3.3, if emissions of one of these two classes of pollutants increases while emissions of the other decreases, whether ambient oxidant concentrations increase or decrease depends on the atmospheric ratio of nitrogen oxides to hydrocarbons.

Finally, as emissions of trace metals and other (nonmetallic) components of flyash increase, airborne concentrations of the emitted compounds will increase. Some of the flyash, both metallic and nonmetallic, will react in the atmosphere, thus changing form. For the most part, however, even after such reactions, the flyash remains in particulate form. The rate of removal of these particulates from the atmosphere depends on particle six and chemical composition. In general, however, total suspended particulate (TSP) will increase if flyash emissions increase as will ajrborne concentrations of specific trace metals.

\subsubsection{Ancillary Air Quality Changes from Reduced Sulfur Dioxide Enissions}

The primary effect of coal blending or coal switching will be, of course, a reduction in emissions of sulfur dioxide. As discussed in Section 3.1.4, in addition to eventually reducing acid deposition, such emission reductions will have a number of impacts on ambient air quality. First, ambient concentrations of sulfur dioxide will decrease. Second, ambient concentrations of sulfate aerosols, including sulfuric acid, ammonium sulfate, calcium sulfate, magnesium sulfate, manganese sulfate, and letovicite, will decrease. Details about the nature of these concentration reductions, including their spatial distribution, are provided in Section 3.1.4.

\subsubsection{Summary of Ancillary Air Quality Changes from Coal Switching and Blending}

As with installation of flue gas desulfurization equipment, coal switching and/or blending will, with high probability, result in significant reductions in the airborne concentrations of sulfate aerosols, which is a major component of total suspended particulate (TSP). Such reductions in primary pollutants may extend hundreds of miles from the plant. In addition, again with high probability, coal switching and/or blending will result in significant reductions in airborne concentrations of sulfur dioxide. Reductions in the 
concentrations of sulfur dioxide will occur over a smaller area than those for sulfate aerosols, although possibly still more than 180 miles away from the plant. Reductions in both sulfate aerosol and sulfur dioxide concentrations occur as a result of sulfur dioxide emissions reductions.

Ambient concentrations of a number of other pollutants will also be affected by coal switching/blending, but it is more difficult to state the direction of these changes. Emissions of any pollutant associated with coal combustion may either increase or decrease, with the direction of change dependent on the relative strengths of these four effects: 1) more or less of the "new" coal may have to be burned to obtain the same amount of electricity; 2) the pollutant content of the "new" coal may be different than that of the "old" coal; 3) the plant may have to be operated at either higher or lower temperatures, and 4) emission control equipment may not work as efficiently with the "new" coal as with the "old" coal. Such emissions changes may potentially cause increases or decreases in the airborne concentrations of: 1) nitrogen dioxide, 2) gaseous and particulate nitrites and nitrates, 3) ozone and other oxidants, 4) carbon monoxide, 5) carbon dioxide, 6) hydrocarbons and other organic compounds, 7) trace metals, and 8) nonmetallic flyash. Some of these possible concentration changes may occur over very large areas (e.g., ozone) while others may be concentrated fairly close to the affected plant (e.g., carbon monoxide).

\subsection{POTENTIAL. ANCILLARY AIR QUALITY EFFECTS OF REDUCED NO ${ }_{*}$ EMISSIONS}

A second source of acid deposition is emissions of nitrogen oxides $\left(\mathrm{NO}_{x}\right)$, particularly nitric oxide (NO) and, to a lesser extent, nitrogen dioxide $\left(\mathrm{ND}_{2}\right)$. Each of these pollutants oxidizes to nitrate $\left(\mathrm{NO}_{3}\right)$, which in the presence of water forms nitric acid $\left(\mathrm{HND}_{3}\right)$, a major component of acid deposition, particularly in the western United States (where sulfur dioxide emissions are not as high). Thus, another strategy to control acid deposition is to reduce emissions of nitrogen oxides.

Emissions of nitrogen oxides occur as the result of nearly all combustion processes. Dxygen $\left(\mathrm{O}_{2}\right)$ and nitrogen $\left(\mathrm{N}_{2}\right)$ are naturally in the air and combine very easily at the high temperatures characteristic of fuel combustion, forming 
NO or $\mathrm{NO}_{2}$. Thus, nitrogen oxides are found in the exhaust of motor vehicles, as well as in the flue gases of fossil fuel-burning electric plants and industrial boilers. In 1970, $40 \%$ (by weight) of all $\mathrm{NO}_{\mathrm{x}}$ emissions in the United States were from motor vehicles, $11 \%$ from other transportation sources, $21 \%$ from electric utilities, $20 \%$ from industrial sources, and the remaining $8 \%$ from miscellaneous stationary and waste disposal sources (EPA 1982).

Because the largest proportion of total nitrogen oxides are emitted by motor vehicles, a number of acid deposition reduction proposals contain provisions to reduce motor vehicle emissions of $\mathrm{NO}_{x}$. While the focus of these provisions is on emissions by heavy-duty trucks, other proposals, noting that automobiles account for approximately $40 \%$ of all mobile source $N_{x}$ emissions and that light-duty trucks account for an additional $10 \%$ of such emissions (versus $25 \%$ for heavy-duty trucks and $25 \%$ for other mobile sources; 0TA 1982), focus on emissions from these vehicles. A number of technologies are currently or potentially available to effect $\mathrm{NO}_{x}$ emissions reductions from automobiles, light-duty trucks, and heavy-duty trucks.

This section discusses the potential ancillary air quality changes that might be associated with implementation of a $\mathrm{NO}_{\mathrm{x}}$ emission reduction policy. Technologies to reduce motor vehicle $\mathrm{NO}_{x}$ emissions are described in Section 3.3.1. Potential changes in emissions of pollutants other than NO $\mathrm{x}_{\mathrm{x}}$ are described in Section 3.3.2, and the impacts of these ancillary emissions changes on ambient air quality are discussed in Section 3.3.3. Ancillary air quality changes associated with reduced $\mathrm{NO}_{x}$ emissions are described in Section 3.3.4, and the potential ancillary air quality changes associated with a $\mathrm{NO}_{\mathrm{X}}$ emissions policy are summarized in Section 3.3.5.

\subsubsection{Description of Motor Vehicle NOx Emissions Reduction Technologies}

Several technologies have been developed in the past ten years, or are currently in the final stages of development, that could be used to reduce motor vehicle emissions of nitrogen oxides. To understand how these technologies cause such reductions, it is first necessary to understand the cause of nitrogen oxides emissions. 
Nitrogen $\left(\mathrm{N}_{2}\right)$ and oxygen $\left(\mathrm{O}_{2}\right)$ are two of the major components of the air we breath. At high temperatures, nitrogen and oxygen typically react to form nitrogen oxide $\left(\mathrm{NO}_{\mathrm{X}}\right)$, typically nitric oxide (NO) and/or nitrogen dioxide $\left(\mathrm{NO}_{2}\right)$. Thus, motor vehicle nitrogen oxide emissions are caused by the hightemperature oxidization of nitrogen to nitrogen oxide.

Once nitrogen dioxide is formed, it is stable, and does not typically become reduced (the opposite of oxidization) at the low temperatures typically encountered in the atmosphere. However, this reduction threshold temperature is increased by some metals, which serve as reduction catalysts. A catalyst is an element or compound which is not itself changed by a chenical reaction, but whose presence creates conditions in which a particular reaction can either take place or proceed more quickly than it otherwise would. In the case of nitrogen oxides reduction, the presence of specific metals allows nitrogen oxides to reduce to nitrogen $\left(\mathrm{N}_{2}\right)$ and oxygen $\left(\mathrm{O}_{2}\right)$ at temperatures below those typically required (in the absence of a catalyst) for such reduction to take place. This chemical reduction process is important to understanding how a catalytic converter reduces emissions of nitrogen oxides.

In addition to nitrogen oxides, motor vehicles typically emit two other types of pollutants that are of major concern: carbon monoxide (CO) and a number of compounds of the hydrocarbon (HC) class. These pollutants are formed in the vehicle's combustion chamber if the fuel is not completely burned, which occurs when there is not enough air in the chamber to permit complete combustion of the fuel. Several other compounds are also emitted by motor vehicles, the most important of which are carbon dioxide $\left(\mathrm{CO}_{2}\right)$, water $\left(\mathrm{H}_{2} \mathrm{O}\right)$, sulfur oxides, and lead. Carbon dioxide and water would be the only emitted substances if the fuel had no impurities, was completely combusted, and done so at a temperature at which nitrogen oxide could not form (or with so little air that there was no "excess" nitrogen or oxygen to react together). Sulfur dioxide and lead emissions are caused by impurities in the fuel.

Reductions in emissions of nitrogen oxides by gasoline-powered automobiles and light trucks could be accomplished by greater use of the three-way catalytic converter (TCC; CARB 1983). The TCC, which is already used in a number of 
automobiles, is a cylindrical chamber placed directly adjacent to the combustion chambers, forming the first component of the vehicle's exhaust system. The chamber contains a lattice grid of a nitrogen oxide reduction catalyst such as rhodium. Thus, when the exhaust passes through the TCC, some of the nitrogen oxide are reduced to nitrogen $\left(\mathrm{N}_{2}\right)$ and oxygen $\left(\mathrm{O}_{2}\right)$. The proportion of the $\mathrm{NO}_{x}$ that is reduced depends on the quantity of rhodium contained in the TCC; the more rhodium, the greater the proportion of nitrogen oxide that is reduced. This rule of thumb is valid only over a limited range of chemical concentrations. The TCC also contains elements/compounds which serve as catalysts in the oxidation of carbon monoxide and hydrocarbons to carbon dioxide and water. Thus, the TCC reduces emissions of all three classes of major automobile pollutants.

Presently, a large number of new gasoline-powered automobiles and trucks are equipped with alternative types of catalytic converters, particularly dualbed catalytic converters, as well as other types of emissions control devices (some of which are discussed below). For these vehicle models, switching to the TCC on future model editions could dramatically reduce $\mathrm{NO}_{x}$ emissions. Furthermore, such a switch should not have a great effect on emissions of carbon monoxide and/or hydrocarbons, because the TCC and the dual-bed converter can contain nearly equal quantities, with nearly identical effectiveness, of the $\mathrm{CO} / \mathrm{HC}$ oxidation catalysts.

The three-way catalytic converter is not an effective NO control device on diesel-powered vehicles (automobiles, light-duty trucks, and heavy-duty trucks) because the exhaust from these vehicles contains a high proportion of oxygen (Sittig 1977). For these vehicles, two techniques are currently employed to reduce $\mathrm{NO}_{x}$ emissions below what they would be in the complete absence of emission control equipment. These two techniques are also employed on gasoline-powered vehicles, frequently in combination with a dual-bed or three-way catalytical converter. Greater use of either or both of these techniques has been suggested to reduce $\mathrm{NO}_{x}$ emissions for both gasoline- and diesel-powered vehicles, but particularly for the latter, where alternative $\mathrm{NO}_{x}$ emission-control devices are not available, and where $\mathrm{NO}_{x}$ emissions are highest. 
The two potential techniques are 1) fuel injection timing and 2) exhaust gas recirculation. Fuel injection timing typically involves computer control of the fuel supplied to the combustion chamber. By carefully controlling the quantity of fuel supplied to the chamber, and the point during the air compression cycle at which the fuel is injected (timing), the amount of nitrogen oxide created during combustion can be reduced. This reduction in the quantity of $\mathrm{NO}_{x}$ produced takes place because 1) the air (containing separated nitrogen and oxygen) can be heated for a much shorter period (due to the timing improvement) and 2) the amount of air in "excess" of that required for combustion can be controlled. With less $\mathrm{NO}_{x}$ created, less $\mathrm{NO}_{x}$ is emitted, regardless of the presence of other emission control devices.

Exhaust gas recirculation (EGR), as its name implies, involves taking some of the exhaust from the combustion chamber (which may or may not have passed through another emissions control device), mixing it with new (clean) air, and using the combined air-exhaust mixture as an input to the combustion process instead of clean or uncombusted air. By recirculating the exhaust, the combus tion temperature can be lowered, so that less nitrogen oxide is formed in the combustion chamber.

\subsubsection{Potential Ancillary Emissions Changes from Motor Vehicle $N_{x}$ Emission Reduction Technologies}

In addition to reducing emissions of nitrogen oxide ( $\mathrm{NO}_{\mathrm{x}}$ ), each of the three technologies described in Section 3.3.2 may either increase or decrease emissions of other motor vehicle-related pollutants, which include carbon monoxide, hydrocarbons, carbon dioxide, and water. Because only the first two of these pollutants are considered harmful, the section will focus on how these emissions might be impacted by greater use of each of the three technologies.

Generally, there is a trade-off between emissions of $\mathrm{NO}_{\mathrm{x}}$ and emissions of $\mathrm{CO}$ and $\mathrm{HC}$. For a given technology, $\mathrm{NO}_{\mathrm{x}}$ emissions can only be reduced at the expense of increased $\mathrm{CO}$ and $\mathrm{HC}$ emissions. This is true primarily for two reasons. First, the air/fuel ratio is a major determinant of how much of each pollutant is created in the combustion chamber, with a higher air/fuel mix creating more $\mathrm{NO}_{x}$ and less $\mathrm{CO}$ and $\mathrm{HC}$, because there is more excess air available to form $\mathrm{NO}_{x}$, but more complete combustion of the fuel due to the increased 
air availability. Second, the techniques to control each of these two ciasses of pollutants once they have left the combustion chamber may work at cross purposes; $\mathrm{NO}_{\mathrm{x}}$ is controlled via reduction, while $\mathrm{CO}$ and $\mathrm{HC}$ are controlled by oxidation, the opposite of reduction. In the past, frequently one of these two processes would take place (e.g., reduction of nitrogen oxide) first, only to be undone later (i.e., the nitrogen would be reoxidized in the presence of the $\mathrm{HC}$ and $\mathrm{CO}$ oxidation catalysts). This, for example, is one of the drawbacks of using the dual-bed catalytic converter for $\mathrm{NO}_{\mathrm{x}}$ control.

Fortunately, the three technologies described in Section 3.3 .1 suffer from this trade-off much less than do other technologies. Switching from dual-bed to three-way catalytic converters, or increasing the quantity of rhodium present in the three-way catalytic converter does not dramatically change the emissions of either carbon monoxide or hydrocarbons. Emissions of $\mathrm{CO}$ may increase slightly, but even these small increases can be overcome through use of other available and relatively inexpensive devices. Likewise, properly employed exhaust gas recirculation should not dramatically increase emissions of either $\mathrm{CO}$ or $\mathrm{HC}$; although the combustion temperature is reduced recirculating the exhaust in effect allows the fuel to be burned twice, allowing more complete combustion. The net effect appears to be a small increase in emissions of carbon monoxide and hydrocarbons (Starkman 1971). Finally, fuel injection timing targeted at $N_{x}$ emissions may increase emissions of both carbon monoxide and hydrocarbons, because the air/fuel ratio and the combustion time are each reduced, causing a decrease in the quantity of fuel that is completely burned. However, the trade-off here is not as severe as it is when the air/fuel ratio is manipulated using traditional means (Sittig 1977), primarily because the fuel can be injected at precisely the "right" time and because the amounts of excess air and excess fuel present in the chamber at each point of the compression cycle can be precisely controlled. Some studies, in fact, have shown that $\mathrm{CO}$ is reduced by fuel injection, while hydrocarbons are unaffected (Starkman 1971).

Finally, emissions of carbon dioxide and water vapor can both be expected to increase slightly through use of any of the three technologies: three-way catalytic converter, exhaust gas recirculation, and timed fuel injection. 
These increases result from the more complete fuel combustion promoted by each technology. Because the products of complete combustion are carbon dioxide and water, emissions of carbon dioxide and water increase with more complete combustion.

\subsubsection{Ancillary Air Quality Changes Associated With Ancillary Emissions Changes}

The primary effect of increases (decreases) in emissions of carbon monoxide, hydrocarbons, and/or carbon dioxide are increases (decreases) in the ambient concentrations of the specific pollutant; e.g., if carbon monoxide emissions increase, the major impact is an increase in ambient carbon monoxide concentrations. Ambient concentrations of several other pollutants would be affected as well. First, an increase (decrease) in carbon monoxide emissions would lead to a small increase (decrease) in the carbon dioxide balance (concentration). Second, some of the specific hydrocarbons emitted may react in a complex manner in the atmosphere to form other hydrocarbons, some of which may be more dangerous to health and vegetation than the emitted pollutant. Third, and finally, increases in emissions of hydrocarbons will cause increases in the concentrations of ozone and other photochemical oxidants (Heicklen 1976). Although the direction of the effect of $\mathrm{NO}_{x}$ changes on ozone levels depends on hydrocarbon concentrations, the reverse is not true; holding nitrogen oxide concentrations constant, the ozone level changes in the same direction as the change in hydrocarbon concentrations. Of course, this point may be irrelevant in discussions of the policy options, since nitrogen oxide concentrations will not be constant, but decreasing; the direction of ozone concentration changes in such a situation is discussed in Section 3.3.4.

\subsubsection{Ancillary Air Quality Changes from Reduced Nitrogen Oxide Emissions}

The main effect of all three technologies described in 3.3 .1 is to reduce emissions of nitrogen oxide $\left(\mathrm{NO}_{x}\right)$, primarily nitric oxide (NO) and, to a lesser extent, nitrogen dioxide $\left(\mathrm{NO}_{2}\right)$. Because nearly all nitric oxide oxidizes to form nitrogen dioxide, changes in emissions of NO can be treated as changes in $\mathrm{NO}_{2}$ emissions, and the question becomes, "What happens to ambient air quality when $\mathrm{NO}_{2}$ emissions decrease?" 
The first effect of a nitrogen dioxide emissions reduction is to decrease ambient concentrations of nitrogen dioxide. Although most of the emitted $\mathrm{NO}_{2}$ oxidizes to another pollutant (EPA 1982), a small portion does not react chemically until removal from the atmosphere (i.e., until it is breathed, or absorbed by a plant or material). Furthermore, as with sulfur dioxide, the oxidation process takes time, so that at any particular point in time some portion of the emitted $\mathrm{NO}_{2}$ which will eventually oxidize is still in its original form.

Second, a reduction in emissions of nitrogen dioxide will cause reductions in the ambient concentrations of a number of gaseous and particulate nitrites $\left(\mathrm{XNO}_{2}\right.$ where $X$ is either a combination of hydrogen and other elements, or an organic group, denoted $R$ ) and nitrates ( $\mathrm{XNO}_{3}$, where $X$ again is either a combination of hydrogen and other elements, or an organic group): nitrous acid $\left(\mathrm{HNO}_{2}\right)$; nitric acid $\left(\mathrm{HNO}_{3}\right)$; alkyl nitrite $\left(\mathrm{RNO}_{2}\right)$; alkyl nitrate $\left(\mathrm{RNO}_{3}\right)$; peroxyacetyl nitrate, called PAN $\left(\mathrm{RCONO}_{3}\right)$; ammonium nitrate $\left(\mathrm{NH}_{4} \mathrm{NO}_{3}\right)$, which is a major component of total suspended particulate. Acids, nitrites, and nitrates are typically created in gaseous form, and transform to a particulate state either 1) by absorbtion into an existing particle, thus changing the chemica? composition of the particle; or 2) via chemical reaction, particulariy with ammonia $\left(\mathrm{NH}_{3}\right)$. Both gaseous and particulate nitric acid are major components of acid deposition.

Modeling the nitrogen oxide-nitrite/nitrate transformation process is much less developed than for sulfur oxide-related transformations (EPA 1982), so that it is difficult to detemine by how much, at any particular point in time and space, concentrations of each of these compounds will change because of changes in NO emissions (at another time and place). It is believed that nearly one-half of atmospheric NO${ }_{x}$ reacts each hour to form gaseous nitric acid (EPA 1982); however, the location of this transformation and the fate of the other one-half are not well understood.

The third effect of $\mathrm{NO}_{x}$ emissions reductions on ambient air quality, changes in ozone concentrations, is also not well understood; in fact, there is substantial disagreement on the direction of impact. It is clear that nitroger 
oxide is required to form ozone, as are sunlight and specific types of hydrocarbons. However, the effects of changes in emissions of one or both pollutants are not clear. The apparent prevaling view is presented in Table 3.1, which shows that, in particular, the effect of a $\mathrm{NO}_{x}$ emission reduction depends on 1) the direction (if any) that hydrocarbon emissions are changing, and 2) the hydrocarbon $/ N_{x}$ ratio (Heicklen 1976 ).

The general explanation of this complex, nonlinear relationship is that the quantity of ozone created from nitrogen oxides depends on both the rate of $\mathrm{NO}_{\mathrm{x}}$ oxidation and the maximum potential ozone concentration. Both of these variables in turn depend on hydrocarbon concentrations. N0 oxidizes more quickly in the presence of specific hydrocarbons than it otherwise would, and the rate increases as the concentrations of these hydrocarbons increases. On the other hand, ozone and hydrocarbons are, in some sense, competitors; the maximum ozone concentration increases as the ratio of hydrocarbons relative to that of $\mathrm{NO}_{\mathrm{x}}$ decreases; thus, if hydrocarbon concentrations are low (relative to $\mathrm{NO}_{\mathrm{x}}$ ), maximum ozone concentrations are high, and this maximum increases as $\mathrm{NO}_{x}$ falls (Heicklen 1976).

TABLE 3.1. Changes in Ozone Concentrations Associated with Changes in Emissions of Nitrogen Oxides

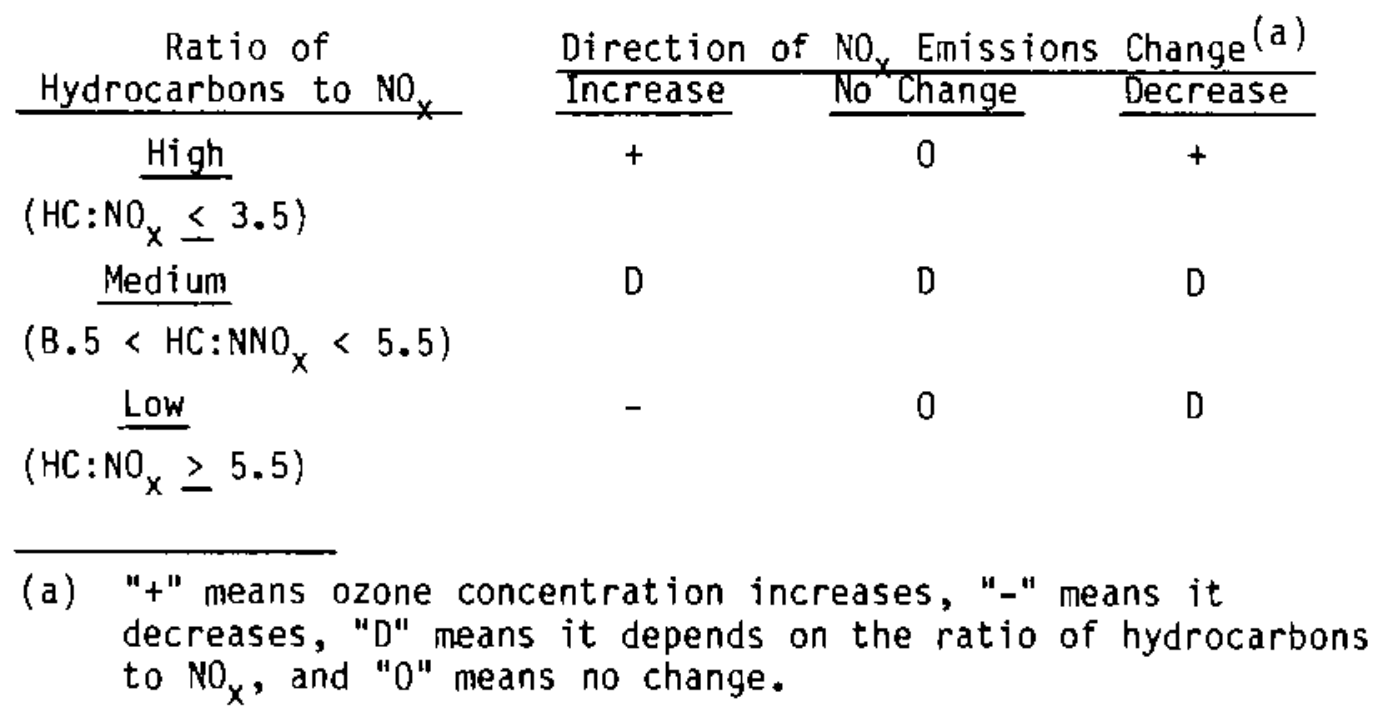




\subsubsection{Summary of Potential Ancillary Air Quality Changes From $\mathrm{NO}_{x}$ Emissions Reductions}

The types and magnitudes of the ancillary air quality changes that would result from reductions in motor vehicle emissions of $\mathrm{NO}_{x}$ depend in part on which of the three technological options considered is actually used. Some impacts, are however, invariant to the type of technology employed. First, for all three technologies, concentrations of nitrogen dioxide, a gas harmful to human health, will be reduced. Second, again, for all three technologies, concentrations of a number of gaseous and particulate nitrites and nitrates, including nitric acid (a major component of acid deposition) and ammonium sulfate (a major component of TSP), will decrease. Third, for all three technologies, concentrations of ozone will change. Because it is likely that hydrocarbon enissions would either not change or slightly increase as a result of any of the three options while $\mathrm{NO}_{x}$ emissions decrease, whether ozone concentrations increase or decrease in a particular area will depend on the ratio of hydrocarbons to nitrogen oxides in the area. If this ratio is high, ozone concentrations will likely decrease as $\mathrm{NO}_{x}$ emissions are reduced; if the ratio is low, ozone concentrations are apparently likely to increase as the $N O_{x}$ emissions are reduced. As discussed above, there is considerable controversy about this issue.

Changes in concentrations of carbon monoxide, hydrocarbons, and carbon dioxide depend on which technology or technologies is employed to effect the $\mathrm{NO}_{\mathrm{x}}$ emissions reduction. Greater use of the three-way catalytic converter may slightly increase concentrations of carbon monoxide, with a small increase in the atmospheric carbon dioxide balance as well. Although these effects are highly uncertain, exhaust gas recirculation and fuel injection timing will likely lead to small increases in carbon monoxide and hydrocarbon concentrations, and a small decrease in the carbon dioxide concentrations.

\subsection{SUMMARY OF POTENTIAL ANCILLARY AIR QUALITY CHANGES}

The likely ancillary air quality associated with each of the three technologies/policy options are summarized in Table 3.2. A "+" in the table indicates implementation of the measure will cause an increase in the airborne 
TABLE 3.2. A Summary of Potential Ancillary Air Quality Changes

\begin{tabular}{lcccc}
\multicolumn{1}{c}{ Pollutant } & $\begin{array}{c}\text { Flue Gas } \\
\text { Desulfurization }\end{array}$ & & $\begin{array}{c}\text { Technology } \\
\text { Coal Switch- } \\
\text { ing/Blending }\end{array}$ & $\begin{array}{c}\text { N0 } \\
\text { Reductions }\end{array}$ \\
\cline { 1 - 1 } Sulfate & - & - & 0 \\
Sulfur 0ioxide & - & - & 0 \\
Nitrogen Dioxide & - & $+/-$ & - \\
Nitrites, Nitrates & - & $+/-$ & - \\
Oxidants & $+/-$ & $+/-$ & $+/-$ \\
Small Particulates & + & $?$ & 0 \\
Large Particulates & - & $?$ & 0 \\
Hydrocarbons & 0 & $+/-$ & $+/-$ \\
Carbon Monoxide & 0 & $+/-$ & $+/-$ \\
Carbon Dioxide & 0 & $+/-$ & $+/ ?$ \\
Trace Metals & $+/-$ & $+/-$ & 0 \\
Nonmetallic Flyash & $+/-$ & $+/-$ & 0
\end{tabular}

concentration of the pollutant, while a "-" indicates a decrease. A "0" indicates a very high probability of no change, a " $+/-"$ indicates a likely change of unknown direction, and a "?" indicates there may or may not be a change. For the $\mathrm{NO}_{\mathrm{x}}$ reduction strategy, it was assumed that the three-way catalytic converter was implemented.

\subsection{REFERENCES TO CHAPTER 3.0}

Battelle Columbus Laboratories. 1975. Energy from Coal: Guidelines for the Preparation of Environmental Impact Statements. Prepared for the U.S. Department of the Interior, Office of Research and Development. Columbus, ohio.

Berkowitz, D. A., and A. M. Squires, eds. 1971. Power Generation and Environmental Change. MIT Press. Cambridge Massachusetts.

California Air Resources Board. 1983. Report to the Legislative on the Benefits and Feasibility of a 0.4 Gram per Mile Oxides of Nitrogen Exhaust Emission Standard for Passenger Cars and Light Trucks. Sacramento, California. 
Ditto, F. H., L. T. Gutierrez, and J. C. Bosch, Jr. 1976. "Weighted Sensitivity Analysis of Emissions Inventory Data." Journal of Air Pollution Control Association 26(9):875-880.

Heicklen, Julian. 1976. Atmospheric Chemistry. Academic Press, Inc., New York.

Kinosian, J. R. 1982. "Ozone-Precursor Relationships from EKMA Diagrams." Environmental Science and Technology. 16(12):880-883.

Leo, P. 0. and J. Rossoff. 1978. Executive Summary. Volume 1 of Controlling $\mathrm{SO}_{2}$ Emissions from Coal-Fired Steam-Electric Generators: Solid waste Impact. EPA-600/7-78-044a.

Markowski, Gregory R., et al. 1983. Sulfate Aerosols from Western Low-Rank Coal-Fired Boilers with FGD: Sumary of Tests at Coal Creak, Clay BoswelT, Milton R. Young, and San Miquel Stations. DER314539.

Miller, J. J., et al. 1979. "Effects of Coal Blending on the Utilization of High-Sulfur Iowa Coal and Low-Sulfur Western Coal." July 87-98.

Monsanto Research Corporation. 1975. Evaluation of Low-Sulfur Western Coal Characteristics, utilization, and Combustion Experience. Prepared for the National Environmental Research Center, Washington, D.C.

Morgenstern, P. and K. A. Hagg. 1972. "A System for Abatement Control Strategy Evaluation." Journal of the Air Pollution Control Association. 22(10):774-778.

National Research Council/National Academy of Sciences. 1983. Acid Deposition: Atmospheric Processes in Eastern North America. National Academy Press, Washington, D.C.

Office of Technology Assessment. 1979. The Direct Use of Coal: Prospects and Problems of Combustion. U.S. GP0 Stock No. 052-003-00664-2. Washington, D.C.

Office of Technology Assessment. 1982. Oraft. The Regional Implications of Transported Air Pollutants: An Assessment Acidic Deposition and Ozone. Washington, $0 . C$.

Prior, Mike. 1977. The Control of Sulphur 0xides Emitted in Coal Combustion. IEA Coal Research, Economic Assessment Service. Washington, 0.C.

Rhoades, Steven L. and P. Middleton. 1983. "The Complex Challenge of Control-ling Acid Rain." Environment. 25(4):6-37.

Rieber, M. 1975. "Low Sulfur Coal: A Revision of Reserve and Supply Estimates." Journal of Environmental Economics and Management. 2:40-59. 
Sittig, Marshall. 1977. Automotive Pollution Control Catalysts and Devices. Noyes Data Corporation, Park Eidge, New Jersey.

Starkman, Ernest S. 1971. "Vehicular Emissions and Control." In CombustionGenerated Air Pollution. ed. E. S. Starkman. Plenum Press, New York.

Streets, David G., D. A. Knudson and J. D. Shannon. 1983. "Selected Strategies to Reduce Acidic Deposition in the U.S." Environ. Science Technology. $17(10): 474 A-485 A$.

Torrey, ed. 1978. Trace Contaminants from Coal. Noyes Data Corporation. Park Ridge, New Jersey.

U.S. Department of Energy. Energy Information Administration. 1983. Cost and Quality of Fuels for Electric Utility Plants: 1982 Annual. DOE/EIA0191(82). Washington, D.C.

U.S. Environmental Protection Agency. 1977. Uses, Limitations, and Technical Basis of Procedures for Quantifying Relationships Between Photochemical Oxidants and Precursors. EPA-450/2-77-02la. Washington, D.C.

U.S. Environmental Protection Agency. 1978. Procedures for Quantifying Relationships Between Photochemical Oxidants and Precursors: Supporting Documentation. EPA-450/2-77-0216. Washington, D.C.

U.S. Environmental Protection Agency. 1981. Guidelines for Use of CitySpecific EKMA in Preparing 0zone SIPS. EPA-450/4-80-027. Washington, D.C.

U.S. Environmental Protection Agency. 1982a. Air Quality Criteria for Oxides of Nitrogen. EPA-600/8-82-026. Research Triangle Park, North Carolina.

U.S. Environmental Protection Agency. 1982b. Air Quality Criteria or Particulate Matter and Sulfur 0xides. EPA-600/8-82-029. Three volumes. Research Triangle Park, North Carolina.

U.S. Environmental Protection Agency, 1983a. The Acidic Deposition Phenomenon and its Effects. EPA-600/8-83-0168. Washington, D.C. 


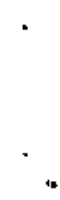

is 


\subsection{POTENTIAL EFFECTS OF ANCILLARY AIR QUALITY CHANGES}

Chapter 3.0 identified potential changes in air quality or changes in the airborne concentrations of specific pollutants that may be caused by implementation of one of the three technological options considered in this study. In brief, depending on which of the three options, if any, are implemented, the degree of implementation, and a number of other factors, it was found that the airborne concentrations of the following pollutants or compounds might change: 1) sulfur dioxide and sulfate aerosols; 2) nitrogen dioxide and gaseous and particulate nitrites and nitrates; 3) ozone, PAN, and other photochemical oxidants; 4) trace metals; 5) carbon monoxide; 6) carbon dioxide; and 7) hydrocarbons and other organic compounds. Changes in the concentrations of each of these compounds or classes of compounds may have significant impacts on human health, visibility, climate, vegetation, and materials. For this study, these impacts are considered the ancillary effects of acid deposition control policies.

These impacts or effects are the subject of this chapter. The chapter comprises nine sections. The first seven sections describe the effects of changes in concentrations of each of the seven poliutants or class of pollutants, in the order 1 isted above (e.g., Section 4.1 discusses the effects of changes in the airborne concentrations of sulfur dioxide and sulfates). Each of these sections discusses the effects associated with a specific pollutant, as if concentrations of all other pollutants were not affected by the policy option, i.e., as if these other concentrations remained constant. Section 4.8 briefly discusses the effects of simultaneous changes in the ambient concentrations of several pollutants. Section 4.9 summarizes the effects on health, visibility, climate, vegetation, and materials of changes in the concentrations of the seven poliutants.

\subsection{ANCILLARY EFFECTS OF CHANGES IN CONCENTRATIONS OF SULFUR DIOXIDE AND SULFATES}

This section identifies and characterizes the potential effects on health, visibility, climate, vegetation, and materials of changes in the airborne 
concentrations of sulfur dioxide and/or the sulfate aerosol component of total suspended particulate. Each of these response categories is treated separately.

\subsubsection{Health Effects of Sulfur Dioxide}

Changes in ambient concentrations of sulfur dioxide may have a number of impacts on human health, particularly lung function. This section discusses the potential effects of sulfur dioxide on human health, describes the mechanisms by which sulfur dioxide impacts health, and reviews a number of estimates of the magnitude of the impact of sulfur dioxide on health.

\subsubsection{Description of Potential Effects}

Sulfur dioxide can induce respiratory illnesses and cause permanent lung injury (Jacoff 1979). Either of these two effects can lead to premature death, particularly for "sensitive" parts of the population such as the aged. Sulfur dioxide can affect the sense of sme11. Its effects on eyes include irritation and increased light sensitivity (EPA 1982b). It may be converted inside the body into compounds such as sulfite and bisulfite ions that can potentially cause cell mutations (Colucci et al. 1976). In numerous studies, laboratory animals died as a result of inhaling large quantities of sulfur dioxide. Available evidence from animal studies support other indications that sulfur dioxide. can be hazardous to human health (Colucci et al. 1976, EPA 1982b).

Respiratory symptoms from sulfur dioxide may take a variety of forms. Wheezing, shortness of breath, and dyspnea or severe breathing difficulties are: only rarely detected in human studies. Sulfur dioxide affects the ease with which air flows through the lung system, as measured or evidenced by changes in bronchoconstriction, pulmonary flow resistance, afrway conductance or resistance, and forced vital capacity. Other effects include changes in the efficiency with which the pulmonary system removes bacteria and other irritants from inhaled air, evidenced by changes in mucociliary activity and tracheobronchial clearance.

\subsubsection{Mechanisms of Action}

Sulfur dioxide in air enters the human body as a gas during breathing. Some of it is exhaled immediately, some of it is extracted from the air by 
various chemical and physical means as it flows through the respiratory tract, and the remainder penetrates deep into the lungs (EPA 1982b). The amount of sulfur dioxide that is not imediately expelled depends on the activity, health and physiology of the individual.

As a gas, sulfur dioxide readily diffuses to the surface of solids, such as moist surfaces within the respiratory tract. Sulfur dioxide readily combines with water and dissociates to form sulfite and bisulfite ions (EPA 1982b). Sulfite and bisulfite ions react with important organic molecules and can have toxic effects. Their adverse impact may partly be explained by their proclivity for participation in organic chemical reactions, with disruptive consequences for the normal functioning of cells (EPA 1982b). An important protective mechanism for detoxifying sulfite exists in the body in the form of an enzyme, sulfite oxidase. Once this protective mechanism has an opportunity to act, the sulfite's toxicity is diminished. Three cases have been reported in which human beings suffered severe neurological problems because of a rare genetic defect affecting sulfite oxidase (Mudd et al. 1976, as cited in EPA $1982 b$ ).

\subsubsection{Estimates of Effects}

Estimates of the effects of sulfur dioxide on both mortality and morbidity are generated using both epidemiological and controlled laboratory techniques. Epidemiology relates the numbers of observed deaths from particular causes and illnesses of particular types in a specific geographical area to the observed concentration of sulfur dioxide (or any other pollutant under study) in the area. Controlled laboratory techniques experimentally measure the biological response of animals or humans to alternative doses of sulfur dioxide. Estimates of the magnitude of the effect of sulfur dioxide on human health generated by each of these two general methods are reviewed below.

Epidemiological Estimates. Epidemiological studies are employed to statistically relate both morbidity and mortality to both acute (episodic) and chronic exposure to $\mathrm{SO}_{2}$. A number of these studies are summarized in Rall (1974). Epidemiological studies of acute exposure to $\mathrm{SO}_{2}$ indicate an association between $\mathrm{SO}_{2}$ exposure and mortality. Deaths resulted from two episodes in London, and one episode in New York, when $\mathrm{SO}_{2}$ concentrations exceeded $700 \mathrm{\mu g} / \mathrm{m} 3$ 
(Rall 1974). During an acute air pollution episode in Donora, Pennsylvania in 1948, high levels of sulfur dioxide in combination with other pollutants were associated with a significant increase in the death rate, in addition to illness of almost 6000 people. The aged were particularly affected (Lave and Seskin 1977). High concentrations of sulfur dioxide and smoke were associated with 4000 excess deaths, over a two-week period, in a London "killer fog" in 1952 (Lave and Seskin 1977). Studies of high particulate matter (PM) and sulfur dioxide $\left(\mathrm{SO}_{2}\right)$ episodes in London seem to substantiate the hypothesis that high levels of PM and $\mathrm{SO}_{2}$ can lead to increased mortality (EPA 1982b).

Epidemiological studies of chronic, rather than acute, exposure to $\mathrm{SO}_{2}$ and $\mathrm{PM}$ also indicate an association between $\mathrm{SD}_{2}$ exposure and mortality. Lave and Seskin (1977) cite studies associating mortality rates with chronic exposure to $\mathrm{SO}_{2}$ and PM (e.g., Pemberton 1961 as cited in Lave and Seskin 1977), and also demonstrate such a relationship in their own work. However, Lave and Seskin have been criticized for over-generalizing their own statistical results and those of others associating mortality with chronic $\mathrm{SO}_{2}$ levels (EPA 1982b). In an EPA review of epidemiological studies of the nonepisodic relationship between $\mathrm{SO}_{2}$ and $\mathrm{PM}$ levels and mortality rates, it was concluded that London data usually indicated significant correlations, although New York City data were generally inconclusive (EPA 1982b).

Studies of acute exposure also indicate a relationship between $\mathrm{SO}_{2}$ exposure and increased $i l l n e s s$ or morbidity. A comparison of respiratory disease in mothers and children in two London suburbs indicated an association between its incidence and past exposure to sulfur dioxide and smoke (Holland et al. 1969, as cited in Lave and Seskin 1977). In a study of more than 10,000 children, Colley and Reid (1970) found a lower frequency of chronic cough and bronchitis in the less polluted areas of England and Wales. A study of Berlin, New Hampshire shows decreased respiratory symptoms corresponding to decreased PM and $\mathrm{SO}_{2}$ (Ferris et al. 1971, 1976). Studies by Lumn et al. $(1967,1970)$ seem to support a correlation between chronic exposure to specific ambient $\mathrm{SO}_{2}$ and PM concentrations with 1) decreased pulmonary function and 2) increased incidence of respiratory disease in children (as cited in EPA 1982b). 
Both hospital admissions (Martin 1964) and a deterioration in the condition of bronchitis patients (Lawther et a 1. 1970) appear to be correlated with smoke and sulfur dioxide levels in London (both cited in EPA 1982b). Bronchitis in workers and respiratory infections in children have been associated with chronic levels of $\mathrm{SO}_{2}$ pollution of approximately $100 \mu \mathrm{g} / \mathrm{m} 3$; this association is found both in Britain and in parts of the United States (Rall 1974). In the eastern United States, several studies have associated increased levels of $\mathrm{SO}_{2}$ and total particulate matter with increased hospital visits (Heimann 1970, as cited in EPA 1982b), mortality rates (Schwing and McDonald 1976, as cited in EPA 1982b), and absenteeism (Dohan and Taylor 1960, Dohan 1961, Ipsen et al. 1969, Verma et a1. 1969; all as cited in EPA 1982b). However, most of the United States studies of chronic effects have been criticized for lack of statistical significance. Overall, American studies in contrast to British studies do not seem to provide significant epidemiological support for the hypotheses that morbidity and $\mathrm{SO}_{2}$ exposure are positively related (EPA 1982b).

The main criticism of epidemiological studies is that they are inadequate to prove causation of a specific illness by a specific pollutant (Somers, in IAEA 1982); Kilburn, in Aharonson et al. 1976). Identification of the specific pollutants which reached individuals prior to and during the study period, and the magnitude of these concentrations, is generally sufficiently difficult that many reviewers question the quantitative estimates.

Controlled Laboratory Estimates. A number of different controlled laboratory methods are used to estimate the magnitude of the effect of sulfur dioxide and health. These include in vitro studies, experimentation with animals, and controlled human studies. "In vitro," a phrase entymologically related to "glass", connotes research conducted in the laboratory that involves the isolation of a specific tissue, cell type, or small organic component for laboratory study, cell type, or small organic component for laboratory study.

In vitro studies show that sulfur dioxide potentially causes cell damage. A review of in vitro studies of potential effects of $\mathrm{SO}_{2} /$ bisulfite is presented in EPA (1982b). A review of in vitro studies of potential effects of $\mathrm{SO}_{2}$ /bisulfite is presented in EPA (1982b). In these studies, human cells and lymphocytes are severely damaged by exposure to as Tittle as 5.7 ppm $\mathrm{SO}_{2} \mathrm{~m}$ 
(Kikigawa and Izuka, 1972, as cited in EPA 1982b). In vitro studies provide a significant causal link between sulfur dioxide pollution and health effects; however, they have heen criticized for failing to accurately represent the organism's complete response to a pollutant (Kilburn, in Aharonson et al. 1976).

Experimentation with animals is another method of estimating the health effects of air pollutants, especially with respect to lung damage (Kilburn, in Aharonson et al. 1976). Such experiments have shown animal responses to sulfur dioxide ranging from the insignificant to death (Colucci et al. 1976). One criticism of animal studies involves the ability to generalize from such studies to human health effects. Animal lungs differ in size, organization and other respects so that study results are not readily comparable, nor are they necessarily applicable to human lung response (Kilburn, in Aharonson, BenDavid, and klingberg 1976).

Controlled human studies providing estimates of the health effects of specific concentrations of sulfur dioxide on human subjects are summarized in an EPA review (1982b). Changes in pulmonary activity often could be detected even in healthy adult subjects at rest. Subjects in some cases had increased difficulty breathing, as demonstrated by bronchoconstriction and increased pulse rate. During exercise, effects ranged from unnoticeable to increased resistance to airflow in airways. The responses of asthmatics to $\mathrm{SO}_{2}$ exposure differed markedly from the response of subjects with no respiratory illness. For example, specific airway resistance increased in some asthmatics during exposure to as little as 0.1 part per million (ppm) for 10 minutes (Sheppard et al. 1981). At $0.5 \mathrm{ppm}$, some subjects developed wheezing and shortness of breath (Sheppard et al. 1981). California recently tightened its one-hour $\mathrm{SO}_{2}$ standard to $0.25 \mathrm{ppm}$ on the basis of new studies on the susceptibility of asthmatics to $\mathrm{SO}_{2}$ (Inside EPA 12/2/83). Healthy adults have tolerated $10 \mathrm{pPm}$ at rest (Melville 1970) and at least 5 ppm during exercise (Von Neiding et al. 1979, Newhouse et al. 1978, Kreisman et a1. 1976, all as cited in EPA 1982b). 
Controlled human studies are also used to study sensory effects of sulfur dioxide. Eye irritation, sneezing, and other sensory effects have been noted at relatively high $\mathrm{SO}_{2}$ concentrations. However, odor is detected and eyes are light sensitive at less than 1 ppm (EPA 1982b).

Controlled human studies have been criticized for consistently underestimating effects of pollutants on susceptible segments of the population (Kilburn, in Aharonson, Ben-David and Kingberg 1976). One potential bias is due to the types of samples used in these controlled experiments, which typically exclude individuals in high-risk groups. Some researchers believe that low levels of cellular damage which produce no observable symptoms in human subjects under experimental conditions may be sufficient to harm high-risk persons in less controlled circumstances (Kilburn, in Aharonson, Ben-David and Klingberg, 1976).

Groups at high risk from sulfur dioxide and other pollutants are identified on the basis of empirical studies and inferences drawn from the pollutant's mechanism of interaction with the human body (Calabrese 1978). There are several environmental, developmental and genetic factors that can potentiate the effects of certain pollutants. While some individuals may always be more sensitive to specific pollutants than the general population, all members of the population experience elevated risk at certain stages of their life cycle, such as infancy and old age (Calabrese 1978).

According to Calabrese (1978), the following groups may be at high risk from sulfur dioxide pollution:

1. People with chronic conditions including:

- respiratory illness

- asthma

- heart disease

2. Children (up to age 10-12) and infants with immature immune systems;

3. People carrying or having the following genetic traits:

- cystic fibrosis

- immunoglobin-A deficiency

- serum alpha antitrypsin

- sulfite oxidase deficiency 


\subsubsection{Health Effects of Sulfates}

Changes in the ambient concentrations of sulfate aerosols may also impact human health. When these particulates, particularly sulfuric acid $\left(\mathrm{H}_{2} \mathrm{SO}_{4}\right)$ are inhaled, they irritate and thus constrict respiratory airways, in much the same manner as does sulfur dioxide (EPA 1982b). In fact, in many studies, the health effects of sulfur dioxide and sulfates are considered together because 1) the effects of the two are so similar in a qualitative sense, and 2) it is difficult numerically to discern their individual effects, particularly in epidemiological studies, because concentrations of the two pollutants are so highly correlated, (Wilson et al. 1980). However, in those studies which have investigated the effects of these two classes of pollutants separately, the general finding is that, although $\mathrm{SO}_{2}$ and sulfate affect human health in a similar manner, acting through similar mechanisms and generating similar types of responses, the effects of sulfate exposure are greater in both magnitude and duration than similar exposure to sulfur dioxide. This is true for both acute and chronic exposures, and is particularly true for specific sulfate aerosols, most notably sulfuric acid.

A number of controlled human studies demonstrate the more severe health effects, at lower doses, of exposure to sulfuric acid aerosol rather than sulfur dioxide. These studies are summarized in EPA (1982b). The health effects, when they occur, are bronchial stress, increased airway resistance, and other pulmonary responses that can lead to breathing difficulties. The health effects are more severe for asthmatics than for other adults of comparable health. Epidemiological studies that isolated the health effects of sulfate were not found, primarily because sulfur dioxide and sulfate concentrations in the atmosphere are so highly correlated that it is difficult statistically to separate the effects on mortality or morbidity of changes in one of these pollutants from the effects of changes in the other; in fact, most of the controlled human studies summarized earlier encounter this same difficulty, and refer not to sulfur dioxide exposure alone but to a combined sulfur dioxidesulfate exposure. 


\subsubsection{Visibility Effects of Sulfate Particulate}

Correlations between poor visibility and ambient leveis of suspended particulate matter are well documented. Sulfates are a major component of suspended particulate matter and are thought to contribute significantly to visibility reduction. In this section, a summary of the effects of sulfates on visibility is presented.

\subsubsection{Description of Potential Effects}

Visibility is usually defined in terms of visual range and color contrast, and visibility impairment as reductions in visual range and/or changes in color contrast (atmospheric discoloration). In turn, visual range is typically defined as the maximum distance that a black object can be seen at the horizon. The median visual range in the United States varies from more than 70 miles in the mountainous southwest to less than 15 miles in areas east of the Mississippi and south of the Great Lakes (EPA 1982b). Atmospheric discoloration is a pollution-caused change in the color of the sky, distant mountains, or other objects. Suspended particulate matter greatly reduces visual range. In addition, in the absence of particles (and other pollutants), the sky is blue and distant objects are their true color, although they become increasingly blue as the distance increases; particles tend to whiten the sky, particularly the horizon, and cause distant objects to appear more gray than otherwise.

\subsubsection{Mechanism of Action}

Sulfate particulates reduce visual range and cause atmospheric discoloration both by scattering and absorbing light. The first mechanism appears to be the most important, although in some cities, for example, Denver, the second also plays a large role. In fact, particulate-related scattering causes nearly $50 \%$ of visual range degradation in the average U.S. city and sulfate accounts for the largest proportion of this $50 \%$ (EPA 1982b). Light scattering refers to the process by which light "hits" a particle and deflects off it, causing the direction of the light to change and its intensity to decrease. The efficiency with which a specific particle deflects light is related to its size (as measured by its diameter); particles with diameter similar to the wavelength of 
visible light scatter light most efficientiy (EPA 1979). The diameter of most sulfate aerosol particles is typically about .3 micrometers $(\mu \mathrm{m})$, well within the range of wavelengths of visible light $(.1$ to $1 \mu \mathrm{m})$, so that sulfate is an extremely efficient light scatterer.

Absorption refers to the process by which light energy "hits" a particle and, instead of deflecting off it, is collected into the particle. The total amount of light energy transmitted through the atmosphere is reduced by such absorption, again contributing to gray haze. Sulfate does not appear to be a major contributor to light absorption except in several western cities (EPA 1979).

\subsubsection{Estimates of Effects}

There are two methods for estimating the contribution of sulfate aerosols to visibility reduction. In one method, empirical visibility models are used to estimate the reduction in visibility attributable to various pollutants at specified relative humidities. In general, greater reductions in visibility are expected in damper weather. The second method of study is to compare timeseries data on anthropogenic emissions of sulfur oxides and other particulates with recorded visibility reports from airports and other observation stations.

Empirical visibility models generally are used to estimate extinction efficiencies of various aerosol species. In various weather conditions, each increment in sulfate concentration can significantly contribute to light extinction efficiencies (White and Roberts 1980, as cited in Cass 1982). The product of the light extinction efficiency of an aerosol species with its concentration, surmed over all aerosol species, is known as the particle scattering coefficient (Cass 1982). The particle scattering coefficient is a measure of the light scattering attributable to aerosol species. In an empirical study sulfates accounted for half of the magnitude of the particle scattering coefficient (Ouimette and Flagori 1981, as cited in Cass 1982).

Visibility reductions and sulfate concentrations in the United States are strongly correlated (OTA 1979). In addition, improvements in visibility are associated with decreased sulfur dioxide emissions (as cited in OTA 1979). Patterns of coal consumption in the eastern United States have been strongly 
correlated with light extinction in a study of time-series data over several decades (Husar et a1. 1979, as cited in EPA 1982b).

\subsubsection{Climate Effects of Sulfate}

Little quantitative information on the effects of sulfates on climate is available. However, it is thought that sulfates, like other aerosols, may cause cooler ground temperatures and warmer temperatures in the lower atmosphere than would prevail otherwise (EPA 1982b). The mechanism of action would be, as in the case of visibility reduction, contributions by aerosols to the scattering of sunlight. Any such perturbation of the qualitative and spatial distribution of solar radiation at the earth's surface could potentially contribute to climatic change. Aerosols may also affect cloud formation and precipitation. In particular, emissions that are precursors to aerosol species may increase downwind rainfall (EPA 1982b).

\subsubsection{Vegetation Effects of Sulfur Dioxide}

Sulfur dioxide that enters plants in the gaseous form (i.e., that has not yet been converted to sulfite or sulfate) may have a number of effects on vegetation. These effects are reviewed in this section; the reader is reminded that the effects on vegetation of the sulfur dioxide which becomes sulfite or sulfate prior to contact with the plant are treated in the acid deposition literature as a direct, not an ancillary, effect of acid deposition reduction. Also, the effects on vegetation of sulfur oxides which do not come into direct contact with the plant are considered in section 4.1.6.

\subsubsection{Description of Potential Effects}

Reductions in the concentration of sulfur dioxide in the gas mixture immediately surrounding a plant may increase, have no effect, or decrease productivity (i.e., growth) of the plant. Such concentration reductions may also damage foliage, or reduce damages to foliage. Types of vegetation that may be affected include crops, timber, and flowers. 


\subsubsection{Mechanism of Action}

Sulfur dioxide from the atmosphere generally enters a plant through the plant stomata (EPA 1982b), which are openings in the plant's leaves that control gas exchange between the plant and its environment. Once sulfur dioxide enters the leaf of a plant, it reacts with wet surfaces within the leaf to forn sulfite $\left(\mathrm{SO}_{3}\right)$, which is highly toxic to the plant. The negative effects of sulfur dioxide on plant productivity and foliage are due to this transformation to sulfite.

Fortunately, the leaves of the plant are capable of further transforming the sulfite to sulfate $\left(\mathrm{SO}_{4}\right)$, which the plants use to build sulfur-containing amino acids and proteins necessary for healthy plant growth. Whether an increase in the sulfur dioxide concentration is beneficial or detrimental to plant productivity and foliage depends on how much of and how quickly the sulfite is transformed to sulfate; if nearly all of the sulfite is transformed and done so quite quickly, the $\mathrm{SO}_{2}$ concentration increase may be beneficial to the plant, while if very little of the sulfite is transformed or the transformation is slow, such a concentration increase may do more harin than good.

Generally, the rate and speed of the sulfite-sulfate transformation depends primarily on the amount of sulfite which must be converted. If the sulfur dioxide concentration is chronically high (i.e., constantiy high, for a large portion of the time), creating a large quantity of sulfite, the plant is unable to transform all of the sulfite to sulfate; on the other hand, if the concentration is low, most of the sulfite can be transformed. Thus, in the context of policies which control (or reduce) the concentration of sulfur dioxide, there are likely to be larger beneficial effects on plant productivity and foliage health the higher the existing $\mathrm{SO}_{2}$ concentration level. Moreover, the effects of such a policy can reduce yields if existing $\mathrm{SO}_{2}$ concentrations are al ready low, because the policy would, in effect, be reducing the amount of sulfate available to the plant.

As is the case with the response of many living organisms to pollutant exposure, the effects of an acute exposure to sulfur dioxide may be much more severe (and more likely to be negative) than the effects of a chronic exposure (one with the same average $\mathrm{SO}_{2}$ concentration). This asymetry occurs because 
the plant cannot transform all of the sulfite to sulfate during an acute episode, because too much sulfite is produced; some of the untransformed sulfite remains to harm the plant. After the episode is over, and $\mathrm{SO}_{2}$ concentrations fall to their typical level (assumed to be lower than the chronic level of the second case), much of the sulfite-sulfate transformation capacity is not used; conversely, during a chronic episode with the same average $\mathrm{SO}_{2}$ concentration, this capacity might be used fully for the entire period, and thus convert more sulfite than in the acute episode case.

\subsubsection{Estimates of Effects}

Dose-response estimates from a number of studies are tabulated in EPA (1982b). The tables summarize studies considering the effects of sulfur dioxide exposure to agronomic crops, horticultural crops, trees, and native plants. The studies show that sulfur dioxide exposure has caused yield reductions or foliar injury in particular cultivars of soybeans, barley, wheat, tobacco, peas, corn, kidney beans, broccoli, beans, sunflowers, apples, begonias, petunias, coleus, snapdragons, and marigolds, although other studies on some of these crops have found insignificant or even slight positive effects. The highest yield reductions estimated were $42-45 \%$ for soybeans, barley, and durum wheat e posed to $0.15 \mathrm{ppm} \mathrm{SO} 72$ hours per week for the growing season. In addition, growth of Norway spruce and American elm has been retarded by $\mathrm{SO}_{2}$ exposure (up to $53 \%$ less growth in the Norway spruce), and exposure has caused foliar injury to pine, spruce, aspen, gingko, maple, and oak trees. Finally, the yields of a number of grasses have been reduced in laboratory studies by $\mathrm{SO}_{2}$ exposure.

\subsubsection{Vegetation Effects of Sulfate Particulate}

The effects of sulfate aerosols, in the form of acid deposition, on vegetation are considered direct, not ancillary, and are included in the acid deposition research. In addition, sulfate aerosol has a potential indirect or ancillary effect on plant productivity. This is accomplished by scattering and, to a lesser extent, absorbing light, sulfate aerosol particles reduce the quantity and change the quality of the light available for photosynthesis of: 
1) phytoplankton in aquatic systems, and 2) terrestrial vegetation. Both plant growth and quality of agricultural crops may be adversely affected by this effect.

The mechanism of action associated with this effect is described in Section 4.1.3; the effect of sulfate particulate on the amount of light available for photosynthesis is analagous to its effect on visibility. The effects on plant growth of changes in the quantity and/or quality of light energy are discussed in most biology texts. The negative repercussions of sulfur-caused haze on agricultural productivity have not, to our knowledge, been estimated precisely. However, hazy episodes in the eastern United States can reduce direct solar radiation by 75 to $90 \%$ (EPA 1982), a magnitude which is apparently large enough to make plausible hypotheses about decreased rates of photosynthesis in affected localities.

\subsubsection{Materials Effects of Sulfur Dioxide and Sulfate Particulate}

Reductions in the ambient concentrations of sulfur dioxide and sulfate aerosol will decrease the rate of corrosion of a number of man-made and natural materials, including metals, fibers, paint, building materials, and works of art. These compounds cause corrosion as an acidic agent, i.e., if the compound is not an acid, it transforms into acid upon contact with the material, and as an acid corrodes the material. Because the effects of sulfur oxides on materials is an acid-related corrosion effect, the acid deposition-related research underway through the Task Group on Effects on Materials and Culturat Resources is considering all materials effects, even in cases where the compound is not deposited as an acid but is transformed into one after deposition (EPA 1983).

\subsection{ANCILLARY EFFECTS OF CHANGES IN CONCENTRATIONS OF NITROGEN OXIDES}

This section identifies and characterizes the potential effects on health, visibility, vegetation, and materials of changes in the airborne concentrations of nitrogen dioxide, nitrites, and nitrates. Each of these response categories; is treated separately. 


\subsubsection{Health Effects of Nitrogen Dioxide}

Reductions in the ambient concentration of nitrogen dioxide may have a number of effects on human health, particularly lung function. This section describes the potential effects of nitrogen dioxide on human health, discusses the mechanisms of action, and reviews estimates of these health effects.

\subsubsection{Description of Potential Effects}

Nitrogen dioxide $\left(\mathrm{NO}_{2}\right)$ is a respiratory irritant, whose effects are characterized by cough, tightness of the chest, tightness of the respiratory tract and damage to cardiopulmonary tissue. Such airway constriction may impair transfer of oxygen to the blood. Acute exposure quickly may be fatal (EPA 1982a). Nitrogen dioxide may also damage cardiopulmonary tissue.

\subsubsection{Mechanism of Action}

$\mathrm{NO}_{2}$, inhaled as a gas, can irritate and damage lung tissue. It does not readily dissolve in the relatively dry trachea and bronchi (Calabrese 1978), and consequently has a high probability of reaching the alveoli. These small moist sacs are the true respiratory surface in breathing, and if they are damaged then it is possible that not enough oxygen will reach the blood. Upon reaching the moist alveolor surfaces, $\mathrm{NO}_{2}$ is converted to nitrous acid $\left(\mathrm{HNO}_{2}\right)$ and nitric acid $\left(\mathrm{HNO}_{3}\right)$. The acidic compounds attack the sensitive alveoli and damage them.

\subsubsection{Estimates of Effects}

A number of studies investigate and attempt to estimate the relationship between nitrogen dioxide exposure and morbidity/mortality. These studies can generally be divided into two groups: 1) controlled studies of acute exposure, and 2) epidemiological studies of chronic exposure.

Controlled Studies. A number of controlled studies of the health effects of nitrogen dioxide measure the response of subjects to a short, single, highconcentration exposure of $\mathrm{NO}_{2}$. These studies supplement the literature on accidental and occupational exposures (Milne 1969, Horvath et al. 1978, both as cited in EPA 1982a). 
Several controlled studies are reviewed by EPA (1982a). These studies generally show that following the $\mathrm{N}_{2}$ exposure, subjects experienced increased respiratory airway resistance for a short period of time. In none of these studies, however, does there appear to be a long-term adverse response to the exposure.

Studies of acute accidental or occupational exposures to $\mathrm{N}_{2}$ appear to confirm these controlled studies. On several occasions, workers were exposed to such high concentrations of $\mathrm{NO}_{2}$ that they died almost immediately from acute bronchitis or pulmonary edema. For smaller concentrations or shorter exposures, however, exposed individuals typicaliy experience respiratory irritation during and shortiy after the exposure, but recover fully without further complications from these problems.

Controlled studies using subjects selected from sensitive population groups (e.g., asthmatics) tell a similar story (EPA 1982a). Generally, the respiratory irritation experienced by these persons upon exposure is greater than that experienced by healthy persons. However, even in these studies, long-term complications caused by acute one-time exposures typically are not discovered.

Epidemiological Studies. Most epidemiological studies of the health effects of chronic nitrogen dioxide exposure do not find significant impacts, either on pulmonary function or on acute respiratory iliness. Several of these studies are summarized in an EPA review (1982a). The evidence presented by EPA suggests that, at least for the general population and ambient $\mathrm{NO}_{2}$ concentrations observed in the past in major U.S. cities, the health effects of ambient $\mathrm{NO}_{2}$ concentrations should not be of concern. This generalization need not be true for sensitive parts of the population or higher concentrations of $\mathrm{NO}_{2}$ than previously observed.

Moreover, there are several studies which find significant health effects. The incidence of bronchitis among infants and school-children in Chattanooga, Tennessee, was significantly higher among children with elevated exposure to $\mathrm{NO}_{2}$ (Shy et al. 1970 and Pearlman et al. 1971, as cited in Calabrese 1978, p. 142). Kagawa and Toyama (1975) found significant pulmonary effects from $\mathrm{NO}_{2}$ in a group of twenty 11-year-old Japanese school-children. 
Significant increased frequency of respiratory illness in children in homes with gas rather than electric stoves may be attributable to higher $\mathrm{N}_{2}$ levels in the homes with gas stoves (Melia et al. 1977 and 1979, Florey et al. 1979, Goldstein et al. 1979, Speizer et al. 1980, Spengler et al. 1979 all as cited in EPA 1982a).

\subsubsection{Health Effects of Other Nitrogen 0xides}

The vast majority of studies on the health effects of $\mathrm{NO}_{x}$ and related compounds focus on $\mathrm{NO}_{2}$. A smaller number of studies consider the health effects of nitrates, nitrites, nitric acid and nitrosamines. These studies generate some interesting hypotheses and preliminary results, although: 1) the mechanisms action are still not well understaod; 2) the empirical estimates have not been reproduced by other researchers, and 3) the findings must be interpreted as hypotheses, not conclusions. Several of these hypotheses are briefly described below.

If sufficient amounts of nitrates are inhaled, some of the nitrates may be reduced to nitrates in the human intensine. These nitrites, as well as those inhaled directly, may react with the iron in hemoglobin to form methemoglobin. The latter compound, if present in sufficient concentrations $10-20 \%$ of hemoglobin) may severely impair the process of transporting oxygen to tissue, causing cyanosis (bluish coloration). However, it is apparently unlikely that the (low) concentrations of nitrates and nitrites found in most locations could contribute very much to this condition (EPA 1982a).

Several studies (Utell et al. 1980, Fairhall 1957, as cited in EPA 1982a) show non-acidic nitrates and nitric acid fumes cause airway resistance and bronchoconstriction. These effects are not, however, well documented. Finally, a few epidemiological studies attempt to link environmental nitrates, nitrites, and nitroso compounds to human cancer. The success of these attempts is mixed, with some studies rejecting such a link, and others supporting it. Inhaled nitrates (and, to a lesser extent, nitrites) may react with amines contained in the diet to form carcinogenic nitrosamines, which cause stomach cancer (EPA 1982a). Inhaled nitrates may also react to induce cancer of the esophagus (EPA 1982a). 


\subsubsection{Effects of Nitrogen Dioxide and Nitrate Particulate on Visibility}

Both nitrogen dioxide and nitrate particulate may cause visibility deterioration, measured in terms of both visual range and atmospheric discoloration. Although the visibility reductions caused by nitrogen oxides is thought at present ambient concentrations to be less than that caused by sulfates (EPA 1982a, EPA 1979) the effects may be significant, particularly in the western United States.

\subsubsection{Description of Potential Effects}

A reduction in the ambient concentration of nitrogen dioxide should increase the maximum distance at which a black object can be seen against the horizon (i.e., visual range), and also reduce the red-brown-yellow tint of the sky. Reductions in the concentrations of nitrate particulates, like those of sulfate particulates, should increase visual range, and also reduce the whiteness or grayness of the sky and distant objects.

\subsubsection{Mechanisms of Action}

Nitrogen dioxide is a light-absorbing gas. It absorbs blue wavelengths of light very effectively, causing the sky to appear reddish or, especially, brown or yellow. Light extinction by nitrogen dioxide also depends on its concentration. Nitrogen dioxide may be partly responsible for brown layers of haze.

Nitrate particulates reduce visibility in much the same manner as do sulfate particulates (see Section 3.1.3). Most nitrate particulates vary in size from .1 to 1.0 micrometers, the same as the range of wavelengths of visible light. Thus, nitrate particulates effectively scatter light. Like sulfate particulates, they are particularly efficient at diffracting red light, whose wavelength is .3 micrometers. By scattering light in general, nitrate particulate changes the direction and intensity of light energy, thus reducing visible range. By scattering red light in particular, nitrate particulate contributes to haze which is grayish in color. 


\subsubsection{Estimates of Effects}

A number of studies investigate the light extinction efficiencies of both nitrogen dioxide and nitrate particulate. Most studies of particulatevisibility relationships estimate the extinction coefficient of nitrate particulate to be about half of the sulfate particulate extinction coefficient (White and Roberts 1980, as cited by Cass 1982); an exception is a study by Trijonis and Yuan (1978), in which the nitrate coefficient is double the sulfate coefficient. As shown in Table 4.1, light extinction coefficients for $\mathrm{NO}_{2}$ absorption range from very high values at wavelengths between 0.4 and $0.5 \mu \mathrm{m}$, to relatively small values at longer wavelengths of approximately $0.7 \mu \mathrm{m}$ (Hodkinson 1966 and Nixon 1940, as cited in Cass 1982).

Although estimates of light extinction coefficients for both nitrogen dioxide and nitrate particulate are available, there are fewer estimates of the actual importance of nitrogen oxides to visibility impairment (EPA 1982a). This is primarily because there are relatively few reliable estimates of $\mathrm{NO}_{x}$

IABLE 4.1. Light Absorption by $\mathrm{NO}_{2}$ as a Function of Wavelength

\begin{tabular}{cc}
$\begin{array}{c}\text { Wavelength } \\
(\mathrm{m})\end{array}$ & $\begin{array}{c}\text { Extinct Coefficient due to } \\
\text { Absorption by } \mathrm{NO}_{2} \\
\text { babs }(10-4 \mathrm{~m}-1 \text { ppm-1) }\end{array}$ \\
\cline { 2 - 2 } 0.400 & 16.60 \\
0.425 & 15.90 \\
0.450 & 13.55 \\
0.475 & 10.00 \\
0.500 & 7.10 \\
0.525 & 5.30 \\
0.550 & 3.32 \\
0.575 & 2.00 \\
0.600 & 1.23 \\
0.650 & 0.44 \\
0.700 & 0.16 \\
\end{tabular}

Source: Hodkinson 1966 and Nixon 1940, as cited in Cass 1982. 
concentrations, which are required to estimate how much visibility reduction is, in fact, caused by the two pollutants. There is evidence that $\mathrm{NO}_{2}$ plays a significant role in atmospheric discoloration and visual range reduction at the ambient concentrations observed in many U.S. cities, particularly in the West (EPA 1982a); the importance of nitrate is thought to be much less, because of the rather low ambient concentrations of nitrate, but is not well documented.

\subsubsection{Effects on Vegetation of Nitrogen Dioxide}

Reductions in the ambient concentration of nitrogen dioxide may have substantial beneficial impacts on vegetation. The same may be true of nitrite and nitrate concentration reductions; however, except for the effects of nitric acid on vegetation (studied in the acidic deposition literature), the effects of nitrites and nitrates on vegetation has been studied much less, to the extent that not very much can be reported about this topic. This section therefore is devoted to the effects of nitrogen dioxide on vegetation, describing the potential effects and mechanisms of action and reviewing estimates of these effects.

\subsubsection{Description of Effects}

Reductions in the ambient concentration of nitrogen dioxide may increase or decrease the prevalence of lesions on the leaves or needles of plants, the extent of other types of foliar injury, and/or plant growth/ productivity (EPA 1982a). As in the case of the effects on plants of sulfur dioxide exposure, both the direction and magnitude of impacts of nitrogen dioxide exposure depend on the concentration and duration of exposure, time of day, edaphic factors such as nutrient and water content the soil, the species affected, the stage of growth of specific plant tissues, and other considerations.

\subsubsection{Mechanisms of Action}

Nitrogen dioxide enters the plant by gas exchange through the stomata. Within the mesophyll tissue of the leaf, where chlorophyll is contained, the $\mathrm{NO}_{2}$ may react to form nitrites and nitrates. Although plants generally need some amount of both nitrites and nitrates to grow properly, plants apparently have a threshold beyond which these ions injure cells within the plant (EPA 1982a). The causes of the resulting injury are unclear. Some researchers 
(Nash 1976, Kandler and Ullrich 1964) found reduced chlorophyll in the plant's leaves prior to observed leaf damage, inhibiting photosynthesis, Others (Taylor and Eaton 1966), however, found that chlorophyll increased.

Thus, for low nitrogen dioxide concentrations, further reductions in these concentrations may harm plants, which would be "robbed" of the nitrites and nitrates they need to grow effectively. At high concentrations, however, reductions will reduce injuries to plant cells, because the number of "excess" nitrite and nitrate ions produced in the plant will be reduced.

\subsubsection{Estimates of Effects}

Although the mechanism for injury to vegetation is not well understood, a number of studies estimate the damage to various species from exposure to $\mathrm{NO}_{2}$. Leaf injury to oats, begonia, chrysanthemum, cotton and other agricultural and horticultural cultivators occurs following exposure to $\mathrm{NO}_{2}$ in controlled experiments. Depending on crop, dose and duration of exposure, leaf area damage ranges from 0 to $95 \%$ (Heck and Tingey 1979, as cited in EPA 1982a). A number of species incurred large leaf injuries for exposures over ten parts-per-million per hour. Test doses in these experiments exceeded high but plausible ambient $\mathrm{NO}_{2}$ concentrations of $0.4 \mathrm{p \rho m}$ in all cases (EPA 1982a). Chronic exposure to high $\mathrm{NO}_{2}$ concentrations can reduce crop yields. In one series of experiments, beans, ondive and carrots were particularly affected (EPA 1982a). The amount of injury varied from no impact to yield reduction of approximately a third.

\subsubsection{Effects of Nitrogen Oxides on Materials}

Oxides of nitrogen can discolor fabric, decrease the strength of fibers and, in combination with other pollutants, corrode metal. Nitrogen oxides cause other damage to materials as well. Direct and ancillary impacts of $\mathrm{NO}_{\mathrm{x}}$ on materials are not demarcated clearly. In this section, effects of $\mathrm{NO}_{x}$ on materials other than or prior to formation of mitric acid, $\mathrm{HNO}_{3}$, will be considered as ancillary impacts.

\subsubsection{Oescription of Effects}

The oxide of nitrogen most damaging to materials is nitrogen dioxide $\left(\mathrm{NO}_{2}\right)$ (US EPA 1982). This brown gas can cause some dyes, on specific materiais, to 
fade. In addition to its discoloring effects, nitrogen dioxide can eaken the fibers of some fabrics. Nitrogen dioxide can also reduce the durability of some fabrics (US EPA 1982, Yocum and Buer 1983).

Nitrogen salts, especially ammonium nitrates, are a factor in the corrosion of metals. Ammonium nitrates contribute to the stress corrosion cracking of wires made of nickel-brass alloy and used in telephone equipment. The presence of nitrate salts, which are hygroscopic and have affinity for water, may cause increased wet corrosion of metals (US EPA 1982).

\subsubsection{Mechanisms of Action}

Nitrogen dioxide's odd-electron, angular molecules react with some fabric and dye combinations. One possible machanism of action is migration of dye to certain sites that are susceptible to $\mathrm{NO}_{2}$ action (US EPA 1982).

Polymer plastics may lose strength upon exposure to $\mathrm{NO}_{2}$. The weakening of nylon may occur as a result of chain scission, a bond weakening in polymers. Bonding in polyprophylene may also be adversely affected.

Nitrate salts seem to be responsible for the acceleration of metals corrosion by $\mathrm{NO}_{x}$. Nitrates have relatively high affinity for water, which they dissolve in to form electrolyte solution. The combination of a salt and moisture at the surface of metals promotes galvanic corrosion. Significant corrosion may occur at lower humidities than would be the case in the absence of nitrate salts.

Another very important mechanism of action occurs when $\mathrm{NO}_{\mathrm{x}}$ and water come together. Nitric acid, which is thereby formed, attacks all kinds of materials with ensuing weight loss and erosion.

\subsubsection{Estimates of Effects}

It is difficult to correlate materials damage to specific pollutant mixtures and dosages. Yellowing of white fabrics in polluted, ambient ajr, has been recorded, but the dosage and composition of pollutant mixtures in the environment are uncertain (Upham and Salvin 1975). Controlled chamber studies 
show yellowing to occur at $0.2 \mathrm{ppm}$ for periods as short as eight hours (Salvin 1974). Under weather conditions of high humidity and warn temperatures, acid dyes tested over severat days even at 0.1 ppm (US EPA 1982).

\subsection{ANCILLARY EFFECTS OF CHANGES IN CONCENTRATIONS OF PHOTOCHEMICAL OXIDANTS--OZONE AND PEROXYACETYL NITRATE (PAN)}

As discussed in Chapter 3.0, concentrations of photochemical oxidants, including ozone and peroxyacetyl nitrate (PAN), are likely to change if NOx reduction strategies are implemented, although the direction and magnitude of the concentration changes are unknown. These changes may have a number of important effects. Stratospheric ozone is beneficial to human beings because it screens harmful rays from the sun before they reach the earth (CEQ 1975, Interdepartmental Committee for Atmospheric Sciences 1975). At the earth's surface, however, ozone can damage human health, vegetation, and materials. This section identifies and characterizes the potential ancillary effects associated with changes in the stratospheric and tropospheric concentrations of ozone, PAN, and other photochemical oxidants.

\subsubsection{Health Effects of Stratospheric Ozone}

Reductions in stratospheric ozone could potentially harm plant and animal life. The potential significance of such effects was considered extensively during hearings in 1974 and 1975 regarding the possible impacts of fluorocarbons on the environment. The eventual economic significance of reductions in stratospheric ozone were, at that time, considered great enough to warrant a ban on fluorocarbons in spray cans and further study of other measures to control pollutants suspected of decreasing the stratospheric ozone layer (U.S. House of Representatives Interstate and Foreign Commerce Committee 1974, U.S. Department of Commerce, Office of Business Research and Analysis 1975).

\subsubsection{Description of Potential Effects}

Reduction of ozone in the stratosphere could adversely affect plant growth, photosynthesis by phytoplankton, insects, freshwater organisms and other animals. In particular, such a reduction could increase the incidence of some types of skin cancer that are not, in general, fatal. 


\subsubsection{Mechanism of Action}

A reduction in stratospheric ozone would allow more ultraviolet radiation of wavelengths 280 to 320 nanometers (UV-8 radiation) to reach the earth's surface. Living organisms are extremely sensitive to increased UV-B radiation and, for the most part, are adversely affected by it. UV-8 radiation can injure the nucleic acids, DNA and RNA, in plant and animal cells. It can also injure protein molecules that include cell structure constituents and enzymes.

Organisms can protect themselves from some UV-8 radiation through protective and repair mechanisms. Sometimes outer structures, like hair on animals or waxy coatings on plants, absorb UV $A$ B radiation before it reaches regions where it may cause significant harm. Some damage to cells can also be repaired. However, some damage is irreversible.

\subsubsection{Estimates of Effects}

In general, specific illnesses cannot be traced to reductions stratospheric ozone. However, ultraviolet radiation has been implicated as a mutagenic agent, i.e., as a cause of cellular mutations. These alterations in genetic structure of cells are in and of themselves, unhealthy; in addition, they may lead to skin cancer, particularly in persons with one of three genetic conditions: albinism, phenylketonuria and xeroderm pigmentosum. These genetic conditions are prevalent in certain ethnic groups. The conditions predispose people to elevated risk from ultraviolet radiation (Calabrese 1978).

\subsubsection{Health Effects of Atmospheric Dzone and PAN}

Changes in the atmospheric concentrations of ozone and PAN may have a number of effects on human health, particularly lung function and eye irritation.

\subsubsection{Description of Health Effects}

Nasal and throat irritation may result from ozone exposure, while eye irritation may accompany elevated levels of PAN. More serious lung damage may result from complex interactions between ozone and components of the pulmonary system. Animals may die more readily from exposure to airborne disease-causing 
bacteria following ozone exposure (Huber et al. in Menzel 1971). Ozone can also accelerate the incidence of lung tumors in laboratory animals (Heicklen 1976, Gardner et al. in Menzel 1971).

\subsubsection{Mechanism of Action}

The health effects of ozone occur after it is inhaled as a gas. In the lungs and respiratory tract, ozone may cause various types of damage, dependent upon the tissue or fluid with which it reacts (Hueter and Fritzhand, in Menze) 1971). It has been suggested that ozone chemically alters a factor in the lungs which normally protects the integrity of alveolar macrophages, cells which normally help defend the lungs against noxious physical and biological agents (Gardner et al. and Cross et al. in Menzel 1971).

\subsubsection{Estimates of Effects}

Human beings can recognize ozone at .015 parts per million (ppm). The dosages at which specific effects occur follow: athletic performance can be impaired at an exposure of .10 parts per million (ppm); coughing and exhaustion occur at about 1.0 ppm; loss of coordination and coherency occur at 1.5 $2.0 \mathrm{ppm}$, and sleepiness occur at $3.0 \mathrm{ppm}$. Asthmatics have increased attacks at $0.15 \mathrm{ppm}$, a level routinely exceeded in parts of the United States (Heicklen 1976).

In a study of metropolitan Washington, 0.C., Seskin (1976) found consistent and statistically significant associations between 1973 and 1974 daily unscheduled eye-doctor visits and ambient concentrations of photochemical oxidant. During intervals of shorter duration, an association between photochemicaloxidant levels and urgent clinic visits was identified (Lave and Seskin 1977).

Segments of the population particularly sensitive to ozone exposure include those sensitive to other respiratory irritants. In addition, ozone may cause elevated risk to people with heart disease. Vitamin E deficiency, estimated to affect $7 \%$ of the general population, heightens risk from ozone. The following genetic conditions, with estimates of the number of individuals in the United States affected, may predispose people to ozone's adverse effects: 
- hypocatalasemia catalase deficiency (5,000,000 heterozygotes)

- acatalasemia catalase deficiency (16,000 homozygotes)

- glucose-6-phosphate dehydrogenase deficiency (G-6-PD) (11\% black males and Mediterranean Jews, 1-2\% Greeks, 1-8\% Sardinians)

- deficiencies in glutathione, glutathione peroxidase, or glutathione reductase (unknown frequency)

- thalassemia (Cooley's anemia), (frequency between 0.1 and $8.0 \%$ of subpopulations of Italians, Greeks, Syrians, and blacks (Calabrese 1978).

\subsubsection{Crop Effects of Tropospheric Ozone and PAN}

Tropospheric concentrations of ozone, PAN and other photochemical oxidants may cause acute or chronic injury to crops and/or changes in crop yields. These effects are described below.

\subsubsection{Description of Potential Effects}

Ozone $\left(\mathrm{O}_{3}\right)$ may cause reductions in crop yields (Heck et al. 1983). Crops that are particularly susceptible to ozone-induced yield reductions include soybeans, wheat, cotton, kidney beans, peanuts, lettuce, turnips, and spinach. All photochemical oxidants may cause leaf injury, including flecking of leaves and other necrotic patterns (Berry 1977, Heicklen 1976). Oxidants may cause more significant damage to root crops than to leafy vegetable crops (University of California Cooperative Extension 1979). A crop susceptible to oxidant-induced leaf injury at ambient concentrations in some regions of the United States include alfalfa, tomato, soybean, lettuce, radish, cotton, potato, spinach, carrot, orange, snapbean, cucumber, okra and grape.

\subsubsection{Estimates of Effects}

Available damage assessments indicate various degrees of crop damage from ozone, depending on species and variety. The most recently published doseresponse data for crops exposed to ozone are presented in Heck (1983). Yield reduction at $0.05 \mathrm{ppm}_{3}$ for 7 hours/day all season may vary from $0.1 \%$ for Coker-16 corn to more than $22 \%$ for Empire lettuce. At double the concentration, the same species experience $3 \%$ and $57 \%$ yield reductions, respectively. 
Yields may be reduced by a third for soybeans and spinach at $0.10 \mathrm{ppm} 0_{3}$, by a fourth for turnips at $0.06 \mathrm{ppm}_{3}$, and by a variety of smaller amounts at lower concentrations.

Agricultural practices may substantially influence the extent of ozone damage. For example, early planting could help reduce the number of months of high ozone concentrations during which potato cultivars in California are exposed (University of California Cooperative Extension 1979). Farmers might also adapt by planting less ozone-sensitive varieties. Alfalfa yield reductions in Riverside, California, in 1975 of approximately $42 \%$ and $33 \%$ for the Hayden and Eldorado varieties of alfalfa, respectively were reported by Moskowitz et aT. (1982). Percentage differences in injury between the most sensitive and tolerant varieties of other crops after 1-1/2 hours exposure to $0.70 \mathrm{ppm} 03$ are: tomato, $63 \%$; soybean, $42 \%$; lettuce, $36 \%$; and radish, $18 \%$ (University of California Cooperative Extension 1979).

\subsubsection{Forest Effects of Atmospheric 0zone}

Atmospheric ozone is suspected of reducing the rate of growth of some tree species. Dose-response data for the potential impact of ozone on mature forests are not available: chamber studies must generally investigate the effects of ozone on saplings, while the specific cause of unexpectedly slow forest growth can rarely be traced. However, classification of various tree species according to their relative sensitivity to ozone may be found in OTA (1982). Several species of sprice are relatively tolerant, while species of ash, aspen, pine, poplar, sycamore, and larch are all suspectible to injury from ozone exposure. White oak is sensitive to ozone, but other species of oak and several type of pine are neither very sensitive nor very tolerant.

\subsubsection{Materials Effects of Atmospheric Ozone}

Ozone, like acid deposition, can cause material damages or reduce product lifetimes. Rubber, may crack if subjected to mechanical stress and exposure to ozone simultaneously. This would reduce the average durability of car tires. Ozone can also damage both the fabric and the dye in textiles (Heicklen 1976). 


\subsection{ANCILLARY EFFECTS OF CHANGES IN AIRBORNE METALS AND METAL OXIDES}

Trace metals have been implicated in a variety of serious illnesses. However, specific trace metals may cause no adverse health effects or may be essential in small quantities to proper body function. Certain metals may accumulate in plants, damaging either the plants themselves or the animals that consume them.

\subsubsection{Description of Potential Effects}

Trace metals in coal that may pose health hazards include nickel, beryllium, boron, arsenic, selenium, yttrium, mercury, and cadmium. In general, specific metals can be associated with specific responses. Several may cause or heighten the probability of cancer (Bailey et al 1978). Arsenic has been implicated as a substance that causes developmental malformations (Hood, in Mahlum et a1. 1978). Cattle in the western United States with "alkali disease" probably consumed unhealthy amounts of selenium in plants (Bailey et al. 1978). Mercury may cause nerve damage and death, and cadmium is associated with a variety of serious health affects. Arsenic emissions have been associated with induced abortions in swine (Hood, in Mahlum et al. 1978).

\subsubsection{Mechanisms of Action}

Metals can be introduced into the human body by ingestion or by inhalation as metal oxide particles; they can also be transferred to fetuses through the placenta. Metals tend to accumulate in organic matter, so organisms higher up in the food chain tend to be subject to more metal contamination for their weight than organisms lower in the food chain. Metals deposited in the environment may contaminate groundwater, which could subsequently be imbibed as drinking water from wells. The body may be protected from some of the consequences of metal oxide inhalation by clearance mechanisms and by the action of alveolar macrophage (Sanders et al. in Menzel 1971).

\subsubsection{Estimates of Effects}

Some trace metals can cause substantial physiological damage even in rela-tively small doses (Bailey et al. 1978). Infants, young children and the fetus 
probably absorb trace metals readily and may be more likely than adults to receive harmful pollutant doses from short-term exposure (Calabrese 1978, Hood in Mahlum et al. 1978).

The absorption of the trace metal selenium by plants is affected by the acidity of the soil. More alkaline soils facilitate its absorption, with consequently heightened danger to grazing animals (Bailey et al. 1978).

Hood (in Mahlum et al. 1978) reports three cases in which arsenic contamination was correlated with effects on livestock or human populations. Severe malformations and birth defects in human beings were associated with environmental contamination by arsenic in two cases. In another incident, a large breeding operation for swine production relocated after arsenic-induced abortions in swine were associated with arsenic emissions from a power plant upwind.

In addition to possible susceptibility to health effects from metals for all people during infancy and childhood, certain genetic conditions, nutritional deficiencies and diseases may result in elevated risk. Numerous individuals may be particularly susceptible to the health effects of lead. Cadmium and mercury may pose a high risk to people with genetic traits for cystinosis, cystinuria and tyrosinemia. Vitamin $C$ deficiency and selenium deficiency also heighten health risks from cadmium and mercury. Cadium also may pose high risks to persons with zinc deficiency and those with heart disease. In general, the impact of heavy metals may be potentiated by preexisting kidney disease such as the genetic diseases listed above and those associated with other illnesses (Calabrese 1978).

\subsection{ANCILLARY EFFECTS OF CARBON MONOXIDE CONCENTRATION CHANGES}

Ambient levels of carbon monoxide (CO) are not generally associated with any adverse effects of vegetation, materials, climate or visibility (Berry 1977). The health effects of increasing concentrations are believed to be insignificant at some levels of exposure, with the following progressive effects: reduced oxygen carrying capacity to the blood, increased light sensitivity, impaired judgment, headaches, nausea, coma, convulsions and, eventually, death. However, there is no conclusive evidence that any of the more 
serious effects occur at ambient carbon monoxide levels that have been observed in the United States. Moreover, the less serious effects of carbon monoxide poisoning which occur at these observed levels appear to be reversible (Heicklen 1976).

\subsubsection{Mechanisms of Action}

Carbon monoxide, after entering the body as a gaseous component of air, is absorbed by the lungs into the bloodstream. Every molecule of carbon monoxide, $\mathrm{CO}$, binds with a molecule of hemoglobin to form a molecule of carboxyhemoglobin $\left(\mathrm{COH}_{6}\right)$. Hemoglobin is the blood's oxygen carrier, but it is not free to carry oxygen when bound to carbon monoxide. According to one source, the affinity of hemoglobin for $\mathrm{CO}$ exceeds its affinity for oxygen by more than a factor of 200 (Berry 1977). Carboxyhemoglobin is a more stable compound than oxyhemoglobin, and the carbon monoxide is unlikely to be displaced readily by oxygen. If carboxyhemoglobin concentrations in the blood are high enough, human beings will suffer discomfort and illness because not enough oxygen reaches vital organs.

\subsubsection{Estimates of Effects}

The results of community epidemiology studies of the relationship between CO exposure and mortality from cardiac disease are inconclusive (Goldsmith and Landau 1968, Kurt et al. 1978 and 1979, as cited in EPA 1983b). Carbon monoxide levels have not been associated consistently with mortality rates. It cannot be inferred from the available data that carbon monoxide was not associated with increased morbidity in individual cases (Lave and Seskin 1977).

The response of healthy adults differs from the response of a less tolerant sub-group. Table 4.2 shows both the response of a healthy adult and an adult with severe heart disease to various concentrations of carboxy hemoglobin. At $\mathrm{COH}_{6}$ blood saturation levels of $16-20 \%$, a leathy adult experiences a headache and abnormal visual response. The same saturation levels can be lethal for a patient with severe heart disease (Stewart 1975, as cited in Calabrese 1978). Subjects with levels of $\mathrm{COH}_{6}$ greater than or equal to $5 \%$ have demonstrated decreased ability to perform complex hand-eye coordination tasks such as are necessary when driving (Putz et al. 1976, 1979). Levels of $\mathrm{COH}_{6}$ of $5 \%$ correspond to $\mathrm{CO}$ concentrations of $30 \mathrm{ppm}$ (Heicklen 1976). 
TABLE 4.2. Human Response to Various Concentrations of Carboxyhemoglobin

Blood Saturation

(percent $\mathrm{COH}_{6}$ )

D.3-0.7

$1-5$

$5-9$

$16-20$

$67-70$

$20-30$

$30-40$

50
Response of Healthy Adult (a)

Normal range due to endogenous CO production; no known detrimental effect

Selective increase in blood flow to certain vital organs to compensate for reduction in oxygen carrying capacity of the blood

Visual light threshold increased in patients with angina pectoris

Headache; visual evoked response abnormal

Coma; convulsions

Throbbing headache; nausea;

manual dexterity abnormal

Severe headache; nausea

and vomiting; syncope

Lethal if not treated
Response of Patient with Severe Heart Disease

Patient with advanced cardiovascular disease lack sufficient cardiac reserve to compensate

Less exertion required to induce chest pain

May be lethal for patients with severely comprised cardiac function

(a) Exposure to $\mathrm{CO}$ in concentrations in excess of $50,000 \mathrm{ppm}$ can result in a fatal cardiac arrhythmia and death before the carboxyhemoglobin saturation is significantly elevated.

Source: Stewart 1975, reprinted in Calabrese 1978.

Federal primary and secondary ambient air quality standards for carbon monoxide, although under review, have been 9 ppm maximum in eight hours and 35 ppm maximum in one hour (Lave and Seskin 1977).

Various factors may impair a person's ability to adapt to carbon monoxide stress. Pregnant women, persons predisposed to coronary heart disease, people with the genetic blood diseases glucose-6-phosphate dehydrogenase deficiency 
(G-6-PD) or sickle cell, and persons deficient in vitamin $C$ may all be more susceptible to carbon monoxide than the rest of the population (Calabrese 1978). In an animal study of mice and rabbits, no statistically significant teratogenic effects of sulfur dioxide $\left(\mathrm{SO}_{2}\right)$ in combination with carbon monoxide (CO) were observed (F.J. Murray et al. in Mahlum et al. 1978).

\subsection{ANCILLARY EFFECTS OF CHANGES IN CARBON DIOXIDE LEVELS}

Carbon dioxide can increase dry matter in some plants. It may potentially make bodies of water more acidic. The most far-reaching consequence of elevated carbon dioxide levels is believed to be potential climatic warming.

\subsubsection{Potential Effects on Climate}

A doubling of atmospheric carbon dioxide is currently expected to make global temperatures 2-3 degrees Celsius warmer than otherwise. The "altithermal" about eight thousand years ago has been associated with a warming by 1 degree (Macoonald 1982). A temperature rise of 2 degrees due to high carbon dioxide levels is possible within the next century (Seidel et al. 1983). DOE, and other federal agencies, are actively researching the problem and potential remedies.

\subsubsection{Oescription of Potential Effects}

Some of the potential consequences of global warming are floods as the polar icecaps melt, significant alterations in regional weather and concomitant changes in regional agricultural productivity (Williams 1978).

\subsubsection{Mechanism of Action}

Carbon dioxide might warm the climate because of the different properties of electromagnetic radiation at the wavelengths $\mathrm{CO}_{2}$ absorbs well and those it does not absorb. Carbon dioxide interferes very little with the passage of sunlight to the earth, where the sunlight contributes to heat. Some of the energy from sunlight that reaches the earth is re-radiated into the atmosphere, but at longer, less energetic wavelengths. Carbon dioxide absorbs energy at the longer wavelengths, and energy is consequently retained in the atmosphere that might otherwise be radiated back into outer space. If other factors influencing climate remain constant, the net result is global waming. 


\subsubsection{Potential Effects on Vegetation}

Plant communities affect the carbon cycle and are affected by it. After entry into plants through gas exchange processes, carbon dioxide may be incorporated by them as organic carbon. Some species of plants may respond to fluctuations in ambient carbon dioxide levels by incorporating carbon more quickly or slowly. The growth of some species may be enhanced; other species in a diverse plant community, may suffer from increased competition for various 1 imiting nutrients. The relative productivities of various crops may be altered, or the ecological balance of plant communities around the world may change due to direct and indirect effects of changes in carbon dioxide levels (Lieth, in Williams 1978).

Relatively few plant species have been rigorously analyzed for their response to carbon dioxide. Increased concentrations of carbon dioxide can enhance photosynthesis and dry weight gain by specific cultivars of soybean (Acock et a1. 1982). Studies of the effects of carbon dioxide on trees are limited to the same considerations as discussed in Section 4.3.4.

\subsection{POTENTIAL EFFECTS OF CHANGES IN THE LEVELS OF HYDROCARBONS AND OTHER ORGANIC POLLUTANTS}

Hydrocarbons and other organic compounds can affect health and vegetation. The number of organic pollutants that have unequivocally been associated with adverse health effects is small compared to the very large number of compounds in this class of pollutants. Those organic pollutants considered to be hazardous generally affect the human body because they are carcinogens. The number of organic pollutants which have been identified as harmful to plants is also quite limited. The effects of organic pollutants on plants depend on several factors, including, but not limited to, the species and variety of plant.

\subsubsection{Organic Pollutants and Human Health}

The effects of organic pollutants on human health depend on the pollutant, its concentration, and the condition of the person exposed. Because a complex illness such as cancer may be difficult to trace to a specific cause, 
epidemiological studies may have only limited usefulness in the estimation of potential carcinogenicity of specific organic pollutants.

\subsubsection{Description of Potential Effects}

Drganic compounds are the substance of life and do not necessarily cause harm. However, some organic compounds may interfere with the biochemistry of cells, with mutagenic potential. Aromatic hydrocarbons from coal soot, coal tar, and other products of coal combustion are classified as potential occupational carcinogens and could lead to eventual lung, larynx, skin and/or prostate cancers (Cole and Goldman 1975, as cited in Calabrese 1978). Neonates might develop a qualitatively distinct type of tumor from that which adult animals would if exposed to the same carcinogen (Mahlum 1978).

\subsubsection{Mechanisms of Action}

Organic pollutants may enter the body through the respiratory tract; some polycyclic compounds may reach the fetus through the placenta (Mahlum 1978). A less likely route of exposure, for the general population, could be skin absorption (D'Appolonia 1982).

An organic compound's toxic potential depends on chemical transformations it undergoes inside the body. Sometimes metabolic processes acting on an organic pollutant will make it toxic, while at other times such process render it harmless (Mahlum 1978).

\subsubsection{Estimates of Effects}

The severity of daily symptoms of chronic bronchitis and emphysema was correlated with ambient hydrocarbon concentrations in a study by Burrows, Kellogg, and Buskey (1968). Studies reviewed by Lave and Seskin do not show that total hydrocarbons affected overall human mortality rates in any statistically significant way (Lave and Seskin 1977).

The risk of cancer from benzene is probably less than $1.1 \times 10^{-7}$ cancers/ $\mathrm{mg} / \mathrm{m}^{3}-\mathrm{yr}$ (Haigh et al. 1983). This estimate was prepared by EPA's Carcinogen Assessment Group (CAG), which studies the cellular changes induced by chemical compounds with in vitro laboratory experiments. Sometimes unusual cellular behavior similar to that correlated with "naturally occurring cancers" is 
observed in experiments whose subjects are exposed to hydrocarbon. However, only a small portion of organic pollutants from coal combustion may have mutagenic potential.

Neonates may be at higher risk from organic compounds than are adults, although the evidence is not conclusive (Mahlum 1977). Iron deficiency, which may be common in some age groups, has been suggested as a factor in the toxicity of hydrocarbon carcinogens (Calabrese 1978).

\subsubsection{Hydrocarbons and Vegetation}

Plant damage has been attributed to ethylene. Ethylene remains in the air long enough to affect some types of vegetation. It damages flowers and flower production and can cause flowers grown commercially to lose their market value. Examples of flowers that ethylene may affect in this manner are orchids, carnations and snapdragons (Darley, in Starkman 1971).

\subsection{POTENTIAL EFFECTS OF ANCILLARY POLLUTANTS IN COMBINATION}

The effect of pollutants in combination sometimes may be different than the sum of the individual effects. This is true for both health effects and effects on vegetation. Experiments to determine the effects of pollutants in combination may simulate field conditions more closely than those which involve a single pollutant.

\subsubsection{Effects on Health}

Studies of the combined health effects of air pollution have had mixed results (Kagawa 1983). A combination of respiratory irritants could conceivably have more than additive toxicity. A possible mechanism of action would be interference by one pollutant with the effectiveness of the lung's clearance mechanisms, possibly resulting in elevated exposure of a potentially sensitive tissue.

\section{8 .2 Effects on Vegetation}

Crops exposed to ozone and sulfur dioxide in combination may experience additive or less than additive effects on growth (Tingey and Reibert 1975). In contrast, leaf damage is generally more than additive. Results from studies of 
the effects of pollutants mixtures of plants are summarized tabulated in EPA (1982b). Peas and spinach are two crops which may be damaged more than additively by exposure to sulfur dioxide and ozone (Fujiwara et al. 1973, as cited in EPA 1982b). Peas, radish, and alfalfa are examples of crops which may be damaged more than additively by exposure to sulfur dioxide and nitrogen dioxide (EPA 1982b).

\subsection{SUMMARY}

As shown in Table 4.3, the impacts identified in this chapter may be regrouped by potentially affected receptors for use in benefits-based analysis (Haigh et al. 1983). The frequency of respiratory illness may be influenced by $\mathrm{SO}_{\mathrm{x}}, \mathrm{NO}_{\mathrm{x}}, \mathrm{O}_{3}$ and metals. $\mathrm{SO}_{\mathrm{x}}$, $\mathrm{NO}$ and $\mathrm{CO}$ may affect the risk of cardiopulmonary disease, white the risk of other health effects may change depending on levels of $\mathrm{SO}_{x}, \mathrm{O}_{3}$, metals, $\mathrm{CO}$ and organic pollutants. $\mathrm{SO}_{\mathrm{x}}$ and $\mathrm{NO}_{x}$ can affect visibility and haziness; ancillary pollutants may also perturb the climate $\left(\mathrm{CO}_{2}\right.$ and $\left.\mathrm{SO}_{\mathrm{x}}\right)$ and radiation-filtering properties of the stratosphere $\left(\mathrm{O}_{3}\right)$. Durability of elastomers, such as rubber, and some fabrics and dyes may be affected by changes in $\mathrm{NO}_{x}$ and $\mathrm{O}_{3}$ levels. $\mathrm{CO}_{2}$ and $\mathrm{O}_{3}$ may affect forest

TABLE 4.3. Summary of the Ancillary Effects of Acid Deposition Reduction Policy-Induced Air Quality Changes

\begin{tabular}{|c|c|c|c|c|c|c|c|}
\hline \multirow[b]{2}{*}{ Effects } & \multicolumn{7}{|c|}{ Changes in Concentrations } \\
\hline & $\$ 0_{x}$ & $\mathrm{NO}_{x}$ & Oxidants & Metals & $\mathrm{CO}$ & $\mathrm{CO}_{2}$ & Hydrocarbons \\
\hline $\begin{array}{l}\text { Health-Mortality } \\
\text { and Morbidity }\end{array}$ & $x$ & $x$ & $x$ & $x$ & $x$ & & $x$ \\
\hline Veget ation & $x$ & $x$ & $x$ & & & $x$ & $x$ \\
\hline Visibility & $x$ & $x$ & & & & & \\
\hline Climate & & & & & & $x$ & \\
\hline Materials & (a) & $x$ & $x$ & & & & \\
\hline
\end{tabular}

(a) Not considered an ancillary effect. 
growth and crops; crop changes may also be induced by effects of $\mathrm{SO}_{x}$, $\mathrm{NO}_{\mathrm{x}}$ and specific organic pollutants. Metals may disrupt ecosystems with possible impacts on grazing animals.

\subsection{REFERENCES TO CHAPTER 4.0}

Acock, B., et al. 1982. "Soybean Responses to Carbon Dioxide: Measurement and Simulation 1981." Response of Vegetation to Carbon Dioxide Series, Number 4, U.S. Department of Energy and Agriculture, Washington, D.C.

Aharonson, E. F., A. Ben-David, and M. A. Lingberg, eds, 1976. Air Pollution and the Lung: Proceedings of the Twentieth Annual "OHOLO" Biologicat Conference Maialot, Israel, March 16-19, 1975. Keter Publishing House, Jerusalem.

Bailey, et al. 1978. Chemistry of the Environment. Academic Press, New York.

Berry, B. J. L., ed. 1977. The Social Burdens of Environmental Pollution: A Comparative Metropol itan Data Source. Ballinger Publishing Company, Cambridge, Massachusetts.

Burrows, B., A. L. Kellogg, and J. Buskey. 1968. "Relationships of Symptoms of Chronic Bronchitis and Emphysema to Weather and Air Pollution." Archives of Environmental Health. 18:768.

Calabrese, Edward J. 1978. Pollutants and High-Risk Groups. John Wiley and Sons, New York.

Cole, P., and M. B. Goldman. 1975. "Occupation." In J. F. Fraumeni, Jr., ed., Person at High Risk of Cancer: An Approach to Cancer Etiology and Control. Academic Press, New York.

Colley, J. R. T. and D. D. Reid. 197D. "Urban and Social Origins of Childhood Bronchitis in England and Wales." British Medical Journal. 2:213-217.

Colucci, A. V., et al. 1976. Sulfur Oxides: Current Status of knowledge. EA-316. Electric Power Research Institute, Palo Alto, California.

Council on Environmental Quality, Federal Council for Science Technology. 1975. "Flurocarbons and the Environment: Report of Federal Task Force on Inadvertent Modification of the Stratosphere (IMOS)." Washington, D.C.

D'Appolonia, J. 1982. "Health Matrix--Toxic Waste Isolation." American Industrial Hygiene Association Journal. 43:1-7.

Dohan, F. C. 1961. "Air Pollutants and Incidence of Respiratory Disease: A Preliminary Report." American Journal of Medical Science. 240"337. 
Fairhall, L. T. 1957. Industrial Toxicology. 2nd ed. Williams and Wilkins Co., Baltimore, Maryland.

Ferris, B. G., Jr., et a1. 1971. "Chronic Nonspecific Respiratory Disease in Berlin, New Hampshire, 1961-1967: A Cross Section Study." American Review of Respiratory Diseases. 113:75-485.

Florey, C. duV., et al. 1979. "The Relation Between Respiratory Illness in Primary Schoolchildren and the Use of Gas for Cooking. III-Nitrogen Dioxide, Respiratory Illness, and Lung Infection." International Journal of Epidemiology. $8: 347$.

Goldsmith, J. R., and S. A. Landau, 1968. "Carbon Monoxide and Human Health." Science. 162:1352-1259.

Goldstein, B. P., et al. 1979. "The Relation Between Respiratory Illness in Primary Schoolchildren and the Use of Gas for Cooking. II-Factors Affecting Nitrogen Dioxide Levels in the Homes." Internationally Journal of Epidemiology. $8: 339$.

Haigh, J. A, et al. 1983. "Benefits Assessment and Environmental Regulation: Case Studies of Hazardous Air Pollutants." E-83-07. John F. Kennedy School of Government, Energy and Environmental Policy Center, Harvard University, Cambridge, Massachusetts.

Heck, W. W. and D. T. Tingey. 1979. Nitrogen Dioxide: Time-Concentration Model to Predict Acute Foliar Injury. EPA 600/3-79-057. U.S. Environmental Protection Agency, Crovallis, Oregon.

Heck, W. W. et al. 1983. "A Reassessment of Crop Loss from Ozone." Environmental Science and Technology. 17(12):572A-518A.

Heicklen, Julian. 1976. Atmospheric Chemistry. Academic Press, New York.

Hodkinson, J. R. 1966. "Calculations of Colour and Visibility in Urban Atmospheres Polluted by Gaseous $\mathrm{NO}_{2} \cdot$ " International Journal of Air and Water Pollution. 10:137.

Holland, W. W., et al. 1969. "Factors Influencing the Onset of Chronic Respiratory Disease." British Medical Journal. 2:205.

Horvath, E. P., et al. 1978. "Nitrogen Dioxide Induced Pulmonary Diseases." Journal of Occupational Medicine. 20:103-110.

Husar, R. B., et a1. 1979. "Trends of Eastern U.S. Haziness since 1948." In Proceedings of the Fourth Symposium on Atmospheric Turbulence, Diffusion, and Air Pollution. American Metorological Society, Reno, Nevada: $24 \overline{9}-256$.

Inside EPA. 12/2/83. Published by Inside Washington Publishers. Washington D.C. 
Interdepartmental Committee for Atmospheric Sciences, Federal Council for Science and Technology. 1975. "The Possible Impact of Fluorocarbons and Halocarbons and 0zone." ICAS 18a-FY 75. Washington, D.C.

International Atomic Energy Agency. 1982. Health Impacts of Difference Sources of Energy. IAEA STI/PUB/594. Vienna.

Ipsen, J., M. Deane, and F. E. Ingenito. 1969. "Relationship of Acute Respiratory Disease to Atmospheric Pollution and Meteorological Condition." Archives of Environmental Health. 18:462-472.

Jacoff, F. S., ed. 1979. Sulfur Enission: Control Technology and Waste Management. EPA 600/9-79-019. 0.S. Envíronmental Protection Agency Decision Series, office of Research and Development, Washington, D.C.

Kagawa, J., and T. Toyama. 1975. "Photochemical Air Pollution." Archives of Environmental Health. 30 117-122.

Kagawa, J. 1983. "Respiratory Effects of Two-Hour Exposure with Intermittent Exercise to Ozone, Sulfur Dioxide and Nitrogen Dioxide Alone and in Combination in Normal Subjects." American Indian Hygiene Association Journal. 44(1):14-20.

Kandler, V., and MY. Ulirich. 1964. "Detection of $\mathrm{NO}_{2}$ Damage to Leaves." Naterwiss. 51:518.

Kikigawa, K., and K. Iizuka. 1972. "Inhibition of Platelet Aggregation by Bisulfite-sulfite." Journal of Phamaceutical Science. 61:1904-1907.

Kreisman, H., et a1. 1976. "Effect of Low Concentrations of Sulfur Dioxide on Respiratory Functions in Man." Lung. 154:25-34.

Kurt, T. L., R. P. Mogielnicki, and J. R. Chandler. 1978. "Association of the Frequency of Acute Cardiorespiratory Complaints with Ambient Levels of Carbon Monoxide." Chest. 74:10-14.

Kurt, T. L. et al. 1979. "Ambient Carbon Monoxide Levels and Acute Cardiorespiratory Complaints: An Exploration Study." American Journal of Public Health. 69:360-363.

Lave, Lester B. and Eugene P. Seskin. 1977. Air Pollution and Human Health. The Johns Hopkins University Press, Baltimore.

Lawther, P. J., R. E. Walter, and M. Henderson. 1970. "Air Pollution and Exacerbations of Bronchitis." Thorax. 25:525-539.

Lunn, J. E., J. Knowelden, and A. J. Mandyside. 1967. "Patterns of Respiratory Illness in Sheffield Junitor Schoolchildren." British Journal of Preventive and Social Medicine. 21:7-16. 
Lunn, J. E., J. Knowelden, and J. W. Roe. 1970. "Patterns of Respiratory Illness in Sheffield Junior Schoolchildren: A Follow-Up Study." British Journal of Preventive and Social Medicine. 24:223-228.

MacDonald, Gordon, J., et. 1982. The Long-Term Impacts of Increasing Atmospheric Carbon Dioxide Levels. Ballinget Publishing, Cambridge, Mass.

Mahlum, D. Do, et a1., eds. 1978. Developmental Toxicology of Energy-Related Pollutants: Proceedings of the Seventeenth Annual Hanford Biology Symposium at Richland, WA, Oct. 17-19, 1977. CoNF-771017, U.S. Department of Energy.

Martin, A. E. 1964. "Mortality and Morbidity Statistics and Air Pollution." Proceedings of the Royal Society of Medicine. 57:969-957.

Melia, R. J. W., et al. 1977. "Association Between Gas Cooling and Respiratory Disease in Children." British Medical Journal. 2:149-152.

Melia, R. J. W., C. DuV. Florye, and S. Chinn. 1979. "The Relation Between Respiratory Illness in Primary Schoolchildren and the Use of Gas for Cooking. I-Results from a National Survey. International Journal of Epidemiology. $8: 333$.

Menzel, Daniel B., ed. 1971. Symposium on Pollution and Lung Biochemisty. Archives of Internal Medicine Symposia, Vor. 9, American Medical Association.

Milne, J. E. H. 1969: "Nitrogen Dioxide Inhalation and Bronchitis Obliterans: A Review of the Literature and Report of a Case." Journal of Occupational Medicine. 11:538-547.

Moskowitz, et al. 1982. "Oxidant Air Pollution: A Model for Estimating Effects on U.S. Vegetation." Journal of the Pollution Control Association. $32(2)$.

Mudd, S. H., F. Irreverre, and L. Laster. 1967. "Sulfite Oxidase Deficiency in Man: Demonstration of the Enzymatic Defect." Science. 156:1599-1602.

Nash, T. H., III. 1976. "Sensitivity of Lichens to Nitrogen Dioxide Fumigation." Bryologist. 79(1):103-106.

Newhouse, M. T., et al. 1978. "Effect of TLV Levels of $\mathrm{SO}_{2}$ and $\mathrm{H}_{2} \mathrm{SO}_{4}$ on bron-. chial clearance in exercising man." Archives of Environmental Health. $33: 24-32$.

Nixon, J. K. 1940. "The Absorption Coefficient of Nitrogen Dioxide in the Visible Specture." Journal of Chemical Physics. 8:157.

Pearlman, M. E., et al. 1971. "Nitrogen Dioxide and Lower Respiratory Illness." Pediatrics. 47(2):391-398. 
Pemberton, J. 1961. "Air Pollution as a Possible Cause of Bronchitis and Lung Cancer." Journal of Hygience, Epidemiology, Microbiology, and Immunology. $5: 389$.

Putz, V. R., B. L. Johnson, and J. V. Setzer. 1976. Effect of C0 on Vigilance Performance. Effect of Low Level Carbon Monoxide on Divided Attention, Pitch Discrimination, and the Auditory Evoked Potential.. DHEW (NIOSH) Publication No. 77-124. U.S. Department of Health, Education and Welfare, National Institute of Occupational Safety and Health, Cincinnati, $\mathrm{OH}$.

Putz, V. R., B. L. Johnson, and J. V. Setzer. 1979. "A Comparative Study of the Effects of Carbon Monoxide and Methylene Chloride on Human Performance." In Proceedings of the First Annual NIOSH Scientific Symposium. Chicago. Pathotox Publishing Co.

Rall, D. P. 1974. "A Review of the Health Effects of Sulfur Oxides." Environmental Health Perspective. 8:97-121.

Salvin, U.S. 1974. "Yellowing of White Fabrics Due to Air Pollutants." Collected Papers of the American Association of Dye Chemists and Colorists. New orleans.

Schwing, R. C., and G. G. McDonald. 1976. "Measures of Association of Some Air Pollutants, Natural Ionizing Radiation, and Cigarette Smoking with Mortality Rates." The Science of the Total Environment. 5:139-169.

Seidel, and Keyes. 1983. Can We Delay a Green House Warming? U.S. Environmental Protection Agency Strategic Studies Staff, Office of Policy Analys is, Office of Policy and Resources Management, Washington, D.C.

Seskin, E. P. 1976. Air Pollution and Health in Washington, D.C.: An Analysis of Some Acute Health Effects of Air Pollution in the Washington Metropolitan Area. Report to the U.S. Environmental Protection Agency, office of Research and Development. Washington, D.C.

Sheppard, D., et al. 1981. "Exercise Increases Sulfur Dioxide--Induced Bronchoconstriction in Asthmatic Subjects." American Review of Respiratory Diseases. 123:486-491.

Shy, C. M., et al. 1970. "The Chatanooga School Study: Effects of Community Exposure to Nitrogen Dioxide. II-Incidence of Acute Respiratory IIIness." Journal of the Air Pollution Control Association. 20(9):582-588.

Speizer, F. E., et al. 1980. "Respiratory Disease Rates and Pulmonary Function in Children Associated with $\mathrm{NO}_{2}$ Exposure." American Review of Respiratory 0iseases. 121:3-10. 
Spengler, J. D., B. G. Ferris, Jr., and D. W. Dockery. 1979. "Sulfur Dioxide and Nitrogen Dioxide Levels Inside and Outside Homes and the Implications on Health Effects Research." Environmental Science and Technology. 13:1266-1271.

Startman, E. S., ed. 1971. Combustion-Generated Air Pollution. Plenum Press, New York.

Steward, R. D. 1975. "The Effects of Carbon Monoxide on Humans." Annual Review of Pharmecology. 15:409-423.

Taylor, 0. C., and F. N. Eaton. 1966. "Suppression of Plant Growth by Nitrogen Dioxide." Plant Physiology. 14:132-135.

Tingey, D. T. and R. A. Reinert. 1975. "The Effect of Ozone and Sulphur Dioxide Singly and in Combination on Plant Growth." Environmental Pollution. (9):117-125.

Trijonis, J., and K. Yuan. 1978. Visibility in the Southwest--An Exploration of the Historical Data Base. EPA-600/3-7B-039. Environmental Protection Agency. Washington, D.C.

Upham, J. B., and V. S. Salvin. 1975. Effects of Air Pollutants in Textile Fibers and Dyes. EPA 650/3-74-008. U.S. Envíronmental Protection Agency, Washington, D.C.

U.S. Department of Commerce. 1975. "Economic Significance of Fluorocarbons." Office Business Research and Analysis. Bureau of Domestic Commerce. Washington, D.C.

U.S. Environmental Protection Agency. 1979. Protecting Visibility: An EPA Report to Congress. EPA-450/5-79-008. Research Triangle Park, North Carolina.

U.S. Environmental Protection Agency. 1982a. Air Quality Criteria for 0xides of Nitrogen. EPA 60D/8-82-026. Research Triangle Park, North Carolina.

U.S. Environmental Protection Agency. 1982b. Air Quality Criteria for Partic-ulate Matter and Sulfur 0xides. EPA-600/8-82-029. Research Triangle Park, North Carolina.

U.S. Environmental Protection Agency. 1983a. The Acidic Deposition Phenomenon and its Effects. EPA-600/8-83-016B. Washington, D.C.

U.S. Environmental Protection Agency. 1983b. Revised Evaluation of Health Effects Associated with Carbon Monoxide Exposure: An Addendum to the Air Quality Criteria Document for Carbon Monoxide. EPA-600/8-83-033a. Office of Health and Environmental Assessment. Washington, O.C. 
U.S. House of Representatives, Interstate and Foreign Commerce Committee. 1974. "Fluorocarbons--Impact on Health and Environment." Serial No. 93-110. Hearings Before the Subcommittee on Public Health and Environment, Interstate and Foreign Commerce Committee. December 11-12, 1974.

U.S. Dffice of Technology Assessment. 1979. The Direct Use of Coal: Prospects and Problems of Production and Combustion. 79-600071. Washington, D.C.

U.S. Dffice of Technology Assessment. 1982. The Regional Implications of Transported Air Pollutants: An Assessment of Acidic Deposition and Ozone, Interim Draft. Washington, D.C.

University of California Cooperative Extension. 1979. Proceedings, Air Pollution Agriculture Seminar. Bakersfield, California. October 10.

Ute11, M. J., et al. 1980. "Development of Airways Reactivity to Nitrates in Subjects with Influenza." American Review of Respiratory Diseases. $121: 233-240$.

Verma, M. P., F. J..Schilling, and W. H. Becker. 1969. "Epidemiological Study of Illness Absences in Relation to Air Pollution." Archives of Environmental Health. 18:536-543.

Von Nieding, G., et al. 1979. "Controlled Studies of Human Exposure to Single and Combined Action of $\mathrm{NO}_{2}, \mathrm{O}_{3}$ and $\mathrm{SO}_{2} \cdot$ " International Archives of Occupational and Environmental fealth. 43:195-210.

Wagner, R. P. et al. 1980. Introduction to Modern Genetics. John Wiley and Sons, Inc., New York.

Williams, J., ed. 1978. Carbon Dioxide, Climate and Society. IIASA Proceedings Series, Environment Volume 1. Pergamon Press, New York.

Wilson, R., et al. 1980. Health Effects of Fossil Fuel Burnings: Assessment and Mitigation. Ballinger, Cambridge Massachusetts.

Yocom, J. E. and N. S. Baer. 1983. "The Acidic Deposition Phenomenon and its Effects on Materials." In Altshuller and Linthurst. eds. 1983. The Acidic Deposition Phenomenon and Its Effects, Critical Assessment Review Papers. EPA-600/8-83-016B. U.S. EPA, Office of Research and DeveTopment. 


\subsection{THE ANCILLARY EFFECTS OF LAKE LIMING}

Lake liming has been suggested as one means of reversing and/or mitigating the effects of acidification in U.S. lakes. The method has been widely used in Europe, particularly in Scandinavia, to mitigate the impacts of acid rain. Liming may be directed at counteracting the depletion of fish stocks in acidified lakes, but it can reverse other effects of acidification as well. Except for changes in fish populations all physical, chemical and biological effects of lake liming are defined as ancillary changes in the present chapter.

This chapter provides an overview of impacts of lake liming on an aquatic ecosystem. Liming application techniques and materials are described briefly in Section 5.1. Changes in the chemistry of a limed lake are discussed in Section 5.2. The turbidity and temperature stratification of a lake may change as a result of liming, and these physical effects are described in Section 5.3 . Ancillary impacts of liming on the flora and fauna of a lake are considered in Section 5.4. A summary of the ancillary chemical, physical, and biological effects of lake liming is presented in Section 5.5. References are provided in Section 5.6.

\subsection{OESCRIPTION OF TECHNOLOGY}

Lake liming is a generic term used to describe the addition of a basic or alkaline material to a lake, thereby making the lake more alkaline and less acidic and increasing its pH. Liming technology involves applying a liming agent to acidified lake water. The alkaline material neutralizes the acid in the water and the $\mathrm{pH}$ rises. The beneficial effects of such alkalinity increases are discussed in later sections, but it should be noted that the magnitude and duration of all effects of liming are influenced by the choice of liming material and application technique (Fares, Kinsman and Britt, 1983).

Several calcium based alkaline materials may serve as liming agents. Basic materials that can be applied as liming agents include calcitic and dolomite limestones ( $\left.\mathrm{Ca} \cdot \mathrm{Mg} \cdot \mathrm{CO}_{3}\right)$, powdered limestone $\left(\mathrm{CaCO}_{3}\right)$, unslaked lime or quicklime $(\mathrm{CaO})$, slaked lime $\left(\mathrm{Ca}(\mathrm{OH})_{2}\right)$, slag limes, lye, olivine $\left((\mathrm{MgFe})_{2} \mathrm{SiO}_{4}\right)$, 
and soda ash $\left(\mathrm{Na}_{2} \mathrm{CO}_{3}\right)$ (Fraser, et a1. 1982). The most readily available materials are usually crushed limestone, slaked $1 \mathrm{ime}$ and quicklime. Liming agents add calcium to the water. They may contain impurities, such as chromium, and nickel that are sometimes found in olivine and slag limes (Swedish Ministry of Agriculture, 1982). However, it will be assumed for the remainder of this chapter that liming agents used are free from impurities. The amount of 1 iming agent required to effect a particular increase in $\mathrm{pH}$ depends on the reactivity of the material in water. Limestone, $\mathrm{CaCO}_{3}$, is less reactive in water solution than either quicklime, CaO, or slaked lime $\mathrm{Ca}(\mathrm{OH})_{2}$ (Fraser et al, 1982). Liming agents tend to dissolve more quickly in water when they are more finely ground; the dissolution time in turn determines whether the induced $\mathrm{pH}$ rise is sudden or gradual.

Liming agents are applied to bodies of water in a variety of ways. The application method chosen depends partly on the accessibility of the water to be treated. A helicopter may spread lime in a one-shot application. Continuous dosers and lime wells can apply smaller dosages more frequently and are sometimes used. If acid surge because of springtime snow melting is a problem, it may be appropriate to apply a liming agent annually to snow (Swedish Ministry of Agriculture, 1982). The necessary dosage and frequency of liming application for successful neutralization depends on variables such as lake turnover time and water humus content.

\subsection{IMPACT OF LIMING ON LAKE CHEMISTRY}

Liming agents are chemicals, and their addition to a lake produces chemical changes. When some of a liming agent dissolves in water, it changes water chemistry not only by adding some new dissolved chemicals, like calcium, but also by changing the nature of the solvent, lake water. The amount of every other chemical dissolved in the lake water depends on the nature of the solvent, so the addition of liming agent indirectly affects several additional chemical characteristics of the lake water. For example, hydrogen ion concentrations decrease, making the $\mathrm{pH}$ higher. The amounts of dissolved organic matter, nitrogen and phosphorous may all change. Metals precipitate out of solution. The sensitivity of the lake to further additions of base (such as 
lime) or acid (such as acid rain), i.e., the lake's buffering capacity, may change. Chemical changes in a 1 imed body of water are discussed further in Sections 5.2.1 and 5.2.2.

\subsubsection{Mechanism of Action}

When slaked lime $\left(\mathrm{Ca}(\mathrm{OH})_{2}\right)$ is added to acidic water, it dissolves almost immediately. The $\mathrm{pH}$ of the water rises in the short run to a level greater than it will stabilize at in the long run. This long-run moderation occurs because over time carbon dioxide enters the lake from the air, and reacts with water to form bicarbonate $\left(\mathrm{HCO}_{3}^{-}\right)$. Ouring this reaction, excess hydrogen ions

$\left(\mathrm{H}^{+}\right.$) are created, thereby lowering $\mathrm{pH}$ (Fraser et al., 1982). The net impact of the addition of slaked lime is, however, a $\mathrm{pH}$ increase.

The speed at which other liming agents dissolve varies, as do specifics of the chemical reactions. However, $\mathrm{pH}$ always rises, and the concentration of calcium ions always increases. Higher levels of calcium, a cation or positively charged particle, lead to increased water hardness. It is not known how long it takes for the impact of this effect to peak, although estimates range from 2 weeks to 3 years (Fraser and Britt, 1982).

The solubility of metals in lake water is pH-dependent. At higher $\mathrm{pH}$, less metal dissolves in water. When the $\mathrm{pH}$ of lake water increases as a resuit of liming, not as much metal can remain in a dissolved state; some metals precipitate and fall to the lake's bottom. The chemical explanation of the precipitation is that metal hydroxides, which are usually insoluble, are more likely to form when more hydroxide ions $\left(\mathrm{OH}^{-}\right)$become available due to the addition of base. However, other chemical reactions are also affected and the entire impact on lake chemistry depends on these reactions as well as the precipitation of metal hydroxides. Physical settling of metals also occurs. Because the solubility of some metals, such as aluminum, are more affected by $\mathrm{pH}$ changes than others, such as zinc, the speciation of soluble metals in the lake also changes. Some dissolved organic matter also precipitates as a result of $\mathrm{pH}$ increases.

The response of nitrogen and phosphorous, important lake nutrients, to liming treatment is poorly understood. The direction and significance of any 
change seems to depend on the characteristics of the watershed, other effects of liming on decomposition of organic matter, and the maturity of the lake (Fraser et al, 1982). For example, the phosphorous cycle in a eutrophic, or mature lake, may respond quite differentiy to liming than the phosphorous cycle in an oligotrophic, or youthful, lake.

\subsubsection{Chemical Changes}

Chemical changes that are observed in a limed body of water are increased alkalinity and decreased acidity, increased concentration of calcium and water hardness, and increased buffering by carbonate, $\mathrm{HCO}_{3}^{-}$. "Buffering by $\mathrm{HCO}_{3}^{-"}$ measures the ability of the water to maintain its existing $\mathrm{pH}$ when acid is added. Metal concentrations in the water decrease but metal concentrations in sediment at the bottom of the lake increase. The speciation of soluble metals a) so changes. Liming affects nutrient concentrations and dissolved organic matter, but the direction of the effects depend on lake characteristics and cannot be predicted easily.

The length of time it takes for liming to produce the above chemical changes varies. The effects may not be uniforn throughout the limed body of water. In addition, imnediate chemical changes may differ from those in the long run. For example, the $\mathrm{pH}$ in the short-run may increase above its long-run equilibrium value. As explained in Section 5.2.1, this modulation of the alkalinity increase may occur, over time, due to carbon dioxide dissolving in the limed body of water.

Lake liming does not prevent reacidification. The impact on lake ecology of chemical changes from reacidification could be more severe than had the lake never been limed (Swedish Ministry of Agriculture 1982). Another area of concern is the potential for new kinds of metallic compounds to appear briefly prior to their precipitation from the limed water, with unknown effects on lake life (Fraser and Britt 1982).

\subsection{PHYSICAL EFFECTS OF LAKE LIMING}

The enormous complexity of a lake ecosystem makes it inappropriate to consider the treatment of liming as a mere acid-base neutralization. The 
interdependency of marine 1 ife and the physical and chemical features of the lake habitat not captured by any analogy of a lake to a chemical solution. In the sections that follow, some of the dynamics of lake ecology will be explored to better understand physical and biological effects of liming.

Following the addition of lime, the transparency of a lake and its temperature depends on particles in suspension. These particles include silt, colloidal clay, minute drifting organisms, and colloidal organic matter. These particles cloud the water and reduce the amount of light reaching plants for photosynthesis. The quality of light penetrating specific depths may also change, with better absorption by suspended particles of some wavelengths of light than other wavelengths (Coker, 1954).

A small change in turbidity, or "cloudiness", affects marine life much more than the analogous weather change effects plants and animals on shore. As on land, increased cloudiness tends to block sunlight and heat, leading to cooler temperatures than would prevail under clear conditions. In the water medium, however, temperature changes affect the amount of oxygen available. At higher temperatures, less oxygen can dissolve in water. In our oxygen-rich atmosphere we rarely need to think about the availability of oxygen, but in the marine world every iota of available "air" counts. Most plants and animals, even underwater, need oxygen for survival and will suffocate when deprived of it. Thus, a change in transparency may have far-reaching effects on the light and dissolved gases that are important to marine life.

The presence and availability of oxygen depends on the metabolism of lake plants and animals, as well as on temperature-dependent gas solubility. Aerobic decay, the respiration of animals, and dark respiration in plants all require oxygen and liberate carbon dioxide. In sunlit areas of the lake photosynthesis occurs, using carbon dioxide and liberating oxygen. In deeper water, oxygen depleting activities occur without compensation by photosynthesis. As the lake water is not throughly mixed during most of the year, and also because gases do not diffuse readily through water as they do in air, the gas content of a lake becomes stratified. Thorough mixing generally occurs only in the fall and spring. In the fall, surface waters become colder and more dense than 
deeper water and sink. In the spring, the density of water at all depths temporarily becomes uniform. At this time, the action of wind and gravity tend to cause water circulation. The result of the spring circulation is that deep water, where photosynthesis cannot take place because it is dark, becomes charged with oxygen so that oxygen requiring processes such as aerobic decomposition can occur (Coker, 1954).

The rates of metabolic activity by plants and animals, however, depend on both temperature and turbidity, which can be affected by lake liming. They also depend on other factors specific to the rates of production and decomposition in the lake. Thus, the impact of any liming-induced variation in turbidity is specific to the initial lake conditions. It is especially important to distinguish a limed clear body of water from a limed humic lake and to further distinguish clear bodies of water according to their fertility. The initial condition of the lake determines not only whether liming decreases or increases water transparency, but also whether the transparency change is beneficial or detrimental to the lake's overall health. Humic lakes differ from clear bodies of water in the rates and efficiency at which organic matter is cycied. In general, the healthiest lake is not that which is most productive, but that in which the rates of production and decomposition are most well-balanced. Over geological timespans material tends to fall into lakes; the lakes fill up and cease to exist. An excess of production over decomposition, however, can hasten a lake's senescence. It is possible for a lake to virtually "choke" itself from uncontrolled primary production.

Humic lakes tend to be dominated by a few acid-tolerant marine animal species. These tend to multiply unchecked by competition, their dead bodies and wastes drifting toward the lake bottom. The recycling of organic matter is retarded in the acidic conditions (Coker, 1954), and fails to keep pace with the rate of its production. Detritus, or dead organic matter, begins to accumulate. The hypolimnion, or cold, deep stratum of the lake, becomes progressively more shallow and oxygen-poor, a population-limiting situation for organisms normally dwelling in the hypolimnion as their habitat becomes smaller 
and less livable. Decomposition of the accumulating organic matter and competition by less acid-tolerant species may both be promoted by the liming of a humic lake (Coker, 1954).

Liming increases the transparency of a humic body of water (Driscoll and Schafran, 1983). The transparency probably increases because of co-precipitation of dissolved organic matter with metals (Yan and Dillon, 1981). Light penetration may increase in the 1 imed humic body of water, with resulting increases in the depth of warm regions. Because humic water already is more productive than can be balanced by decomposition processes, increased light and warmth in the upper lake regions is not unambiguously good. However, the addition of lime to humic waters also helps increase the rate of decomposition of organic matter, with a net beneficial effect.

The transparency of a clear body of water is usually increased by liming only in the short term. This is partially due to the effects of a sudden rise of $\mathrm{pH}$ on phytoplankton. Large numbers of the microscopic floating plants die and settle to the bottom (Yan and Dillon, 1981). Transparency also increases initially because of the co-precipitation of organic matter with metals. In the long run, however, liming decreases the transparency of most previously clear bodies of water. Turbidity of surface waters in a limed lake is probably due to long-run increases in the population of a kind of small phytoplankton called chrysomonads. This is clearly an instance where a biological family modifies its physical surroundings so that biological and physical effects are intertwined.

\subsection{BIOLOGICAL EFFECTS OF LAKE LIMING}

Liming quite suddenly results in changes in $\mathrm{pH}$, composition and quantities of suspended particles, turbidity, temperature stratification and the distribution of dissolved gases. Obviously, the flora and fauna of the lake respond to these impacts. The new conditions may favor species which are not, at the time of liming, indigenous to the lake but which may be introduced thereafter. Indigenous species may become more or less numerous according to their ability to adapt. The actual impact of liming on lake biology seems to depend on initial lake acidity, metal concentrations and nutrient levels. 
The effects of liming on fish are considered a direct impact of liming and are thus not considered in this chapter. Other biological groups affected by liming are bacteria, phytoplankton and other primary producers (plants), zooplankton and benthic (bottom-dwelling) macro-invertebrates.

Bacteria are almost everywhere in a lake. Some types are anaerobic and do not require oxygen. Others aid in fixing nitrogen into forms useful to aquatic plants. Still others are essential to the decomposition of organic matter, a process which allows essential nutrients to continue to contribute to the cycle of marine life. The lakes that have been studied after liming show increased populations of certain kinds of bacteria. Middle and Lohi Lakes near Sudbury, Ontario, experienced large increases in numbers of aerobic heterotrophic bacteria subsequent to liming. These bodies of water had very high metal concentration prior to their neutralization. The liming of a body of water in Nova Scotia with low metal concentrations led to increased bacterial populations.

Phytoplankton are small drifting organisms with relatively feeble locomotive powers of their own. Like other primary producers, they use energy from sunlight to make sugar from carbon dioxide and water. Individually, phytoplankton are tiny, but they make up in numbers what they lack in size. Following the liming of very acidic water, phytoplankton biomass initially declines sharply. However, less acid-tolerant species tend to build up quickly so that total phytoplankton biomass several months after liming may be as high as were pre-liming levels. Following the liming of a lake that is only mildly acidic, there may be no change in phytoplankton biomass (Fraser et al., 1982).

Bottom dwelling sphagnum mosses and algae, which sometimes spread in thick. mats over the bottom of acidified lakes, die when lakes are limed (Fraser and Britt, 1982). Their disappearance increases the availability of nutrients and ions for productive growth of other species (Hultberg and Grahn, 1975; Hultberg and Anderson, 1981).

Zooplankton are microscopic drifting animals. Their reaction to liming is similar to the reactions of phytoplankton, except that several years rather than months may elapse before biomass gets as high as pre-liming levels. 
Benthic macro-invertebrates include such bottom-dwellers as chironomids, a family of midge larvae who feed on organic detritus and microscopic beasts and are fed on by fish. Liming seems to reduce chironomidae population while encouraging less acid-tolerant bottom dwelling species (Fraser et al., 1982).

\subsection{SUMMARY OF LAKE LIMING ANCILLARY EFFECTS}

The ancillary chemical, physical, and biological of lake liming are summarized in Table 5.1, which is a list of the effects described in Sections 5.1 to 5.4 .

\section{TABLE 5.1. Summary of Ancillary Effects of Lake Liming}

Chemical Effects

- Increase in $\mathrm{HCO}_{3}$ buffering

- Increase in $\mathrm{pH}^{-}$

- Increase in alkalinity

- Decrease in acidity

- Increase in hardness

- Increase in calcium concentration

- Decrease in metal concentrations in the lake water--precipitation or physical settling

- Increase in metal concentrations in bottom sediment

- Change in speciation of soluble metals

- Decrease in dissolved organic matter concentrations

\section{Physical Effects}

- Short-term increase in transparency (clear water body)

- Long-tem decrease in transparency (clear water body)

- Decrease in temperature (clear water body)

- Increase in water transparency (humic water body)

Biological Effects

- Increase in bacteria

- Change in composition of bacteria

- Short-term decrease in phytoplankton biomass

- Change in species of phytoplankton

- Short-term decrease in zooplankton biomass

- Change in species of zooplankton

- Decrease in benthic biomass 


\subsection{REFERENCES TO CHAPTER 5.0}

Coker, Robert E. 1954. Steams, Lakes, and Ponds. Chapel Hill. The University of North Carolina Press. Chapel Hill, North Carolina.

Driscol1, C. T., and G. C. Schafran. 1983. "Mitigative Strategies for Improvement of Surface Water Quality." In A. P. Altshuller and R. A. Linthurst, ed., The Acid Deposition Phenomena and Its Effects. U.S. EPA-600/8-83-016B. Washington, D.C.

Fares, D., G. Kinsman, and D. Britt. 1983. Description of Potential Mitigatory Techniques That May Be Applied to Receptors Affected By Acid Deposition: Phase I. Prepared for Oak Ridge National Laboratory by General Research Corporation, Mclean, Virginia.

Fraser, J. E., and D. L. Britt. 1982. Liming of Acidified Waters: A Review of Methods and Effects on Aquatic Ecosystems. U.S. Department of Interior, Fish and Wildlife Service. OBS-80/40.13. Washington, D.C.

Fraser, J. E., and D. L. Britt. 1983. Lake Restoration, Protection, and Management. U.S. Environmental Protection Agency, Office of Water Regulations and Standards. EPA 440/5-83-001. Washington, D.C.

Fraser, J. E., et al. 1982. Feasibility Study to Utilize Liming as a Technique To Mitigate Surface Water Acidification. Electric Power Research Institute. EA-2362. Palo ATto.

Swedish Ministry of Agriculture. 1982. Acidification Today and Tomorrow. Environment ' 82 Committee. Prepared for the 1982 Stockholm Conference on the Acidification of the Environment, Stockholm, Sweden.

Thomann, R. V., and R. P. Winfield. 1975. "Dn the Verification of a ThreeDimensional Phytoplankton Model of Lake Ontario." Summary of work performed for U.S. Environmental Protection Agency, Office of Research and Development. EPA-660/3-75-005. Corvallis, Oregon.

U.S. Fish and Wildlife Service. 1982. Liming of Acidified Waters: Issues and Resolutions. A Report of the International Liming Workshop. FWS/OBS80/40.14. Washington, D.C.

Yan, N. D. and P. J. Dillon. 1981. Studies of Lakes and Watersheds Near Sudbury Ontario. Ontario Ministry of the Environment, Rexdale, Ontario. 


\subsection{ECONOMIC VALUATION OF POTENTIAL ANCILLARY EFFECTS}

In Chapters 4.0 and 5.0, several ancillary effects of acid deposition control and mitigation policies were identified that may have direct value to individuals or directly affect their decisions. Briefly, the following ancillary effects were identified: changes in visibility, changes in mortality, changes in morbidity, changes in crop and timber yields, and changes in the useful life of selected materials. Of course, the policies considered also have other effects; for example, installation of $F G O$ equipment may lead to a change in the ambient concentration of sulfate. Such a change is important and should not be overlooked; however, we believe that changes in sulfate concentrations do not directly affect human behavior and are not directly valued by individuals. Instead, it is the effects of sulfate changes on visibility, etc. that are of direct value to individuals.

The focus of this chapter is valuing those ancillary effects that may be of direct value to individuals and thus society. For example, in this chapter we will review studies that have estimated the value to individuals of a visibility improvement of a particular magnitude. "Value" in this sense (as will be described further below) is the dollar amount an individual is willing to pay for the specified visibility improvement or, alternatively, the "benefits" he or she receives from the improvement.

The interest in obtaining such value estimates stems primarily from their use in benefit-cost analysis. The types of value estimates considered in this chapter (which pertain, again, to individuals and to unit changes), when multiplied by the actual magnitude of the environmental change caused by a policy and when aggregated over all affected individuals, yield estimates of the dollar benefits of the policy in question in the effected area considered (e.g., visibility). For example, suppose the average individual in the state of ohio is willing to pay $\$ 5.00$ per year for a $1 \%$ visibility improvement, that a par ticular acid deposition control policy will improve visibility in ohio 10\%, and 
that the population of Ohio is 10 million. Then the annual benefits of the policy per person are $\$ 50(\$ 5.00 \times 10)$ and the annual benefits to the population of Ohio are $\$ 500$ million.(a)

As discussed in Chapter 1.0, it is important when performing benefit-cost analyses of acid deposition control and mitigation policies, to include in the calculation all of the effects of the policy that are of value to individuals, even if these effects are not directiy related to, or the direct result of, acid deposition. According to this view, the types of values considered in this chapter, when appropriately multiplied and aggregated, should be included in any benefit-cost analyses of acid deposition policies.

Because of 1 imited resources to perform this review, the chapter focuses on two effects, visibility and health. These two effects were selected for several reasons. First, the set two effects involve commodities that are not traded in markets, whereas the other effects generally involve market commodities. Environmental changes involving market goods can be valued in a manner that is both conceptually and empirically agreed upon and straightforward. This is not true of nonmarket goods like visibility and health. Thus, consideration of these two effects in a benefit-cost analysis requires significant conceptual and empirical research. Second (and perhaps more importantly), as discussed in Chapter 1.0, because acid deposition directly affects crop and timber yields and the useful life of materials, the National Acid Precipitations Assessment Program (NAPAP) is funding development or enhancement of models that estimate the dollar benefits of such changes. These economic models require input on yield changes and corrosion rates; by providing these models with data on these effects caused by nonacidic phenomena, the models may be used to assess the value of changes caused by nonacidic, phenomena such as those identified in Chapters 4.0 and 5.0, was well as by acid deposition. Further economic research (i.e., in addition to these other NPAP efforts) in these areas thus does not appear necessary in order to value the ancillary effects

(a) This assumes, for purpose of illustration only, that the benefit relationship is linear, $i . e .$, that a $2 \%$ visibility improvement has twice the value of a $1 \%$ improvement. We will argue below that this is not necessarily (or even probably) true. 
involving crops, timber, and materials. On the other hand, NPAP is not currently funding research in the areas of visibility or health, and thus consideration of these effects in a benefit-cost analysis will require further economic research.

The remainder of this chapter is organized in the following manner. In Section 6.1 we briefly present a simple theoretical model for the valuation of nonmarket environmental commodities. This simple model will form the basis for consideration of the value to society of changes in visibility and health. Section 6.2 considers the value or benefits of changes in visibility. The value of changes in health is considered in Section 6.3 .

\subsection{ECONOMIC VALUATION OF ENVIRONMENTAL CHANGES}

The objective of benefit-cost analysis is to measure the dollar value of the benefits and the costs to society of a particular project, program, or policy. Measurement of these societal values is typically based on the premise that the benefits to society of a particular change (e.g., an increasing visibility) is equal to the sum of the benefits to each of the individuals that make up society. The basic approach typically followed in performing a benefit-cost analysis (at least on the benefit side) is to estimate the benefits of the action under consideration to each of the individuals affected by the change, and then to aggregate these estimates to a societal total. The problem of societal benefit estimation thus becomes one of measuring the benefits or value of a particular change to an individual. (a,b)

(a) This discussion ignores distributional considerations, which are occasionally included in benefit-cost analysis. By weighting the individual benefit estimates before aggregation, one can take into account the impact that a policy has on the distribution of "income" in society.

(b) In many cases individuals' values do not have to be measured directly because aggregates of these values are observable. It is important to note, however, that these aggregates are indeed the sum of benefits to individuals, and that the use of aggregates is a short-cut in the benefit estimation process, not a conceptually distinct approach. 
Policy-induced changes in the quantity of an environmental commodity such as visibility or health have value to individuals because these commodities appear in the individuals' preference or utility functions. Holding an individual's consumption of all other commodities constant, the greater the visual range, color contrast, or longevity, or the freer he is from illness, the greater is the individual's utility or satisfaction. Changes in these variables that do not affect the consumption of other commodities, i.e., which are provided to the individual without charge, are of value to him because they increase his utility. The primary objective of environmental economics is to measure this value, which can be interpreted as the dollar value equivalent of the increase in utility cause by a particular change.

In fact, the individual would be willing to pay some dollar amount, i.e., reduce his consumption of other goods by some amount, in order to increase his consumption of the environmental good. In other words, there is a dollar amount which the individual would pay, which in combination with the increase in the quantity of the environmental good, would leave him better off (i.e., at a higher level of utility) than before the environmental change. As will be shown in the following paragraphs, the approach typically taken by economists to measure the dollar value of a utility change is to determine the individual's willingness to pay (WTP) to obtain the utility change.

To determine WTP, and to show that it is equivalent to the dollar value of the utility increase caused by a particular environmental change, a simple model of individual's behavior is frequently employed. The model is based on the assumption that the individual seeks to maximize his utility in the present time period, subject to his income, the prices of goods that are traded in markets, and the quantity of nonmarket commodities such as visibility, which are provided exogenously to him (i.e., which are not traded in markets). This model is derived in the remainder of this section. Readers not interested in the technical details may skip this discussion and begin Section 6.2 on page 6.10 . 
The assumption that consumers maximize utility can be written

$$
\begin{array}{ll}
\max u(x, q) \\
\text { s.t. } p_{x} x=M
\end{array}
$$

where $x=$ an $n$-dimensional vector of the consumption of traded goods

$q=$ The consumption of the environmental good, which is determined exogenously

$P_{x}=$ The $n$-dimensional vector of the prices of traded goods

$M=$ money income

$U()=$ The utility function.

Solution of this constrained maximization problem results in the individual's demand functions for the traded goods

$$
x_{i} *\left(P_{x}, M, q\right) \quad i=1,,, n \text {. }
$$

The dual of this problem, which is used to measure the benefits of exogenous (i.e., policy-induced) changes in the quantity of the environmental good, $a$, is based on the assumption that the individual minimizes his expenditure (E) on traded goods subject to meeting a particular level of utility $U^{0}$ :

$$
\begin{gathered}
\min E=P_{x} x \\
\text { s.t. } u(x, q)=u^{0} .
\end{gathered}
$$

Solution of this constrained minimization problem results in the individual's "compensated" demand functions for traded goods 


$$
x^{i} \star \star\left(P_{x}, u^{0}, q\right) \quad i=1,,, n
$$

and, by insertion of these compensated demands into the objective function (E:= $\left.P_{x} x^{\star \star}\right)$, we obtain the "expenditure function"

$$
E^{\star \star}=P_{X} X^{\star \star}\left(P_{x}, U^{0}, q\right)=E \star \star\left(P_{x}, U^{0}, q\right) .
$$

The expenditure function $E^{\star \star}\left(P_{x}, U^{0}, q\right)$ describes the expenditure or money income required to attain a level of satisfaction $U^{0}$, given prices $P_{x}$ and the quantity of the environmental good $q$. The dollar amount that an individual is willing to pay for a specified change in the quantity of the environmental good $q$, i.e., the change in the individual's money income which in combination with the environmental change leaves him at the same level of satisfaction as before the environment change, can be calculated by evaluating this expenditure? function at alternative levels of $q$. For example, suppose initially the quantity of the environmental good is $q^{0}$, and that to attain utility $U^{0}$ thus requires money income or expenditure $E^{0}$, where

$$
E^{0}=E^{\star \star}\left(P_{x}, U^{0}, q^{0}\right)
$$

Suppose that the quantity of $q$ increases to $q^{1}$; this increase causes an increase in the individual's utility, so that to obtain utility $U^{0}$ he need not consume as much of the traded goods $(x)$ and thus not expend as much on traded goods $\left(P_{X} X\right)$. Therefore, the expenditure required to obtain utility level $U^{0}$ with the environmental good at $q^{l}$, which we call $E^{1}$, is less than $E^{0}$, where

$$
E^{1}=E^{\star \star}\left(P_{x}, U^{0}, q^{1}\right)
$$


Furthermore, the difference between $E^{0}$ and $E^{1}$ is the amount of money income an individual could sacrifice as $q$ increases from $q^{0}$ to $q^{1}$, and still be able to attain the same level of satisfaction $U^{0}$ as before.

$$
\text { WTP }=E^{\star \star}\left(P_{x}, U^{0}, q^{0}\right)-E^{\star *}\left(P_{x}, U^{0}, q^{1}\right)
$$

This is a useful result, because an expenditure function for a single individual or a "typical" individual can be estimated statistically using observable data on market prices, consumption levels, money incomes, and quantities of the environmental good $q$. More importantly, it demonstrates to the analyst what it is that he is trying to measure; i.e., that "what the individual is willing to pay" for a particular change is the proper measure of the value or benefits of the change. A potentially more useful result, however, which avoids collection and analysis of all of the market prices and consumption data, can be derived from the expenditure function $E^{\star \star}\left(P_{X}, U^{0}, q\right)$.

The partial derivative of the expenditure function with respect to $q$ provides, for small changes in $q$ a measure of the change in expenditure or money income required to maintain utility $U^{0}$. This function is called the marginal willingness-to-pay (MWTP) function, and is graphed in Figure 6.1 for fixed levels of $U^{0}$ and $P_{x}$. This function also represents the compensated inverse demand function; its height displays the "price" an individual would pay to obtain any particular quantity of $q$. For example, in Figure 6.1, the individual would be willing to pay "price" $p^{0}$ to obtain quantity $q^{0}$ of the environmental good, if he were able to purchase $q$ in the market. Conversely, if $q$ was a commodity that could be traded in a market, this curve would represent the quantity of $q$ that would be purchased at any particular price. Because many environmental goods, such as visibility and health, have market and nonmarket features (i.e., and individual can take actions for which he pays a market price to increase his visibility or health, such as moving to a less polluted location) this dual interpretation of the MWTP function is useful: it permits estimation of the MWTP function (whose usefulness is addressed in the next paragraph) from market behavior. 


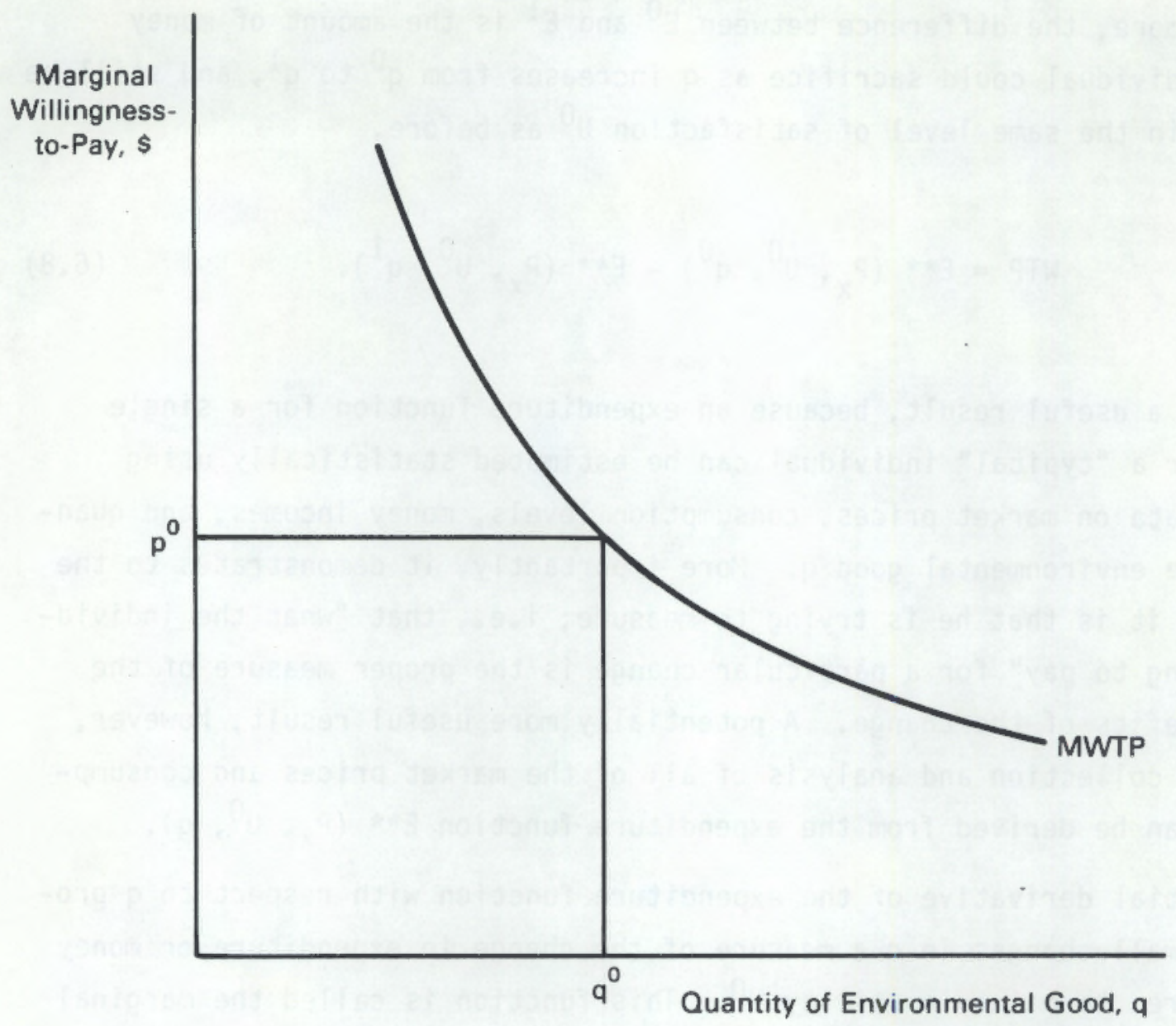

FIGURE 6.1. Marginal Willingness to Pay Function for an Environmental Good

The useful aspect of the marginal WTP function or curve is that Equation (8) can be expressed in terms of it, i.e.,

$$
\text { WTP }=E^{\star \star}\left(P x, U^{0}, q^{0}\right)-E^{\star \star}\left(P x, U^{0}, q^{1}\right)=\int_{q^{1}}^{q^{0}} \frac{\delta E^{\star \star}}{\delta q} d q
$$

and furthermore, that this integral, which equals WTP, is equal to the area under the marginal WTP curve between $q^{0}$ and $q^{1}$, as shown in Figure 6.2. Thus, the analyst need only estimate the marginal WTP curve or function and calculate 


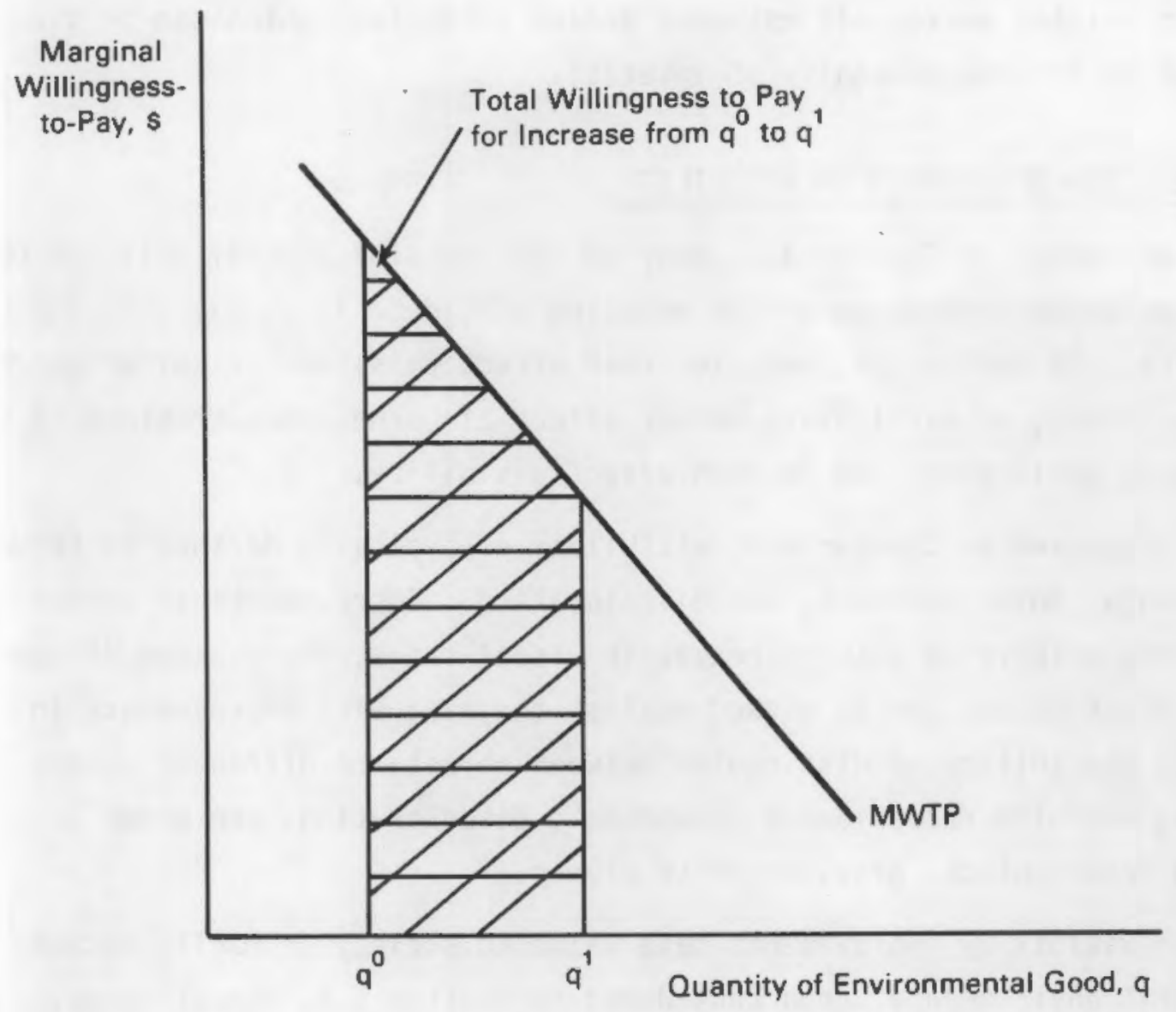

FIGURE 6.2. Benefits of Total Willingness to Pay for a Change in Environmental Good from $q$ to $q^{1}$

its integral to measure the benefits associated with a particular environmental change. As will be shown in the next two sections, this is not a trivial task, but is one that can be performed in many different ways.

There are several approaches to measuring an individual's willingness to pay for a particular environmental change. First, one could simply ask the individuals affected by a particular environmental change how much they would be willing to pay for it. This approach is used frequently by economists but has several problems (to be addressed below) and the results of such an exercise are usually not generalizable to environmental changes other than those which the specific questions addressed. An individual might be willing to pay 
$\$ 10$ for a $6 \%$ visibility improvement, but how much would he be willing to pay for a 10\% improvement? The second approach is to use data on prices and quantities in related markets to estimate demand schedules, which can be used to infer values for the commodity of interest.

\subsection{VALUATION OF CHANGES IN VISIBILITY}

As discussed in Chapter 4.0, many of the emission control policies or strategies under consideration for reducing acid deposition may also impact visibility. In particular, policies that affect emissions of sulfur oxides, nitrogen oxides, or particulate matter affect airborne concentrations of these and related pollutants, and in turn affect visibility.

As discussed in Chapter 4.0, visibility is typically defined in terms of visual range, color contrast, and discoloration. Improvements in visibility are thereby associated with increases in visual range, the maximum distance at which a black object can be viewed against the sky; with improvements in color contrast, the ability to distinguish between objects of different colors at a distance; and with reductions $n$ atmospheric discoloration, the brown or gray haze and brown, black, gray, or white plumes.

Such visibility improvements have value to society primarily because, like the general environmental good considered in Section 6.1, visual range, color contrast, and atmospheric discoloration enter individuals' utility functions. Holding consumption of all other goods constant, a particular individual's utility will be higher or greater, the greater the visual range; the greater the color contrast; and the lower the atmospheric discoloration. Thus, like the general environmental good considered in Section 6.1 , an individual's utility would be increased by policy-induced exogenous improvements in visibility, and there is some dollar amount that he would be willing to pay that in combination with a visibility improvement of a particular magnitude would leave him at the same level of utility as before the improvement.

In other words, visibility improvements can be valued in the exact manner discussed in Section 6.1. The problem facing analysts attempting to estimate such values is measuring or estimating the individual's margin willingness-topay (MWTP) function (as graphed in Figure 6.1) for visibility improvements. 
$H$ is section discusses several methods that economists have used to estimate this function and the value estimates they have derived for particular visibility improvements. In Section 6.2.1, we describe methods used to value visibility and other air quality improvements. In Section 6.2.2 we review estimates of visibility improvements. In Section 6.2 .3 we evaluate this literature and summarize the findings of this section.

\subsubsection{Empirical Methods of Valuing Visibility Changes}

In order for a change in visibility to be significant, the change must be perceptible to the observer. Establishing economic values for visibility depends on obtaining quantitative measure of visibility impairment as perceived by the human eye. These values must involve relating visibility to indices such as visual range, color alteration, or contrast transmittance. Visibility is a nonmarket good for which no direct prices or quantities consume exist, but the "market" value of visibility, measured in dollar terms, can be estimated from revealed consumer preferences in either a market or market-like situation. Economists have had some success quantifying the values of visibility. For example, visibility impairments, such as haze diminishing the view of a scenic vista, may impinge on the residential site of a household; such effects may be reflected in housing prices or property values. Alternatively, economic values for visibility improvements may be derived indirectly through survey questionnaires by asking individuals their willingness to pay for visibility improvements. A brief review of empirical methods for valuing visibility changes using market data and survey data (i.e., contingent market data) is described below.

Actual Market Approaches for Valuing Visibility Improvements

In the following paragraphs, we describe and briefly critique potential methodologies for valuing visibility improvements with actual market data. One of the most frequently used approaches for valuing nonmarket goods is the property value approach. The price paid for a market good--in these cases, residential property and labor, respectively--may, in fact, be influenced by visibility levels. Consequently, an analysis of air quality and residential property values may reveal the values individuals place on visibility. 
The property value approach has been frequently applied in economic valuation studies to determine the value of nonmarket goods. Property value studies use the hedonic price technique to estimate an implicit price for housing characteristics that may include visibility or air quality. If one is able to define and quantify attributes of residential property, the one can determine the effect of an attribute, such as visibility, on the price of a house by observing the price of the house in relation to different levels of the attribute. For example, if there are two houses in the same housing market (i.e., city) that are identical in every respect except that one has a view of an aesthetic resource (e.g., a lake, or the ocean) and the other does not, and the first house sells for $\$ 85,000$ and the second for $\$ 80,000$, the one could conclude that the view has a value of $\$ 5,000$. The relationship between the price of a market good and its characteristics is defined by a hedonic or implicit price function. An implicit price of a housing characteristic is calculated by estimating the relationship between the prices of housing units and their characteristics. The hedonic technique, then, can determine how differences in visibility, or air quality, would affect housing prices if the houses were identical in all other respects.

The hedonic technique has several strengths, including: 1) data on housing prices and attributes are usually available; 2) a theoretical ability to value highly specific attributes of nonmarket goods; and 3 ) a reasonable approximation to a theoretically correct welfare measure, provided that underlying assumptions are not seriously violated.

However, the method also has several shortcomings. First, households or individuals must perceive the nonmarket characteristics being evaluated. Poilutants that cannot be seen or smelled, such as airborne toxic substances, may not be perceived by either buyers or sellers and therefore may not affect prices. This does not however, mean that changes in the concentrations of such pollutants have no value. Other valuation techniques (e.g., the contingent valuation method) could value the effects of such pollutants, by ignoring the problem of whether the pollutants are actually perceived. Second, benefits accruing away from the consumption good are not valued (e.g., in residential housing studies, nonmarket benefits accruing at the work place are not 
considered). Third, temporal and spatial synchronization of data for both effluents and consumption goods are necessary. For example, data on air quality at each specific house in the sample must be gathered, so that a relationship can be developed between the value of that house and the air quality at that house. Because air quality varies tremendously within a community, and because housing prices most likely reflect these variations, using communitywide air quality data will result in a biased estimates of the value of visibility. Finally, many of the empirical studies have not attempted to isolate health effects from aesthetic effects of air quality in valuing environmental changes. Most economic studies have chosen one pollutant to represent air quality. Sulfates are known, however, to affect both visibility and health. Rowe and Chestnut (1982, p. 99) recommend that a measure of visibility must be developed that is distinct from the other impacts of air pollution. Consequently, it is not clear to what extent double counting occurs when estimates of benefits from other sources (e.g., health and materials) are added to property value estimates that are intended to measure visibility benefits.

At present, visibility alone has not been used in any hedonic price study. It may very well be the case that the pollutants used in certain property value studies do, indeed, reflect those visual impacts that are most readily perceived. However, measured air quality at a site may not be an adequate representation of visibility at the site because visibility is affected by air quality at other locations surrounding the site. For example, the visual range at a specific house is affected by the sulfate concentration at the house, as well as sulfate concentrations within a 5-mile radius, a 10-mile radius, etc., with the effects decreasing as the distance increases. As a result, new measures--other than the amount of pollution at a site-may have to be developed in order to effectively apply the property value approach to estimation of visibility benefits (Rowe and Chestnut, 1982).

Contingent Market Approaches for Valuing Visibility Improvements

Contingent market approaches employ survey techniques in an attempt to elicit values of proposed environmental changes from respondents in hypothetical situations. Individuals are asked to predict how they would behave in response to hypothetical changes in environinental quality. In contrast to 
market approaches, values are inferred from hypothetical rather than actual data. In the following paragraphs, we explicitly consider four contingent methods--the contingent bidding method; the contingent adjustment method; the direct utility method; and the contingent ranking method.

The Contingent Bidding Method. The contingent bidding method is a direct inquiry technique that attempts to value visibility by directly asking individuals to state their maximum willingness to pay (or their minimum willingness to accept compensation) for a change in visibility. This method can be structured to obtain theoretically correct measures of welfare for any given system of property rights. That is, in applying the bidding method, the correct choice of welfare measures depends on whether individuals believe they have (property) rights to their preferred state of environmental quality. This notion influences the acceptability of the hypothetical situation to the respondent.

Similar to the other contingent market approaches described below, the contingent bidding method relies heavily on five critical assumptions. First, consumers must "value" the hypothesized changes being made in the contingent market. Second, the changes must be capable of being depicted by various stimuli. Third, consumers must comprehend the stimuli. Fourth, consumers must accurately determine the value of the hypothesized changes. And fifth, consumers will accurately reveal these values.

The bidding method may be an important technique for valuing changes in air quality, or visibility. It is well grounded in economic theory and allows for a wide range of applications. For example, one can examine impacts at a single site or across entire regions with this method. Moreover, in contrast to property value approaches, different aspects of air quality (e.g., visibility and health) can be analyzed separately.

Several important problems, however, are associated with the contingent bidding method. Foremost is the problem of bias--hypothetical, strategic, information, and interviewer. Hypothetical bias arises from the fact that the respondent knows he is merely playing a game, and thus may not expend resources in developing his responses. More importantly, it may arise from the fact that the respondent may be asked to value a commodity that he is not accustomed to either valuing or explicitly purchasing in a market, and thus may not have a 
very good idea of how much he is willing to pay for the commodity. Strategic bias is an attempt by the respondent to influence the outcome of the bid process by revealing a bid other than his true valuation. Information bias relates to the potential biases introduced by the survey design or information availabie to the respondent. Interviewer bias is the bias due to variations among the interviewers conducting the (personal) interview.

The Contingent Adjustment Method. Rather than ask individuals their willingness to pay for a given quantity of a public good (i.e., visibility) as in the contingent bidding method, in this method consumers are asked to indicate their preferred quantity of a nonmarket good, given the relative prices of the goods under consideration. For example, survey respondents would be asked "how many miles of visual range" they would like to purchase if the price per mile was $\$ 1$. By varying the price, a demand curve for visual range could be derived. This demand curve could then be used to estimate the respondents WTP for visual range increases. The strengths and limitations of contingent bidding techniques apply to this method as well.

Direct Utility Method. This method involves deriving consumer demands based on cardinal utility functions and indifference maps. Ordinary least squares methods are used to fit a utility function to the indifference points revealed through a "Ramsey" game. In such a game, a survey respondent is asked how much satisfaction he derives from various "bundles" of commodities. He might, for example, be asked the level of utilities he associates with a bundle that includes five miles of visual range and a disposable income of $\$ 50,000$; a second bundle might include ten miles of visual range and a disposable income of $\$ 40,000$. Alternatively, individual commodities (e.g., food, housing, automobile, etc.) may be included in the bundles instead of disposable income. The respondents' answers can be used to estimate a utility function that, in conjunction with information about his actual disposable income and his actual expenditures, can be used to derive his demand function (i.e., curve) for the relevant nonmarket goods (e.g., visual range). A major shortcoming of this 
approach is the lengthy time necessary for the interviewer to obtain information about indifference maps, budgets, and expenditures. However, a probabi1istic rating method has recently been devised, and this newer method appears to have improved performance characteristics over the Ramsey approach.

The Contingent Ranking Method. The use of this method for valuing environmental goods is a relatively recent development. This procedure maintains that an individual's valuation of environmental goods can best be estimated by presenting individuals with a set of alternatives. Each alternative describes a specific state of the world by characterizing the features and cost of the good to the individual under specified conditions. Individuals are then asked to rank the alternatives from most to least preferred. Because each alternative includes both a level of environmental quality and a "price," these responses can be used to statistically estimate the value to the respondent of an improvenent in environmental quality. Implicity, the contingent ranking method assumes that individuals are more likely to accurately order hypothet $i-$ cal combinations of environmental goods and fees than to directly reveal their willingness to pay for specified changes in any of the goods.

\subsubsection{Review of Economic Valuation Studies}

The economic literature on valuing visibility improvements indicates that visibility is important to individuals. While most of the economic valuation studies involve analyses of federal land areas situated in the Western U.S., a recent study by Tolley et al. (1983) and SAI (1984) provide an economic analysis of visibility improvements in urban areas of the eastern U.S. In this section we provide a review of the literature and a summary of the empirical findings for each study. We wish to point out that the economic literature is not consistent in its use of terms for representing the concept of visibility. At times, visual aesthetics and air quality are also used when visibility is implied.

Visibility alone has not been used in any hedonic price study (i.e., residential property or water), although several studies have used this technique to estimate the implicit price of air quality in general. With one exception (Brookshire, et a1. 1979) we have not identified studies that decompose the implicit price of air quality into a price for visibility, a price for health, 
etc., and thus are not of immediate relevance to this study. This part of the section therefore concentrates on studies that have employed contingent valuation methods, in which the implicit price of visibility has been directly estimated.

In this part we briefly review nine studies that use the contingent bidding method to value visual aesthetics. Two other studies were not reviewed, but are important because they provide valuable information on urban visibility in the East. The first of these studies, performed by Rae et al. (forthcoming) for the Electric Power Research Institute, uses a contingent ranking method to determine the economic value of visibility to residents in Cincinnati. It has not yet been publicly released and so could not be reviewed here. The second study, performed by Latimer et a1. (1984), attempts to estimate visibility benefits associated with an $\mathrm{SO}_{2}$ emission control strategy. This report presents estimates of 1 ) the changes in state-level $\mathrm{SO}_{2}$ emissions associated with particular emission reduction proposals, 2) the changes in state-level sulfate concentrations associated with these emissions changes, 3) the changes in state-level visibility associated with these concentration changes, and 4 ) the mandatory value of these visibility changes. It is not reviewed here because the monetary value estimates are based on a review of the studies that are reviewed here.

The nine visibility studies reviewed here are sumarized in Table 6.1. The first column lists the study, by (lead) author, with the year of publication in parentheses. The second column describes the specific contingent method used in the study: contingent bidding, contingent ranking, or contingent adjustment. One study (Thayer 1981) used both bidding and adjustment methods, and values from both are presented. The third column presents the year in which the survey was conduced and the fourth the site of the survey. Note that all but two of the studies focused on visibility improvements in rural or scenic areas, such as the Grand Canyon or Great Smoky National Park. Finally, the fifth column provides the dollar value estimated in the study. A11 values are measured in constant 1982 dollars, and were inflated from those of the reference year using the annual Consumer Price Index. In most cases, the dollar amounts represent mean bids; where appropriate, we have presented 
TABLE 6.1. Contingent Market Estimates of the Value of Visibility Improvements

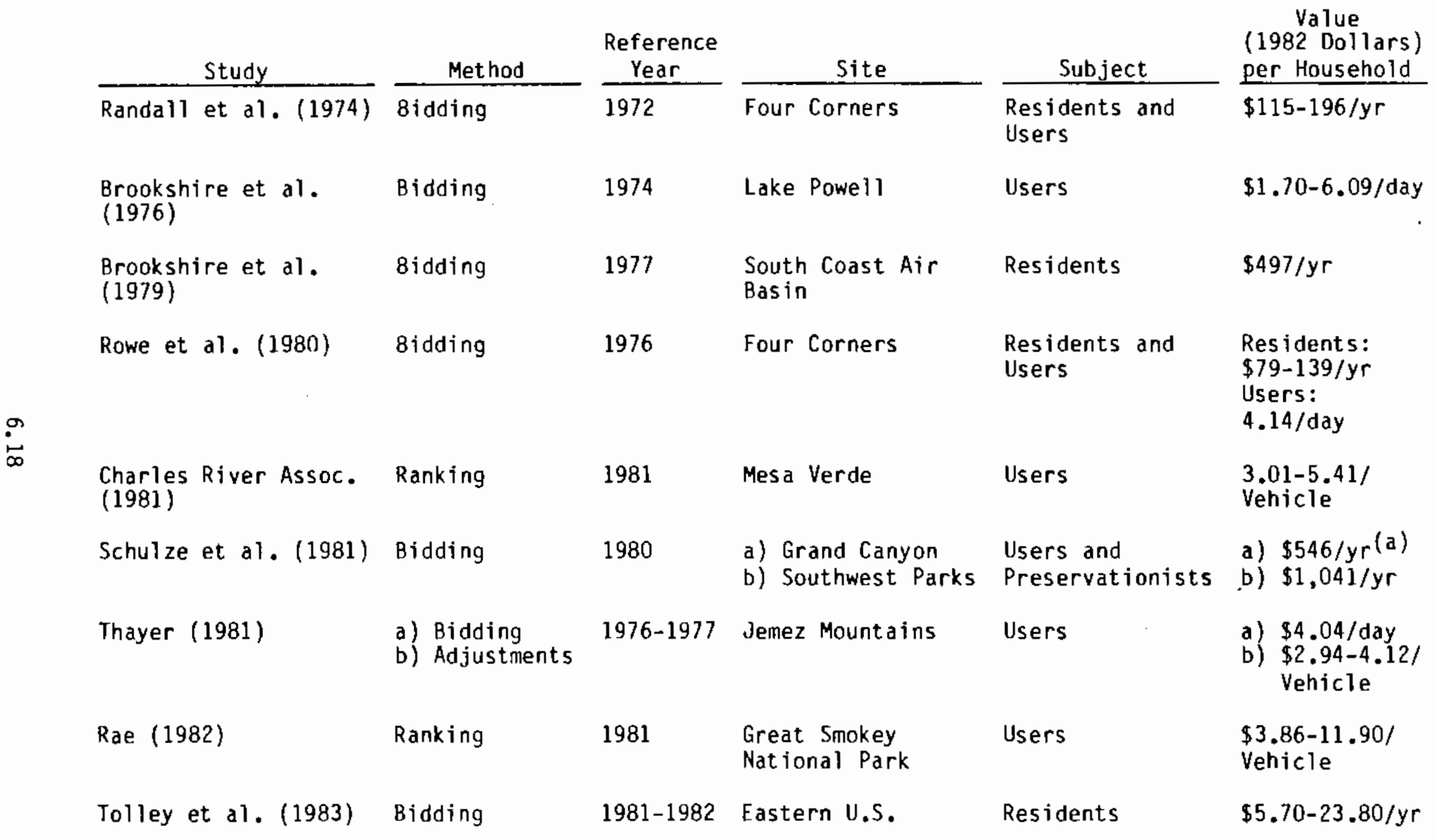

(a) Aggregate annual value of preserving visibility in the site to residents of six states. 
ranges of such bids (e.g., in cases where more than one type of magnitude of environmental improvement was considered).

Summarizing the value estimates is difficult, if not impossible, because of the heterogeneity of the sites and types of visibility changes considered. the only statement that can be made in reference to all nine studies is that each found that the visibility changes considered were of significant value to individuals, i.e., the value of the visibility improvements each considered was greater than zero. Beyond this statement, comparisons of value estimates do not appear fruitful, because 1) one would not expect two different types of visibility changes (e.g., removal of a power plant plume, increase in visual range) at a single site to have the same value and 2) one would not expect a specific visibility change (e.g., $10 \%$ increase in visual range) occurring at two different sites (e.g., Great Smoky National Park and Lake Powell) to have the same value.

Randall et al. (1974). This study represents the first empirical application of the contingent market approach. Benefits that would accrue from the abatement of aesthetic environmental damages associated the the Four Corners Power Plant and Navajo mine in New Mexico were estimated. An iterative bidding procedure, in which three payment vehicies (sales tax, user fee, and electricity bil1) were used, revealed that substantial benefits could be gained from the abatement of environmental damage associated with air pollution (visibility), power lines, and land disturbance (from strip mining). Although few empirical results are actually reported, residents were found to elicit mean bids ranging between \$115-\$196 per year for the abatement (all dollar values in this chapter are reported in 1982 dollars). The effect of higher incomes on bids was not significant, and no bias test were explicitly reported.

Brookshire et al. (1976). Through an iterative bidding approach, this study evaluates the visual aesthetic impacts of large power plants in a national recreational area. Recreators were asked what entrance fee they would be willing to pay to prevent the construction of a power plant in the Lake 
Powell area of the Glen Canyon National Recreation Area in Arizona. The proposed power plant, similar to the existing Navajo power plant, had $700 \mathrm{ft}$ stacks that would be visible from the lake. In addition to the stacks, smoke plumes would also obscure the view and reduce visibility.

An analysis of the data centered on strategic bias, which was found not to be present; other biases were not addressed. The average bid expressed in additional entrace fees per family, or recreator, was found to be in the range \$5-41. The total annual bid to prevent pollution from an additional power plant near Lake Powell was about $\$ 1,423,000$ in 1975 . Recreators were also willing to pay an additional $\$ 809,00$ in 1975 in order to avoid the stacks.

Brookshire et al. (1979). This study uses both the property value approach and the contingent bidding method to obtain values for visibility (a) and health effects (acute and chronic) in the South Coast Air Basin of California. The purpose of this research was to compare valuations from each approach. In order to compare the two methodologies for estimating benefits, a common sampling methodology was developed. This approach involved forming pairs of Census tracts in the South Coast Air Basin using data from the Market Data Center in Los Angeles.(b) Ultimately, the sampling methodology yielded a set of paired communities that were similar in all relevant characteristics but air quality.

Hedonic price functions were estimated for two pollution variables, $\mathrm{NO}_{2}$ and TSP. Both pollution variables had negative coefficients and were found to be highly significant in a nonlinear specification of sale prices of owneroccupied houses. A unit improvement in $\mathrm{NO}_{2}$ (one part per hundred million) was estimated to increase property values by $\$ 3,200$ at the mean; the marginal implicit price for TSP was approximately $\$ 478 \mathrm{per} \mathrm{g} / \mathrm{m}^{3}$ at the mean. The community sample that was used to provide these estimates did not match the survey sample that was later used for the contingent bidding approach. A second set

(a) An attempt was made to define visibility in terms of visual range in this study.

(b) The authors point out that this approach was possible only because an extensive data base on household information existed. Similar analyses may not be possible for other locations. 
of hedonic equations that was estimated yielded marginal implicit prices that were close to estimates from the first hedonic equation. In fact, a one pphm (part per hundred million) reduction in $\mathrm{NO}_{2}$ would raise property values by $\$ 2,930-5,352$, and a one $\mathrm{g} / \mathrm{m}^{3}$ reduction in TSP would increase property values by $\$ 293-376$ (See Rowe and Chestnut, 1982, p. 1984). Average annual benefits from reducing air pollution by $30 \%$ were estimated to be in the range of $\$ 841-937$ per household.

In contrast to the property value approach, the bidding approach was able to separate perceptions and values of air quality into three characteristic parts: visibility effects, acute health effects, and chronic health effects. Personal interviews were conducted for 345 residents in the area. In communities where air quality was poor, the average bid was $\$ 23.16$; where air quality was fair, the average bid was \$32.19; and finally, an overall average bid of $\$ 54.30$ was estimated in communities where air quality was good. of the total mean bids, the aesthetic, acute health, and chronic health components constituted about $34 \%, 40 \%$, and $26 \%$, respectively. Finally, aggregate annual benefits for a $30 \%$, region-wide increase in improved air quality was estimated between $\$ 0.92$ billion and $\$ 1.04$ billion.

Rowe et al. (1980). This study estimates the economic value of visibility (visual range) over long distances for Farmington residents in New Mexico and recreators at the Navajo Reservoir in the Four Corners Region. Efforts were made to explicitly examine and test for biases, including information, strategic, and instrument biases. Although information bias was found, strategic bias was not detected. While this study was similar in structure to those of Randall et al. (1974) and Brookshire et al. (1976), the research by Rowe et al. was the first study to use a household production function approach to analyze how behavior changes in response to visibility changes. Moreover, this experiment was the first among visibility studies to test the differences between the willingness-to-pay and willingness-to-accept-compensation approaches for visibility valuations (Rowe and Chestnut, 1982, p. 158).

The payment vehicles that were used included electricity bill additions and payroll deductions for resident respondents, as well as user fees for 
recreators. Willingness to accept compensation bids were as much as fourteen times greater than willingness to pay bids. In the study, this observation was explained, in part, by the fact that willingess-to-pay bids are bound by income while willingess-to-accept-compensation is not. Such a difference between the two bid types also suggests that property right perceptions are important and must be accounted for in contingent market studies.

Yearly mean bids (equivalent surplus) ranged between $\$ 97$ and $\$ 139$ per household. The overall mean bid for users was estimated at $\$ 4.14$ per day.

Charles River Associates, Inc. (1981). A contingent ranking approach was used to quantify visibility benefits in the federal Class I area of Mesa Verde. Respondents viewed four variations in visibility conditions. The analysis revealed that the average visitor was willing to pay: 1) $\$ 5.41$ per vehicle to improve visibility from an intense plume to a clear conditions; 2) \$4.86 per vehicle to improve visibility from an intense haze to clear conditions; and 3) $\$ 3.01$ per vehicle to improve visibility from a moderate haze to a clear condition.

In addition, visitors valued reducing emissions at a typical power plant to New Source Performance Standard (NSPS) levels at about \$0.37 per vehicle; in this case the percentage of time clear visibility conditions would occur was $5 \%$. An increase in the frequency of clear conditions from $14 \%$ to $38 \%$ was valued between $\$ 1.27$ and $\$ 2.27$ per vehicle. Assuming a yearly average of 500,000 visitors and about 167,000 vehicles, this study found annual user benefits to be on the order of $\$ 0.1$ million to reduce emissions to levels that approximate NSPS and about \$0.20-0.38 million to completely reduce emissions.

Schulze et al. (1980). The analysis in this study attempted to explicitly link emission rates $\left(\mathrm{SO}_{2}\right)$ and sources (coal-fired power plants) to visibility conditions and the economic benefits of control. Economic benefit values were determined for controlling both haze and plumes in the Grand Canyon, as well as haze in the Southwest National Parks. This research is the first to estimate existence values, in addition to the typical user values. Existence value, sometimes called preservation value, is the amount an individual would be willing to pay to maintain the quality or existence of a resource simply for the 
pleasure of knowing that the resource exists at a particular level of quality. Motives for existence value include knowing that other people can enjoy the resource, a desire to bequeath the resource to future generations, and a feeling of "environmental responsibility."

A contingent bidding approach was used with two payment vehicles--an entrance fee for users and increase in monthly utility bills for preservationists. Preservation questionnaires were administered to residents in Albuquerque, Los Angeles, Denver, and Chicago. User questionnaires were administered in each of those cities with the exception of Chicago. User elicited a mean bid ranging from between $\$ 1.97-\$ 6.03$ per day $\rightarrow$ park entrance fee. The mean bid by preservationists for maintaining visibility in the Grand Canyon region was approximately $\$ 6.33$. Bids from the preservation value questionnaires were then aggregated to obtain estimates of total benefits collectively for residents of California, Colorado, Arizona, Utah, Nevada, and New Mexico. Annual benefits for preserving visibility in the six state region were estimated to be $\$ 546$ million in the Grand Canyon, \$1,041 million in the region (i.e., Grand Canyon, Mesa Verde, and Zion), and $\$ 437$ million to avoid plume blight in the Grand Canyon.

Thayer (1981). This study uses both the contingent bidding technique and a contingent adjustment approach to estimate environmental damages associated with the potential development of a geothermal power plant in the Jemez Mountains of New Mexico. The study was structured to test for consistent estimates between the two contingent valuation methods. A contingent bidding game was conducted using a uniform entrance fee as the payment vehicle to prevent development of the power plant. In addition, respondents were asked what their contingent recreation plans would be is development were to take place. For example, they were asked to list the alternative sites they would visit and how often they would visit each.

The survey results indicated that $32 \%$ of the respondents would discontinue visiting the Jemez area if development were to occur. This percentage translates into approximately $40 \%$ contingent decrease in visitation. Moreover, about $65 \%$ of the respondents stated they would visit alternative sites more 
frequently. Average bids were estimated to be $\$ 4.04$ per visitor party day, while the contingent adjustment method yielded estimates in the range of $\$ 2.94-$ 4.12 depending on the driving cost per mile.

Rae (1982). This study uses a contingent ranking method to quantify the benefits of improving visibility in the Great Smoky National Park. To test the importance of visibility to visitors, a survey choice situation was created in which respondents compared and ranked various combinations of attribute levels, including visibility and entrance fees. Generalized haze conditions were visually represented in four slides and ranged from $10 \mathrm{~km}$ to $100 \mathrm{~km}$ of visual range. Respondents were willing to pay an average of $\$ 10.07$ per vehicle to obtain a clear condition rather than an intense haze condition. Improving visibility from an intense haze condition to a slight haze condition was valued about $\$ 13.89$ per vehicle trip, and, rather unexpectedly, a slight haze condition was worth $\$ 3.86$ per vehicle more than a clear condition.

Income had a significant effect on willingness to pay for improved visibility. Individuals with average annual family incomes of $\$ 21,200(\$ 20,000$ in 1981 dollars) were willing to pay approximately $\$ 7.85$ per vehicle trip to obtain a $100 \mathrm{~km}$ visibility condition rather than $10 \mathrm{~km}$ condition. Individuals with incomes of $\$ 42,420(\$ 40,000$ in 1981 dollars) were willing to pay $\$ 11.90$ per vehicle trip.

Tolley et al. (1983). The objective of this study was to use data obtained from a contingent bidding survey conducted in six cities to measure values for visibility in the entire eastern U.S. Individuals were asked to value increases in visibility of 5,10 , and 20 miles in the urban residential areas of Cincinnati, Mobile, Atlanta, Boston, Miami, and Washington. For a ten mile improvement, the average annual bid per household ranged between $\$ 5.70$ and $\$ 23.80$ per mile across the six cities. An aggregate value of visibility improvement $(10 \%$ to $30 \%$ ) in the eastern U.S. was estimated to be in the range of $\$ 0.5$ to $\$ 2.0$ billion.

\subsubsection{Summary and Evaluation of Literature}

The studies reviewed in Section 6.2.2 have all contributed to the field of environmental economics in general and valuation of nonmarket commodities in 
particular. The area of contingent valuation is quite obviously a rather new area of inquiry, and much effort is still being devoted to improving the method. Nevertheless, there is much that can be learned from the studies reviewed above regarding valuing the visibility-related ancillary benefits of acid deposition control policies.

First, the review makes clear the fact that there is no widely accepted estimate of the value of visibility improvements. The studies reviewed above have investigated the value of a particular type of visibility improvement at a particular site or set of sites. The value of visibility improvements to U.S. residents in general has not been assessed, although Tolley et al. (1983) take a step in this direction.

In particular, regarding potential acid deposition policies, the existing literature suffers from two shortcomings that. cause the results of previous studies to prevent generalizing to the types of visibility improvements that may be caused by acid deposition policies. First, all previous studies we identified have estimated the mean value of a visibility improvement in a specific location (or a small set of locations). These studies have not typically attempted to related (in an econometric fashion) the value to an individual of a specific improvement to its potential determinants in a manner that would permit generalizing the results to populations in other locations (not included in the survey sample). Developing such a relationship would require surveying individuals residing in a number of locations. This is a serious limitation, because acid deposition policies are likely to cause visibility improvements in a large number of locations, and individuals in different locations may value a visibility improvement of a fixed magnitude differently, due in part to location-specific pre-improvement visibility levels as well as location-specific states and demographic/socioeconomic characteristics. Second, all previous studies we identified have estimated the mean value of a visibility improvement of a specific magnitude. Again, these studies have not typically attempted to relate the value to an individual of a specific improvement to its determinants in a manner that would permit generalizing the results to improvements of magnitudes different than that explicitly considered in the survey. Developing such a relationship would require asking survey respondents to value a number 
of visibility improvements. This is also a serious limitation, because acid deposition policies are likely to cause visibility improvements of varying magnitudes, and an individual may not value visibility improvements linearly, $i . e .$, the value of an $x \%$ improvement may be less than double the value of a $1 / 2$ $X \%$ improvement.

These shortcomings are the result of the focus of each investigator or set of investigators, which was typically to study a specific methodological issue or value damages or benefits at a particular site, not to perform general policy analysis or predict the value of the visibility improvements associated with any public policy that might someday be proposed. The shortcomings also point out what is required to value the visibility improvements associated with a specific acid deposition policy: a model that can predict the value of affected residents of a visibility improvement of any magnitude occurring in any location, such a model would be based on the responses to a CV survey that asks survey respondents in a large number of locations (with varying base-level visibility and varying demographic/socioeconomic characteristics) to value a number of visibility improvements of varying magnitudes.

Moreover, the values of each of the three types of visibility improvements (visual range, color contrast, atmospheric discoloration) to U.S. residents has not been adequately assessed. With regard to acid deposition policies, we believe this is a serious shortcoming of the existing literature, and one that emphasizes the need for additional research in this area.

The review demonstrates the power of the contingent valuation (CV) approach. The $C V$ approach appears to be the only available method for valuing changes in the provision of specific environmental commodities like visibility. Hedonic techniques, which can be used to value air quality changes in general, require data on both property values of specific residences and the level of the characteristic under study (e.g., visibility, air quality) at the residence; and while air quality data is routinely gathered in most cities and can be used in such studies (by assuming that city-average air quality prevails at each residence in the city), visibility data is not typically collected in this manner. Moreover, hedonic techniques are not appropriate for valuing changes in scenic areas because 1) the property in such areas is typically not 
privately owned nor frequentiy sold in market transactions, so that the value of such changes is not reflected in the market value of the property in the area, and 2) when the property is privately owned, there are typically benefits associated with "viewing" the changes that cannot be appropriated by property owners and are this not reflected in property values.

Third, the review also identifies the problems associated with use of the contingent valuation approach. Value estimates based on contingent surveys are potentially subject to several biases. While some researchers have tested for and found such biases, and others have tested for and not found such biases, the one thing that is clear is that this issue has not been laid to rest. Again, we believe further methodological development is required in this area.

We believe that the contingent valuation approach can be used to value the visibility-related ancillary benefits of acid deposition control policies. As a first approximation, we believe the estimates generated by Tolley et al. (1983) could be used to value such benefits. We believe, however, that use of the Tolley estimates should be considered a first approximation; the number of sites considered in the study (six). their location (all Eastern cities), the types of changes considered, and the statistical techniques employed have resulted in value estimates that may not be appropriate to acid deposition policies in general.

We therefore propose that a research project be undertaken to develop a statistical model of individual's willingness-to-pay for visibility improvements. This model could be used to predict the WTP of individuals (or the aggregate WTP of a group of similar individuals) using only secondary data. Previous research at Pacific Northwest Laboratories (Adams et al. 1980) demonstrates that such a CV model can be developed and be used to value the benefits of particular policies or actions.

The proposed model would be based on a contingent valuation survey of a number of individuals in cities and rural areas scattered across the United States. Individuals would be asked to state their willingness to pay for particular improvements in 1) visual range, 2) color contrast, 3) atmospheric discoloration, and 4) combinations of these three, both in the area surrounding their residence and in other (e.9., vacation) areas. Individuals would be 
asked questions about their income and other sociodemographic characteristics, as well as their "feelings" about a number of environmental issues, particularly the importance to them of visibility (e.g., on a one-to-ten scale). Most importantly, average levels of the three visibility characteristics in the area around each respondents residence would be measured.

The responses to this survey would then be econometrically analyzed to develop an equation (or set of equations) explaining an individual's willingness-to-pay for visibility improvements in the area surrounding his residence. The individuals WTP would be a function of: 1) the size of the improvement in each of the three visibility characteristics; 2) his income; 3) whether or not he lives in an urban area, and 4) the existing levels of each of the three visibility attributes and other variables. A similar equation would be developed for areas not immediately adjacent to the respondent's residence. Combined with data on income, urban/rural population, and existing visibility, this model could be used to predict the WTP of all individuals in an affected population for an air quality improvement affecting each of the three measures of visibility.

The important characteristics of such a model, distinguishing it from the other contingent valuation studies of visibility, are the following. First, it would be able to predict the WTP of any group of individuals in the United states. Second, it would be able to consider visibility improvements at any location or set of locations in the United States. Third, it would be able to consider air quality changes leading to visibility improvements of any magnitude. Fourth, it would be able to consider improvements in any or all of the three visibility characteristics.

We believe these four characteristics are important in considering the value of visibility-related ancillary benefits. Because such improvements wil: occur in the future, it is important to be able to predict their value, not merely measure what their value was in a particular reference year. Acid deposition policies may affect visibility in a number of cities and rural areas scattered across the United States, and it is important to be able to value the improvements in all of these areas. Moreover, one must take into account that improvements of a particular magnitude will have different values in different 
places. Acid deposition policies to be considered may result in visibility changes of various magnitudes, and each of these policies must be consistently valued. Moreover, one must take into account that a $10 \%$ visibility improvement is not twice as valuable as a $5 \%$ visibility improvement. For these reasons, we believe development of the model proposed above is both warranted and necessary for a complete benefit-cost analysis of acid deposition control policies.

\subsection{VALUATION OF CHANGES IN HEALTH}

Several of the policies or strategies currently under consideration for reducing or mitigating acid deposition may indirectly affect health, as discussed in Section 4.0. Specifically, changes in ambient concentrations of sulfate and other sulfur oxides, total suspended particulate, nitrogen oxides, carbon monoxide and ozone/PAN may 1) change the incidence of acute pollutionrelated $i l l n e s s, 2)$ change the incidence of chronic pollution-related illness, and 3) change the rate of mortality. The literature reviewed in Section 4.0 suggests that all three of these effects may be significant, and thus that the capability to value all three types of effects should be developed. This section focuses on the value of changes in the mortality rate, for the simple reason that the value of changes in the incidence of illness (morbidity) has not been thoroughly studied and thus there is not much of a literature in this area for us to review. We will provide a brief analysis of morbidity at the conclusion of this section.

Government policies in general affect the mortality rate in two different ways. First, policies or programs impact activities that have the characteristic that today's action affects whether or not the individual who take the action dies today. Mandatory seat belt regulations and, perhaps more importantly, occupational safety programs are examples of such actions: whether or not and individual wears a seat belt today affects whether or not he dies today, but not whether or not he dies tomorrow (if we define the program as lasting one time period, so that having the program in place tomorrow is a distinct program).

Second, there are policies or programs impacting activities that have the characteristic that today's action affects whether or not the individual taking 
the action dies today and also whether or not he dies tomorrow, the next day, the day after that, etc. Programs to reduce cigarette smoking are an example; cigarette smoking today affects the probability of dying today, and also at all points in the future, even if the individual does not smoke in the future. Programs and policies which reduce air pollution clearly fall into this second category.

Regarding analysis of the benefits of the two types of policies, the key distinction between the two is that policies affecting the first type of activity change a single probability (i.e., the probability of dying during this time period) while policies affecting the second type of activity change a stream of probabilities (i.e., the probability of dying during this time period, the probability of dying during next period, etc.). This is an important distinction. Government policies affecting single-period activities can "reduce the mortality rate," or reduce the probability that an individual will die this period. Policies that affect multiple-period activities cannot "reduce the mortality rate" in the same sense, because everybody will eventually die. Such policies are able to alter the stream of probabilities, making it less likely that a particular individual dies in the near future and more likely that he will die in the long-term future. Viewed from another standpoint, such policies are able to reduce the conditional probability that an individual will die in each future time period. This conditional probability is the probability that an individual will die in a particular period, given that he survived through the previous period. The distinction is thus important in a valuation sense because the former type of policy affects quantity of a single commodity (the probability of dying today) while the latter type of policy affects the quantities of a bundle of commodities (the stream of conditional probabilities of dying in individual time periods).

As might be imagined, it is more straightforward to value changes of the first type than of the second type, and most empirical studies in this field have considered changes in single-period probabilities. It is also clear that a large number of government programs that affect mortality, one might even say the majority of such programs, are of the multiple-period type, and that most, if not all, environmental policies are included in this category. Because of 
this, we will attempt in the remainder of this section to maintain the distinction between the two types of policies/activities, and emphasize analyses of the latter type.

\subsubsection{Approaches to Measuring The Value of Mortality Reductions}

Two primary approaches have been utilized by economists in the past to value government policies that affect mortality. These two approaches are the Productivity, or Human Capital Approach, and the Willingness-to-Pay Approach.

Human Capital Approach

This approach is based on the premise that when an individual dies, society losses 1) the medical and burial costs expended as a result of death and 2) the stream of his future net output (his future production less his future consumption). (a) The approach is implemented in the following manner. First, expected future earnings and expected future consumption streams are calculated for a typical 1-year-01d, 2-year-01d, ... 96-year-old, etc. These streams are discounted to the present and sumed to obtain a measure for each age cohort of the expected net present value of net output. Second, for each age cohort, the net present value of the death-related medical, burial, and other society-borne costs are calculated, using the "expected lifetime" of the age cohort to determine the time period that these costs would be incurred. These costs are subtracted from the corresponding costs which would be borne in the current period to obtain a measure of the value to society of the delay in incurring these costs. Third, for each age cohort, the value from the first step is added to the value from the second step. The result is an estimate of "the age-cohort from this time period to the period in which he is "expected" to die (according to the life expectancy tables for his age-cohort). Fourth, the number of

(a) As state, this is the human capital or net productivity approach, which consider future streams of output net of the individual's consumption. A variant of the human capital approach, the gross productivity approach does not subtract the individual's consumption; such consumption is included because it approximates the value to the individual of his future consumption. Analysts who use this approach typically argue that the value of future consumption is equal to the value of the individual's life to himself. This gross approach therefore includes both the value of the individual to society at large and, in a roundabout way, to himself. 
deaths which will be avoided this time period because of the policy in question is calculated for each age cohort. 'Fifth, the number of lives saved in each class is multiplied by the "social benefits" (step three) associated with the class, and the result is aggregated over age groups. The result is the estimate of the "social value" of the lives saved by the policy.

This approach is by far the most common employed in the literature, primarily because the data required to estimate human life values using this approach are readily available. This is certainly the primary asset of the approach. The approach also has several drawbacks. The first and most serious problem with this approach is that it is inconsistent with the assumption employed in benefit-cost analysis that changed in economic welfare are based on individuals' preferences. Using the net human capital approach, the value of a person's life to the individual is not considered, and a number of empirical studies (Usher 1971; Conley 1976; Linerooth 1979) have shown that the values obtained using this approach are far less than those obtained from simply asking people what their life is worth to them. On the other hand, using the value of future consumption as a proxy for the value of an individual's life, as is done in the Human Capital Approach, is clearly inappropriate; there is no reason that these two values would be related at all. In addition, labor market imperfections may bias the valuation because earnings do not necessarily measure output (which are used as the measure of output). The approach also understates the worth of nonmarket activity, such as work performed in the home. In many cases, the approach produces negative estimates for the value of mortality reductions (e.g., housewives, the elderly, infants). Finally, the approach is most useful in considering single-period policies such as safety programs; in such cases, the life expectancy of those saved is a fixed constant. It is not clear how they approach would be used in a multiperiod setting in which the life expectancy itself is altered, and nobody is "saved" today.

Willingness to Pay Approach

This approach is based on the premise that individual preferences are the basis for calculating changes in economic or societal welfare. In this approach, increases in longevity are valued according to what the affected 
individual is willing to pay to obtain such increases. This approach is consistent with the general approach to valuing the environmental commodities discussed in Section 6.1. Its strength, of course, is its consistency with economic theory. It also has several drawbacks. First, longevity is not a commodity explicitly traded in an organized market, so the "price" or value of longevity is not directly observable. Nonmarket techniques must frequently be employed to estimate the willingness-to-pay for reduced mortality. Such techniques are subject to a number of problems, which are discussed in Section 6.2 above and in Freeman (1979). Second, the approach (as typically implemented) only considers the value of a life to the individual, and does not consider the value of a particular life to others. This latter value may include part of the value considered by the Productivity (Human Capital) Approach, as well as the value of a life to friends and relatives of the individual. It is possible to construct a valuation process in which these other values are considered, but such a process is not typically used.

\section{Evaluation of Approach}

In the most extensive study of the value of human life to be published, Jones-Lee (1976) identified three ways in which delaying an individual's death (or, alternatively, increasing his expected lifetime) affects societal welfare: 1) it delays the medical and other costs which are typically borne by society; 2) it delays the loss of the individual's net output that is consumed by other members of society; and 3) it increases the utility of the individual and friends and relatives who care about him. For each of these three reasons, an individual in society will value a reduction in the societal mortality rate, both for a reduction in this period's absolute or unconditional probability or death and a reduction in current and future conditional probabilities of death. These three factors correspond quite closely to those which are considered by the Productivity Approach (factors one and two) and the Willingnessto-Pay Approach (factor three).

This funding suggest that both approaches should be performed and the

results of the two summed together. We agree with Jones-Lee that this combined approach is appropriate, as long as in performing the two separate analyses 
care is taken to prevent double-counting, which could occur if the value-oflife estimates from the Human Capital approach included the value to the individual of delaying his own death. We also agree with his finding that the first two factors, which coincidentaliy are those addressed by the Productivity Approach, are likely to be small, particularly because the second factor can be negative. Because these two factors are likely to be small land, in the empirical studies cited above, have been found to be small) and because these two factors can be easily calculated using actuarial, earnings, and medical cost data that is readily available, we will focus the remaining parts of this section on the willingness-to-pay approach.

\subsubsection{A Basic Model of The Willingness to Pay for Mortality Reductions}

The primary aspect of the fnortality reduction valuation problem which distinguishes it from the general environmental commodity valuation questions considered in Section 6.1 is that it involves individual choice under uncertainty. Government policies do not, with certainty, change the date of any particular individual's death; they may, however, affect the probability that an individual dies on a particular day or in a particular time period or, alternatively, change his life expectancy. To consider this aspect of the problem, Freeman (1979) constructed a simple one-period model in which the individual is paid a salary dependent on the riskiness of his occupation (i.e., the greater the probability of death due to occupational accident during the period, the greater the salary), consumes a riskless commodity and several "risky" commodities (i.e., consumption of these goods, while providing utility, also increase the probability of death during the period), and also faces exogenous risks. His objective is to maximize his expected utility, which is equal to the probability that he survives through the end of the period multiplied by the utility he attains if he does survive. He is constrained by the fact that his salary must exceed his expenditures. (a) Freeman derives several interesting results from this problem. First, he finds that individuals will select the level of occupational riskiness so as to equate the marginal wage premium

(a) The dual of this problem, which is more appropriate for calculation of welfare changes, can also be formed. The results Freeman obtains are applicable to either problem. 
(the dollar increase in salary associated with a unit increase in occupational riskiness) to the marginal willingness to pay for reduced occupational risk. The marginal WTP function for reduced occupational risk can thus be estimated from the salary function. Second, he finds that the marginal WTP for reduced occupational risk and the marginal WTP for reduced risk from exogenous factors are identical functions, and that each is dependent on $q$, the probability of survival. The marginal WTP for increased safety from exogenous risks (equivalent to the function graphed in Figure 6.1) can thus also be estimated from the salary-risk function.

Freeman (1979) went on to construct a simple multi-period model in which individuals consume one good each period and face a vector of known exogenous conditional survival probabilities. The $i^{\text {th }}$ element of this vector represents the probability of surviving through the $i^{\text {th }}$ time period, given that the individual survived through i-1 periods. The individual's objective is to maximize the present value of his expected utility. Freeman's objective in this exercise is to determine whether the marginal rate of substitution between present mortality reduction and present consumption, which could be estimated from a study of the demand for occupational safety, can be used to estimate the marginal rate of substitution between present consumption and future mortality reductions. This latter information is required to estimate the current demand for future mortality reductions, and thus the individual's WTP for future mortality reductions.

The results of this exercise are that the two marginal rate of substitutions are not related in any systematic way that can be empirically exploited. Thus, knowledge of the value of present reductions in mortality (of the single period type) cannot be used to estimate the value of future mortality reductions.

\subsubsection{Approaches to Measuring Willingness to Pay for Mortality Reductions}

Three basic approaches have been employed in the literature to measure willingness to pay by individuals for reductions in the probability of death. All three approaches have been utilized in analyzing policies such as occupational safety programs which affect the probability of death in the current period; they have also been used to value environmental regulations which 
affect expected mortality rates in both the current and all future periods. In this latter use, however, the problem has always been addressed as if it were a single-period-type policy; we are aware of no studies which have explicitly considered the WTP today for a reduction in the conditional probability of dying in some later period. Because of Freeman's findings (discussed in Section 6.3 .2$)$ that the WTP for future reductions cannot be inferred from the WTP for current reductions, we therefore conclude that no published analysis has adequately addressed this issue, regardless of the approach to measuring wTP that was used.

The basic approach that each of these three valuation methods utilizes is to estimate the dollar value associated with a very small change or increment in the probability of death. This value $c$ an be inferred from analysis of market data or from direct survey. Once this value has been estimated, the second step is typically to calculate the "statistical value of life," which is equal to the value of the probability increment divided by the probability increment. For example, if the typical individual is willing to pay $\$ 1000$ for a .01 reduction in the probability of death this period, then the value of statistical life is $\$ 100,000$ ( $\$ 1000$ divided by .01). This represents the aggregate dollar amount that a group made up of "typical" individuals would be willing to pay to have the death of one member of The group prevented. To continue the example above, if the group contains 100 members each willing to pay $\$ 1000$ for a .01 reduction in the probability of death, and a particular policy reduces the probability of death to members of the group by .01 , then the death of one member of the group will be prevented; each member is willing to pay $\$ 1000$ for the probability reduction, so the aggregate dollar amount is $\$ 100,000(\$ 1000$ multiplied by 100 people). On the other hand, if the policy reduces the probability of death by .05 , each member would be willing to pay $\$ 5000$, so the aggregate willingness to pay is $\$ 100,000(\$ 500,000$ divided by 5$)$, which equals the value of a statistical life.(a)

(a) Note that it is assumed that the marginal WTP function is linear, i.e., that a .05 probability reduction has five time the value of a .01 probability reduction. Given that the marginal WTP function or curve is downward sloping (see Freeman 1979, p. 179), this assumption is theoretically invalid. 
The three basic approaches to measuring the dollar amount an individual is willing to pay for a small reduction in the probability of death are 1) to measure the "wage premium" discussed in Section 6.3.2, by estimating the wage differential paid to workers in occupations/industries with differential risks;

2) to measure the "price discount" associated with risky products by estimating the price differential paid for products that differ only with respect to the risk of using them; and 3) to directly inquire from individuals the dollar amount they would pay for a reduction in the probability of death. The steps comprising each approach as well as the strengths and weaknesses of each are discussed in the following paragraphs.

Wage Differential Approach

In this approach, the willingness to pay for reductions in the probability of death is approximated by the annual wage or salary increase or differential required to "attract" workers into "risky" occupations or industries. Of the three willingness-to-pay approaches, this is the most frequently used method. To estimate the wage differential, data is collected for a number of occupations or, more commonly, industries. For each unit of observations coccupation or industry and year) data on the number of occupational deaths, the number of workers, and annual wages and salaries is collected, along with information about other occupational/industrial characteristics that might affect or determine wages/salaries. A variable representing "risk" is formed for each unit by dividing number of workers into number of deaths; this risk variable measures the probability that any particular worker in the unit will die during the year due to an occupational accident. Annual wages are then regressed on the risk variable and other characteristics. The coefficient on the risk variable in this equation represents the increase in the annual wage that must be paid per unit of risk to attract workers to risky occupations/industries.

The method suffers from several shortcomings that are typically "assumed away." The problem is that it does not, in our opinion, adequately control for 
the fact that workers who are less risk averse(a) than the "typical" worker will tend to work in riskier-than-average occupations and/or industries. Thus, if we are considering two industries, $A$ and $B$, where $A$ is riskier than $B$, then the workers employed in $A$ would tend to be less risk averse than those employed in $B$. The problem that this phenomenon creates is the following: the wage differential between industries $A$ and $B$ does not represent the wage premium that must be paid to induce the worker with average risk aversion to accept the risk associated with industry B instead of the risk associated with industry $A$.

From an econometric standpoint, the problem is that the estimating equation is misspecified. The wage a worker is paid depends both on the amount of risk he is accepting and his degree of risk aversion; however, this latter variable is not directly observable and thus not inc?uded in the equation. Its exclusion biases the estimated coefficient of the former variable downward. (b) From this standpoint the only way to solve the problem is to include the workers' risk aversion as an explanatory variable. Information on the risk aversion of individual workers is not typically included in the data bases used to estimate these equations, and a large effort would be required to "construct" this variable for existing data bases.

An alternative "solution" is to assume that the problem does not exist. This can be done in the following manner. If we assume that demand for workers into a particular risky occupation/industry is not entirely fulfilled by less

(a) Risk aversion is a measure used by economists to represent the degree to which an individual dislikes risk. It is typically measured as the dollar amount (premium) required to induce an individual to accept additional risk (e.g., in a lottery); the greater this among, the more risk averse he is. Those for whom this amount is negative are called risk lovers, and those for whom this amount is zero are considered risk neutral.

(b) The sign of the bias caused by a left-out variable on the estimated coefficient of another variable is equal to the sign that the coefficient of this left-out variable would have if it were included in the equation multiplied by the sign of the correlation between the left-out variable and the included variable of interest. In this case, the coefficient of the left-out variable would be positive (an increase in risk aversion would, holding everything else constant, increase the required wage), the correlation between risk aversion and occupational/industrial risk would be negative (the riskier the occupation/industry, the less risk averse the individual working in it), and the product negative. 
risk-loving, risk neutral, or less risk-averse workers, than a number of risk averse individuals will have to be hire to fulfill the demand. In this case, the wage premium that must be paid to these risk averse individuals, and therefore to all workers in the unit (because it is assumed that it is impossible to discriminate on the basis of risk aversion) would represent the true risk premium. The key aspect of this assumption is that the degree of risk aversion of the marginal worker (which determines the wage paid to all intramarginal employees) is the same in all occupations/industries, so that the wage differential between industries does reflect the premium that must be paid to the typical worker. We do not find this argument very compelling, for the reasons cited in the preceeding two paragraphs.

An additional but somewhat related shortcoming of this approach is related to its use in assessing environmental risks. Our assessment is that the approach is only able to assess the value of changes or differences in the risk of dying in the current period. Given Freeman's (1979) finding that this value cannot be used to infer the value of reductions in probabilities of future death, and the fact that environmental policies explicitly affect both present and future death, and the fact that environmental policies explicitly affect both present and future (conditional) probabilities of death, we believe that the usefulness to environmental assessments of estimates derived from this approach are limited.

The method has several other shortcomings. First, as typically implemented, onty deaths from fatal occupational accidents are included in the variable representing risk. The probability of nonfatal accidents is sometimes included as an explanatory variable; however, we are aware of no studies that include a variable or variables representing the probability or risk of death from nonaccidenta) deaths (i.e., of death caused by an occupational accident occurring in a previous time period, or death from occupational "events" other than accidents, such as exposure to carcinogens). The reason for this is that it is difficult to measure this variable, particularly because such deaths may occur years after employment has been terminated and because it is difficult in many cases to attribute a specific death to employment in a particular occupation/industry. It is clear, however, that annual wages are affected by the 
probabilities of nonfatal accidents and occupation-related nonaccidental deaths; the wage paid to coal miners, for example, most certainly includes a premium paid to workers for accepting the risk of contracting black lung disease. Second, the coefficient estimates obtained from this method vary significantly depending on the functional form used for the estimating equation and the variables other than risk that are included in the equation. As is typically the case in empirical economics, the "correct." functional form is not implied by theory and is largely the analyst's choice; theory does suggest in this case that the equation is nonlinear, because risk averse individuals will require greater wage differentials the greater the risk they are already bearing.

The approach also has several strengths. First, it is consistent with economic theory. As discussed above in Section 6.3.2, Freeman (1979) has shown that the marginal willingness to pay inferred from the wage-occupational risk schedule is identical to the MWTP for reductions in the probability of death from environmental causes. Second, the approach utilizes market data and is, in this sense, objective (although the analyst uses this objective data in a subjective manner). The approach therefore avoids the problems of bias associated with the direct inquiry approach. Third, data required to implement this approach is readily available.

\section{Prices Differential Approach}

The second approach, which has been used or suggested by analysts on several occasions, is the price differential approach. This approach is similar to the wage differential approach, except that the prices of nonlabor comodities are analyzed instead of wages. In the approach, data on the market prices of a set of goods that differ only (or primarily) in the risk of death associated with consumption of them is collected, along with data on characteristics of these goods. One of the characteristics is the riskiness of the product. Prices are then regressed on the riskiness of the commodity and the other characteristics. The coefficient of the riskiness variable represents the risk premium which individuals must be paid to accept additional risk of death.

The approach has the same shortcomings as those of the wage differential approach. The primary problem with both of these approaches is controlling for 
all of the nonrisk factors that 1) may influence the wage or prices and/or 2) may be correlated with the riskiness. An additional problem with the price differential approach is that the commodities analyzed (the individual observations must be very, very similar. One would not want to include firecrackers and automobiles in the same analysis, because it would be impossible to control for all of the factors other than risk that influence price. One could, however, regress car prices on the characteristics of the cars, including risk of death as a characteristic. Similarly, the prices that various airlines charge for trips from a particular origin to a particular destination may be regressed on the probability of death on the trip and other characteristics.

One assumption employed by both the wage differential and price differential approaches that ought to be noted is that the affected individuals perceive the differences in risk between various occupations/industries and/or commodities. For differences that are very small, this assumption may not be true.

A variant of the price differential approach that has been used several times to value human life is the Consumption Approach. In this technique, observations of the quantity consumed of particular goods is combined with data and assumptions about their prices to infer the "price" individuals attach to risk reductions. For example, whether or not an individual uses seat belts, combined with information about the time required to fasten and unfasten them, the value of his time, and the reduction in risk associated with seat-belt use can be used to infer the value to the individual of reductions in the probability of death. The main problems we see with this approach are 1) the number and importance of questionable assumptions that have to be made and 2) the failure to control for other factors that influence consumption of the good (e.g., the discomfort associated with wearing seat belts).

Direct Inquiry Approach

In this approach, individuals are asked directly what they are willing to pay to have the probability of their death reduced by a particular amount or by various amounts. The results of this survey process can then be used to estimate the WTP of the typical individual either by simply calculating mean responses or by more sophisticated statistical analysis of the response. 
The primary strength of this method is its flexibility. Individuals can be asked to value probability increments of various sizes, so that the nonlinearity of the marginal WTP function can be addressed. We also believe that this approach could be used to consider increments to both present and future probabilities, although to our knowledge it has not yet been used in this manner. The approach can also take into account (or be used to test the hypothesis) that individuals "car" about how they die; that is, they might be willing to pay more to reduce the probability of death caused by environmental degradation than by occupational accident. This hypothesis, considered by Freeman (1982a), considers the fact that the amount of pain and suffering varies from one cause of death to another, and also that individuals "feel" differently about risks that they voluntarily assume (as in the occupational or consumption cases) from those that they voluntarily assume (as in the environmental case). By tailoring the survey questions to address death from environmental degradation, this approach has the additional advantage that it is direct, i.e., that nothing needs to be inferred from market data, and that there are not "other factors" whose influence needs to be controlled.

The approach also has several shortcomings. These shortcomings are a result of the fact that this is basically a contingent market or contingent valuation technique; the approach basically attempts to establish a "market" in which increments to probabilities of death are bought and sold. As such, the approach suffers from many of the same problems discussed in Section 6.2. 0 f The typical problems associated with contingent valuation, we believe on is particularly problematic here: the fact that individuals are not accustomed to valuing death (or its avoidance/delay). or to thinking in terms of probabilities. We therefore believe the analyst has to be particularly careful to make the "market" as real and as unemotional as possible, and further believe that the results of surveys in which this care is not taken may be virtually useless.

\subsubsection{The Value of Life: A Review of The Estimates}

In this part, we present the most frequently cited estimates of the value of $1 \mathrm{ife}$ and briefly review the methods used to generate these estimates. 
Estimates of The Value of Life

Table 6.2 presents estimates of the value of a statistical life from 14 of the most frequently cited studies of the issue. The studies are grouped according to the approach (Productivity; Willingness-to-Pay), and within WTP, the method (Wage Differential, etc.) employed in the study. The year in which the study was published appears in parentheses, while the year that the data used in the study refers to is listed in the second column of the study. For example, Reynolds employed 1952 data in his study. All dollar values in the table are in thousands of real (constant, or inflation-adjusted) 1982 dollars. Annual values of the Consumer Price Index were used to inflate the

TABLE 6.2. Estimates of the Value of a Statistical Life (Thousands of 1982 Dollars)

\begin{tabular}{|c|c|c|}
\hline Approach/Study & Reference Year & Value \\
\hline \multicolumn{3}{|l|}{ Productivity Approach } \\
\hline Reynolds (1956) & 1952 & 20.3 \\
\hline Fromm $(1956)$ & 1960 & 531.2 \\
\hline Dawson (1967) & 1963 & 30.3 \\
\hline Cooper and Rice (1976) & 1972 & 48.5 \\
\hline \multicolumn{3}{|l|}{$\begin{array}{l}\text { Willingness-to-Pay Approach } \\
\text { Wage Differential Method }\end{array}$} \\
\hline Thaler and Rosen (1975) & 1967 & 573.9 \\
\hline Smith (1976) & 1967 & 3203.3 \\
\hline Viscusi (1978) & 1969 & 3336.8 \\
\hline Dillingham (1979) & 1969 & 440.5 \\
\hline Brown (1980) & $1966-1973$ & 1241.3 \\
\hline 01 son $(1981)$ & 1973 & 7167.4 \\
\hline \multicolumn{3}{|l|}{ Consumption Method } \\
\hline Blonquist (1979) & 1972 & 574.2 \\
\hline Ghosh et al. (1975) & 1972 & 413.8 \\
\hline \multicolumn{3}{|l|}{ Direct Inquiry Method } \\
\hline Acton (1973) & 1972 & 66.7 \\
\hline Jones-Lee (1976) & 1975 & $11,879.0$ \\
\hline
\end{tabular}


original estimates, and estimates originally developed in foreign currencies (several studies were performed in the United Kingdom) were transformed to dollars using the average exchange rate that prevailed during the reference year. The estimates vary tremendously, with a low value of $\$ 20,400$ and a high value of $\$ 11,879,000$. The WTP estimates are all higher than the Productivity Approach estimates, with the exception of the Fromm estimate that, as discussed below, is more of a hybrid estimate than a straight Productivity estimate. Even within the WTP category, however, estimates range from $\$ 66,700$ to $\$ 11,879,000$, a factor of almost 200. It is interesting to note that the high and low WTP estimates were generated using the same technique; this fact, as much as any other, has discredited the direct inquiry method among practitioners in this field. The ratio of the highest to the lowest wage differential estimates is 16 , indicating that even using observed market data there is substantial disagreement about the "true" value of life. It is, of course, not only possible but likely that there is no single "true" value, but that this value varies over time and across income groups and other groups of the population. Despite this, in our review of these studies we were unable to develop a "theory" that would explain very many of the variations exhibited in the WTP part of Table 6.2.

\section{Productivity Approach}

Reynolds 1956. In a study of the cost of 1952 British road accidents, Reynolds estimates cost in four categories: 1) property damage (e.g., to vehicles). 2) medical costs, 3) administrative costs (e.g., insurance), and 4) net reduction in output. For the latter category, he divides Net Domestic Product by the working population to obtain a measure of per capita output. He uses this in combination with expected working life estimates and a $4 \%$ discount rate to calculate the discounted present value of present and future per capita output, from which he subtracts the discounted present value of present and future consumption. Reynolds thus ignores the time pattern of earnings, but does value the output of housewives at the same value as that of working women.

$$
\text { From (1965). Fromm investigated the loss per air carrier fatality in }
$$

1960. He argued that the loss per fatality was $\$ 400,844$ to the individual's family and $\$ 130,356$ to society. The former figure included both productivity 
and willingness to pay by family members, making this a hybrid, not a purely Productivity Approach Study. In addition, Fromm estimates the value of the individual's life to himself to be $\$ 684,368$, making the total value of a fatality (to both the individual and others) $\$ 1,215,568$. Unfortunately, Fromm offers little information about how he calculated either this total, the three individual components, or parts of these components.

Dawson (1967). Dawson essentially attempted to update the estimates made by Reynolds using 1963 British automobile accident data. He uses the same cost categories as Reynolds, but calculates costs in a slightly different manner. Per capita output is measured in terms if earnings, for example, not average per worker output.

Cooper and Rice (1976). This study examines the direct (i.e., medical care), morbidity (lost output, institutionalization costs), and mortality costs associated with 16 categories of illness. The value presented in Table 6.2 represents the average mortality cost only (across the 16 categories) for the year 1972. Aggregate mortality costs were calculate by multiplying the number of deaths in each age, sex, and race group by the discounted value of the expected lifetime earnings of the typical member in each group, and aggregating across race-age-sex groups. a $4 \%$ discount rate was used. One this aggregate mortality loss was calculated, division by the total number of deaths yielded the estimate presented in Table 6.2 of the average loss per death. Note that consumption is not subtracted from earnings; instead of net output, the authors attempted to measure gross output.

Willingness-to-Pay Approach Wage Differential Method

In each of the following studies, wage or salary data for individuals, industries, or occupations was regressed on the associated risk of death and other "control" variables in an attempt to estimate the wage premium discussed above.

Thaler and Rosen (1975). In one of the first applications of the hedonic prices technique developed by Rosen (1975), Thaler and Rosen used 1967 earnings, occupational risk (of death), and other job and individual characteristics data for some 900 individuals in 37 risky occupations. Using standard 
econometric techniques, they regressed the weekly wage for each individual on risk and the other characteristics. Thaler and Rosen tested a number of functional forms and variable combinations (including interaction terms between risk and other characteristics, such as education). The value presented in Table 6.2 represents the approximate midpoint of the range of values they estimated. The study was unable to control for risk of occupational injury.

Smith (1976). Smith used wage and job/individual characteristic data for 3,200 white males sampled in the 1967 Current Population survey, and calculated the probabilities of death, permanent disability, and temporary disability from occupational accidents for each worker as the average for the industry in which he works. Some reviewers (Freeman 1982b, Chapter 4) have suggested that use of industrial risks instead of occupational risks is inappropriate. One strength of this study is that Smith does attempt to control for nonfatal injuries, although he is not completely successful in this regard.

Viscusi (1976). Viscusi used a sample of 496 fulltime blue-collar workers in the 1969-1970 Survey of Working Conditions. Like Smith, Viscusi used the death rate in each worker's industry, not occupation, as a measure of risk. He was also attempted to control for nonfatal injuries.

Dillingham (1979). Dillingham uses a sample of some 3,700 New York males who were employed fulltime during 1969 in "blue-collar" manufacturing and construction jobs. By using State Workmen's Compensation Board injury data, he was able to more accurately estimate the risk each individual faces from jobrelated death, because he could calculate this on an occupation-by-industry basis, not just by industry or by occupation, as in the other studies reviewed here. Dillingham was also able to include variables representing the risks of nonfatal injuries of several degrees of severity, thereby controlling for the influence of these characteristics on wages.

Brown (1980). Brown was the first to investigate the mortality risk wage premium using longitudinal instead of cross-sectional data. Brown used data on earnings, individual characteristics, and job-related characteristics for 470 individuals for each of the years 1966-1971 and 1973 from the National Longitudinal Survey Young Men's Sample (NLS), the Dictionary of Occupational Titles, and the Society of Actuaries. Brown restricted his estimation sample 
to those without a college education. By using a longitudinal sample, Brown was able to more effectively capture the effects of individuals' characteristics on the wage-risk tradeoff.

0lson (1981). 0lson used industry-based data on probabilities of death and nonfatal accidents for 6,000 workers who participated in the 1973 Current Population Survey. He included a set of "control" variables similar to those used in other cross-sectional studies.

Consumption Method

The following two studies employed a variant of the price differential method that is frequently called the consumption method.

Blomquist (1979). Blomquist used data on seat belt use, earnings, and individual characteristics for a sample of 1,854 individuals surveyed in the 1972 Panel Study of Income Dynamics. He estimated a profit equation, which "explains" whether or not an individual uses seat belts as a function of his wages, wealth, and other characteristics. The parameter estimates from this equation were combined with the results from a time-and-motion study and evidence on the probability of death from an automobile accident with and without seat belts to calculated the value of life estimate presented in Table 6.2.

Ghosh, Lees, and Seal (1975). Ghosh et al. used British data for 1972 on average highway speed (which they assumed to be the optimal speed), the relationship between speed and time saved, the relationship between fuel consumption and speed and the probability of death to calculate the value of life.

\section{Inquiry Method}

The following two studies employed the direct inquiry method.

Acton (1973). Acton asked 36 residents of the Boston area how much they were willing to pay for a community-financed emergency coronary care program that would reduce each individuals probability of death by heart attack. Two different forms of the question implied values of a statistical life that were $50 \%$ different. The value presented in Table 6.2 are the lower estimate, which represents willingness-to-pay. 
Jones-Lee (1976). In his exhaustive theoretical study of the value of life, Jones-Lee interviewed 30 British academic and research workers. He asked them to state their willingness to pay for improved airline safety. The value of a statistical life presented in Table 6.2 is the mean of the 30 responses. Jones-Lee also asked each respondent to state his/her willingness to pay for changes in environmental pollution that would extend the individual's life expectancy by one year. The mean response to this question was $\$ 3,585$. When the individual's entire immediate family was included in this latter question, the mean response increased to $\$ 7,132$.

\section{Evaluation of Estimates}

We believe that all of the studies reviewed above are useful contributions to the field of valuation of lives. Of course, we feel that some made more valuable contributions than others, both to the field in general and particularly to the specific issues addressed in this chapter. We will close this section of the chapter by offering a few thoughts on the studies.

First, regarding the studies that employed the Productivity Approach, we do not believe that this approach can be used to estimate the value of a person's life to the individual, but only to the remaining segment of society that does not "care" about the individual per se. We therefore believe that the studies by 1) Fromm and 2) Cooper and Rice are not very useful, because they do attempt to include some subjective nonoutput (or medical cost)-related values (and therefore mix elements of several value-of-life components). The other two studies utilizing this approach are both dated and apply only to British earnings data. Because value estimates of this type are, we believe, required to estimate the value of a 1 ife, we recommend that a study to estimate such values be undertaken. We also suggest that the researchers investigate the role of the Productivity Approach value estimates in analysis of a policy like air pollution controls that affect the probability of death both this period and in future periods.

Second, regarding the wage differential studies, we believe that these studies are interesting and have generally been performed well, but we are perplexed by the wide variation of value estimates generated by this method. We are concerned that none of the studies have effectively controlled for the risk 
aversion of the workers, and thus that the estimates are biased downward. More importantly, we are concerned that this method may not be useful in assessing policies that affect and entire stream or vector of conditional mortality rates. We believe that additional research is required to investigate this question and also to attempt to explain some of the variation observed in the estimates.

Third, we believe that the two studies reviewed that employed the consumption approach are highly imaginative, but that the estimates depend on so many untenable assumptions that they lack credibility. We therefore believe that these estimates should not be used for policy analysis and that this method or approach should be not followed in assessing the value of acid deposition ancillary benefits.

Fourth, regarding the direct inquiry approach, we believe that this is the only technique that currently exists that can be used to value policies affecting mortality rates both in this and in future periods. On the other hand, we believe that this approach is fraught with problems of bias and improvision, as demonstrated in the two studies reviewed above. We recommend that this approach be pursued for valuation of multiple period policies, such as those affecting air or water quality. Such research should employ larger sample sizes, more carefully constructed interview instruments, and more sophisticated statistical techniques than those used in the two studies reviewed above. In particular, the entire literature on contingent valuation methods should be considered in designing and performing this research effort.

In summary, we do not believe that any of the studies (with the possible exception of Jones-Lee) has attempted to estimate the value of life in a manner appropriate for consideration of policies affecting air or water quality. We therefore do not suggest that a particular dollar amount be used to value the mortality-related ancillary benefits of acid deposition control policies.

\subsubsection{The Value of Morbidity}

The preceding parts of this section have focused exclusively on valuation of changes in mortality rates. Acid deposition control policies may also have dramatic effects on morbidity. These morbidity changes may have significant 
value to society, for several reasons. First, as the incidences of both acute and chronic $i l l n e s s e s$ decrease, the amount of resources that society must expend to care for the $i l 1$ decreases. The first component of the value of morbidity reductions is this resource cost saving. Second, as illness incidences decrease, the number of work days lost because of illness will decrease, increasing the net output available to society. Third, individuals are willing to pay some dollar amount to avoid or have reduced the pain and discomfort associated with either chronic or acute $i 11$ ness.

These three categories of val ue correspond closely to the categories Jones-Lee (1976) identified for valuation of life-saving activities. Despite the similarity between valuation of morb id ity and valuation of mortality, we are aware of no studies which have considered all three categories in valuing morbidity. Cooper and Rice (1976) considered medical costs and lost output, but not "psychic" costs. In fact, we are not aware of any studies that have attempted to value such costs. Given that policies that affect air and water quality may have substantial impacts on morbidity, we believe that this is an important shortcoming in the environmental valuation literature and one that should be corrected.

\subsubsection{Sunmary of Health Valuation}

Valuing policy-induced changes in rates of mortality and morbidity is a relatively new or young endeavor for economists. The relatively "simple" questions, like the types of values that should be included in such a valuation process, have only recently been answered in a manner consistent with established welfare economic theory. Estimation of each of these types of values has occurred slowly. It is obvious from a review of the literature that many questions remain to be answered in this field.

Answers to many of these questions are required in order to value all of the benefits of potential acid deposition control policies, because such policies may affect human health. We therefore recommend a research program containing both theoretical and empirical components to answer some of these questions. Specifically, we believe the theoretical research should focus on the types of values that should be included in an analysis of policies affecting both present and future health, how these values ought to be addressed and, in 
particular, how the individual's willingness-to-pay for future mortality reductions should be approached. We believe that the empirical component should obtain data on both mortality and morbidity and develop estimates of the values of present and future changes in these rates in a manner consistent with the theoretical framework and the relevant aspects of the policies in question. We believe that until such a program is implemented, policymakers will have to rely on cursory literature reviews like the present report instead of "real" numbers.

\subsection{REFERENCES TO CHAPTER 6.0}

Acton, J. P. 1973. Evaluating Public Programs to Save Lives: The Case of Heart Attacks. Rand Corp., Santa Monica, Californía.

Adams, R. C., et a1. 1980. The Visual Aesthetic Impact of Alternative ClosedCycle Cooling Systems. PNL-2952, Pacific Northwest Laboratory, Richland, Washington.

Blomquist, G. 1979. "Value of Life Saving: Implications of Consumption Activity." Journal of Political Economy. 87(3):540-558.

Brookshire, D. S., B. C. Ives, and W. D. Schulze. 1976. "The valuation of Aesthetic Preferences." Journal of Environmental Economics and Management. $3: 325-346$.

Brookshire, D. S., et al. 1979. Experimental Methods for Valuing Aesthetics and Heaith Effects on the South Coast Air Basin: An Overview. University of Wyoming, Resource and Environmental Economics Laboratory, Laramie, Wyoming.

Brown, C. 1980. "Equalizing Differences in the Labor Market." Quarterly Journal of Economics. 94(1):113-134.

Charles River Associates, Inc. 1981. Benefits of Improving Visibility at Mesa Verde National Park. Charles River Associates, Inc., Boston, Massachusetts.

Cooper, B.S., and D. P. Rice. 1976. "The Economic Cost of Illness Revisited." Social Security Bulletin. 39(2):21-26.

Conley, B. C. 1976. "The Value of Human Life in the Demand for Safety." American Economic Review. 66(1):45-55/

Dawson, R. F. F. 1967. Cost of Road Accidents in Great Britain. Ministry of Transport, Road Research Laboratory, London. 
0illingham, A. E. 1979. The Injury Risk Structure of Occupations and Wages. Unpublished doctoral dissertation, Cornell University.

Freeman, A. M., III. 1979. The Benefits of Environmental Improvement: Theory and Application. Johns Hopkins University Press, Baltimore, Maryland.

Freeman, A. M., III. 1982a. "The Health Implications of Residuals Discharges: A Methodological Overview." In Explorations in Natural Resource Economics, eds. V. K. Smith and J. V. Krutilla. Johns Hopkins University Press, Baltimore, Maryland.

Freeman, A. M., III. 1982b. Air and Water Pollution Control: A Benefit-Cost Assessment. Wiley, New York.

From, G. 1965. "Civil Aviation Expenditures." In Measuring Benefits of Government Investment, ed. R. Dorfman. Brookings Institute, Washington, D.C.

Ghosh, D., D. Lees and W. Seal. 1975. "Optimal Motorway Speed and Some Valuations of Time and Life." Manchester School.

Jones-Lee, M. W. 1976. The Value of Life: An Economic Analysis. University of Chicago Press, Chicago.

Latimer, D. A., et al. 1984. Visibility and Other Air Quality Benefits of Sulfur Dioxide Emission Controls in the Eastern United States. SYSAPP84/165. Systems Applications, Inc., San Rafael, California. Prepared for U.S. Environmental Protection Agency, Office of Policy Analysis.

Linerooth, J. 1979. "The Value of Human Life: A Review of the Models." Econorsic Inquiry. 17(1):52-74.

01son, C. A. 1981. "An Analysis of Wage Differentials Received by Workers on Dangerous Jobs." Journal of Human Resource. 16(2):167-185.

Rae, D. A. 1982. "The Value to Visitors of Improving Visibility at Mesa Verde and Great Smoky National Parks." Paper presented at the Visual Values Workshop, Colorado, May 11-13, 1982.

Rae, D. A. Forthcoming. Benefits of Visual Air Quality in Cincinnati: Results of a Contingent Ranking Survey. Prepared by Charles River Associations, Inc. for Electric Power Research Institute, Palo Alto, California.

Randa11, A., B. Ives and C. Eastman, 1974. "Bidding Games for Valuation of Aesthetic Environmental Improvements." Journal of Environmental Economics and Management. (1):132-149.

Reynolds, D. J. 1956. "The Cost of Road Accidents." Journal of the Royal Statistical Society. 
Rowe, R. D., R. C. d'Arge and D. S. Brookshire. 1980. "An Experiment on the Economic Value of Visibility." Journal of Environmental Economics and

Management. 7:1-19.

Rowe, R. D., and L. G. Chestnut. 1982. The Value of Visibility: Economic Theory and Applications for Air Pollution Control. Abt Books, Cambridge, Massachusetts.

Schulze, W. D., et al. 1981. Methods Development for Environmental Control Benefits Assessment. Vol. $X$ : The Benefits of Preserving Visibility in the National Parklands of the Southwest. U.S. Environmental Protection Agency, office of Research and Development, Washington, D.C.

Smith, R. 1976. "The Feasibility of an 'Injury Tax' Approach to Occupational Safety." Law and Contemporary Problems. 38:730-744.

Thaler, R., and S. Rosen. 1975. "The Value of Saving a Life: Evidence from the Labor Market," in Household Production and Consumption, N. E. Terlieckyj, ed. National Bureau of Economic Research, New York.

Thayer, M. A. 1981. "Contingent Valuation Techniques for Assessing Environmental Impacts." Journal of Environmental Economics and Management. $8: 27-44$.

Tolley, G. S. et al. 1983. Establishing and Valuing the Effects of Improved Visibility in the Eastern United States. Prepared for the U.S. Environmental Protection Agency, Washington, D.C.

Usher, D. 1973. "An Imputation to the Measure of Economic Growth for Changes in Life Expectancy," in The Measurement of Economic and Social Performance, M. Moss, ed. National Bureau of Economic Research, New York.

Viscusi, W. K. 1978. "Labor Market Valuations of Life and Limb: Empirical Evidence and Policy Implications." Public Policy. 26(3):357-386. 
4

i) 
PNL $=5938$

DISTRIBUTION

No. of

Copies

OFFSITE

David Bennett

Acid Deposition Assessment

Staff-R0676

U.S. EPA

401 M St. S.W.

Washington, D.C. 20460

30 DDE Technical Information Center

Allen Basala

U.S. Environmental Protection Agency, MD-12

Research Triangle Park, NC 27711

Eugene $E$. Berkau

Gas Research Institute

8600 West Bryn Mawr Avenue

Arlington, VA 22209

Richard Bradley

Office of Environmental Analys is

U.S. Department of Energy 1000 Independence Ave. S.W. Washington, D.C. 20585

Glen Hilst

Electric Power Research Institute

P.0. Box 10412

Palo Alto, CA 94303

John Huckabee

Electric Power Research

Institute

P.0. Box 10412

Palo Alto, CA 94303
No. of

Copies

Douglas A. Latimer

Systems Application Inc.

101 Lucas Valley Road

San Rafael, CA 94903

Stale Navrud

Agricultural University of Norway

Department of Forest Economics

P.0. Box 44, N-1432, As-NLH

NORWAY

Stephen Peck

Electric Power Research

Institute

P.0. Box 10412

Palo Alto, CA 94303

Paul Schwengels

Office of Program Development

U.S. Environmental Protection Agency

401 M St. 5.W.

Washington, O.C. 20460

Ron Wyzga

Electric Power Research

Institute

P.0. Box 10417

Palo Alto, CA 94303 
No. of

Copies

ONSITE

DOE-Rjchland Operations Office

J. J. Sutey

34 Pacific Northwest Laboratory

R. C. Adams

J. M. Callaway

J. W. Currie

A. J. Lyke (3)

R. J. Moe (8)

R. J. Nesse (8)

Economics Library (5)

Publishing Coordination MH (2)

Technical information (5) 